\title{
Methodologies for measuring fugitive methane emissions from landfills - A review
}

\author{
Mønster, Jacob; Kjeldsen, Peter; Scheutz, Charlotte
}

Published in:

Waste Management

Link to article, DOI:

10.1016/j.wasman.2018.12.047

Publication date:

2019

Document Version

Peer reviewed version

Link back to DTU Orbit

Citation (APA):

Mønster, J., Kjeldsen, P., \& Scheutz, C. (2019). Methodologies for measuring fugitive methane emissions from landfills - A review. Waste Management, 87, 835-859. https://doi.org/10.1016/j.wasman.2018.12.047

\section{General rights}

Copyright and moral rights for the publications made accessible in the public portal are retained by the authors and/or other copyright owners and it is a condition of accessing publications that users recognise and abide by the legal requirements associated with these rights.

- Users may download and print one copy of any publication from the public portal for the purpose of private study or research.

- You may not further distribute the material or use it for any profit-making activity or commercial gain

- You may freely distribute the URL identifying the publication in the public portal

If you believe that this document breaches copyright please contact us providing details, and we will remove access to the work immediately and investigate your claim 

Monitoring”.

4 Methodologies for measuring fugitive methane emissions from landfills $-\mathbf{a}$

5 review

7 Jacob Mønster, Peter Kjeldsen and Charlotte Scheutz ${ }^{\mathrm{a}}$

Department of Environmental Engineering, Technical University of Denmark, $2800 \mathrm{Kgs}$.

Lyngby, Denmark

${ }^{a}$ Corresponding author

E-mail address: chas@env.dtu.dk

ORCID: 0000-0003-2218-5934

Address: Department of Environmental Engineering, Building 115, Technical University of Denmark, 2800 Kgs. Lyngby, Denmark.

\section{Highlights}

- Several methods exist for quantifying fugitive methane emissions from landfills

- Temporal and spatial variations in methane emissions are a challenge for all methods

- Downwind methods are best for quantifying methane emissions

Keywords: Landfill gas, qualitative methane reconnaissance techniques, surface flux 


\section{Abstract}

Fugitive methane $\left(\mathrm{CH}_{4}\right)$ emissions from landfills are significant global sources of greenhouse gases emitted into the atmosphere; thus, reducing them would be a beneficial way of overall greenhouse gas emissions mitigation. In Europe, landfill owners have to report their annual $\mathrm{CH}_{4}$ emissions, so direct measurements are therefore important for 1) evaluating and improving currently applied $\mathrm{CH}_{4}$ emission models, 2) reporting annual $\mathrm{CH}_{4}$ emissions and 3) quantifying $\mathrm{CH}_{4}$ mitigation initiatives. This paper aims at providing an overview of currently available methodologies used to measure fugitive $\mathrm{CH}_{4}$ emissions escaping from landfills. The measurement methodologies are described briefly, and the advantages and limitations of the different techniques are discussed with reference to published literature on the subject.

Examples are given of individual published studies using different methodologies and studies comparing three or more methodologies. This review suggests that accurate, whole-site $\mathrm{CH}_{4}$ emission quantifications are best done using methods measuring downwind of the landfill, such as tracer gas dispersion and differential absorption LiDAR (DIAL). Combining aerial $\mathrm{CH}_{4}$ concentration measurements from aircraft or unmanned aerial vehicles with wind field measurements offers a great future potential for improved and cost-efficient integrated landfill $\mathrm{CH}_{4}$ emission quantification. However, these methods are difficult to apply for longer time periods, so in order to measure temporal $\mathrm{CH}_{4}$ emission changes, e.g. due to the effect of changes in atmospheric conditions (pressure, wind and precipitation), a measurement method that is able to measure continuously is required. Such a method could be eddy covariance or static mass balance, although these procedures are challenged by topography and inhomogeneous spatial emission patterns, and as such they can underestimate emissions significantly. Surface flux chambers have been used widely, but they are likely to underestimate emission rates, due to the heterogeneous nature of most landfill covers resulting 
in sporadic and localised $\mathrm{CH}_{4}$ emission hotspots being the dominant emission routes. Furthermore, emissions from wells, vents, etc. are not captured by surface flux chambers. The significance of any underestimation depends highly on the configuration of individual landfills, their size and emission patterns.

\section{Introduction}

Landfill gas (LFG) is generated when organic material disposed in landfills decomposes anaerobically. The main components in LFG are methane $\left(\mathrm{CH}_{4}: 55-60 \% \mathrm{v} / \mathrm{v}\right)$ and carbon dioxide $\left(\mathrm{CO}_{2}: 40-45 \% \mathrm{v} / \mathrm{v}\right)$, the production of which occurs through three initial sequential phases followed by a phase characterised by stable $\mathrm{CH}_{4}$ and $\mathrm{CO}_{2}$ production (Christensen et al. 1996). LFG will continue to form until the majority of the organic material in the waste has been degraded, which can take several decades. Landfill gas that is not recovered or microbially oxidised in the landfill cover will be emitted into the atmosphere. Factors affecting the transport processes of $\mathrm{LFG}$, leading to $\mathrm{CH}_{4}$ migration and emission, can be divided into three classes: meteorological conditions (barometric pressure, precipitation, temperature, wind), soil/cover conditions (cracks, fissures, permeability, diffusivity, porosity, moisture content, organic content, $\mathrm{CH}_{4}$ oxidation capacity) and waste and landfill conditions (gas production rate, internal barriers, gas vents, lateral migration area) (Kjeldsen, 1996). Of particular importance are spatial and temporal variations in the soil's physical and chemical properties that influence soil gas transport and microbial activity (composition, depth, moisture, temperature, aeration status) (Scheutz et al., 2009).

The global emission and accumulation of greenhouse gases in our atmosphere is of great concern, and many countries have consequently committed themselves to reducing their emissions. Therefore, it is of the utmost importance to understand greenhouse gas sources and 
sinks. $\mathrm{CH}_{4}$ is a potent greenhouse gas with a global warming potential of 28 over a 100 -year timeframe (without including climate change feedback) (Myhre, 2013). The global atmospheric concentration of $\mathrm{CH}_{4}$ has increased from a pre-industrial value of about 722 to 1803 parts per billion (ppb) in 2011 (Hartmann et al., 2013), and it was about 1850 ppb in 2017 (Dlugokencky, 2018). The current atmospheric concentration of $\mathrm{CH}_{4}$ far exceeds the preindustrial range of the last 800,000 years (350 to $800 \mathrm{ppb}$ ) as determined from ice cores (IPCC, Masson-Delmotte et al., 2013). Of the approximately $49 \mathrm{GtCO}_{2} \mathrm{eq}^{-1}$ in total anthropogenic GHG emissions in 2010, about 16\% ( 7.8 $\left.\mathrm{GtCO}_{2} \mathrm{eq} \mathrm{y}^{-1}\right)$ came from $\mathrm{CH}_{4}$ (Victor et al., 2014). An important source of anthropogenic $\mathrm{CH}_{4}$ involves the disposal of organic waste in landfills. Of the total amount of municipal solid waste generated globally, about $67 \%$ is disposed in sanitary landfills or discarded in non-sanitary landfills or dumps (Fischedick et al., 2014). In Europe, landfills are the second largest (20\%) anthropogenic $\mathrm{CH}_{4}$ emission source, while in the United States, they are the third largest (20\%) (EEA 2016, USEPA 2016). On a global scale, $\mathrm{CH}_{4}$ emissions from landfills are estimated to account for about $8 \%$ of anthropogenic $\mathrm{CH}_{4}$ emissions (Blanco et al., 2014). Between 1970 and 2010, $\mathrm{CH}_{4}$ emissions from solid waste disposal almost doubled (Fischedick et al., 2014), and future gas emission as a result of waste disposal will depend on generated waste amounts, the success of diverting waste away from landfilling and the implementation of mitigation actions. Estimates indicate that annually about $12 \%$ of $\mathrm{CH}_{4}$ generated in global landfills is captured at sanitary landfills (Themelis and Ulloa, 2007), and so controlling fugitive $\mathrm{CH}_{4}$ emissions from landfills should be prioritised in waste management procedures. In Europe, for instance, landfills have to be registered nationally if they receive more than $10 \mathrm{Mg}$ waste per day or have a capacity above $25,000 \mathrm{Mg}$ (CEC, 2006). Moreover, if the emission is greater than $100,000 \mathrm{~kg} \mathrm{CH}_{4}$ annually, it should be reported to the European Pollutant Release and Transfer Register (CEC, 2006). 
The amount of $\mathrm{CH}_{4}$ emitted from landfills is often estimated using theoretical gas generation models, applying standard conditions with respect to waste composition and surface $\mathrm{CH}_{4}$ oxidation. The first-order decay (FOD) model is generally recognised as being the most widely used approach, as recommended by the Intergovernmental Panel on Climate Change in the IPCC Waste Model (IPCC, 2006). The FOD model assumes that the degradable organic matter in waste decays slowly over a few decades, during which time $\mathrm{CH}_{4}$ and $\mathrm{CO}_{2}$ are formed. If conditions are constant, the rate of $\mathrm{CH}_{4}$ production depends solely on the amount of carbon remaining in the waste. The FOD models in the IPCC (2006) guidelines are multi-component with individual values for $\mathrm{CH}_{4}$ generation potential and $\mathrm{CH}_{4}$ generation rate constants from the degradable organic carbon contained in various waste fractions. In some countries other FOD models have been developed to estimate $\mathrm{CH}_{4}$ emissions from specific landfills - examples being LandGEM (US) (Alexander et al., 2005), GasSim (UK) (Gregory et al., 2003) and Afvalzorg (The Netherlands) (Afvalzorg, 2015; Scharff \& Jacobs, 2006). The landfill $\mathrm{CH}_{4}$ emission is obtained by subtracting the fraction of $\mathrm{CH}_{4}$ that is collected and the fraction of the uncollected $\mathrm{CH}_{4}$ that is oxidised from the modelled $\mathrm{CH}_{4}$ generation. At landfill sites with gas collection, the amount of gas collected is often well-known, whereas the fraction of $\mathrm{CH}_{4}$ oxidised is unknown. The IPCC (2006) suggests a default value of maximum 10\%, which has been highly debated (e.g. Chanton et al., 2009). Stable carbon isotopic analyses have been used for in-situ landfill $\mathrm{CH}_{4}$ oxidation quantification (e.g. Chanton et al., 2008a; 1999; Börjesson et al., 2007); however, the validity of several assumptions in the methodology remains unresolved. FOD gas generation models have been complemented with more recent, sitespecific process-based emission models that take into account local conditions such as soil type, climate and $\mathrm{CH}_{4}$ oxidation rates to calculate overall $\mathrm{CH}_{4}$ emissions. One example in this regard is the Californian process-based $\mathrm{CH}_{4}$ emission model CALMIM, which includes site- 
specific seasonal soil microclimate and $\mathrm{CH}_{4}$ oxidation data (Spokas et al., 2015; 2011; Bogner et al. 2014; Bogner et al., 2011; Spokas and Bogner, 2011). The CALMIM model assumes that gas transport solely is governed by diffusion processes, while a similar model, the LandSEM model, also includes advective gas transport (Abichou et al., 2015). The process-based cover models estimate methane emission from the landfill cover using representative soil characteristics, and are thus not able to include emissions from landfill infrastructures such as leachate wells. Only few of the available models have been validated, and it is uncertain as to what extent they describe actual $\mathrm{CH}_{4}$ emissions (Cambaliza et al., 2017; De la Cruz et al., 2016; Mou et al., 2015; Spokas et al., 2015; Bogner et al. 2014; Scheutz et al., 2011a; 2011b; Scharff and Jacobs, 2006). In addition, input parameters such as deposited waste amounts and compositions are often of low quality or even unknown, and no single model is applicable to all landfills, due to the significant variations in landfill designs and operation (construction and aftercare), meteorological conditions (precipitation, temperature, wind, etc.) and landfill cover design and conditions. To assess landfill $\mathrm{CH}_{4}$ emissions, and to evaluate the efficiencies of mitigation initiatives such as gas collection, recovery systems and $\mathrm{CH}_{4}$ oxidation installations, measurement methods that can directly quantify $\mathrm{CH}_{4}$ emissions are thus needed. Furthermore, the quantification of $\mathrm{CH}_{4}$ emissions based on measurements will provide more accurate estimations and help evaluate the performance of currently used landfill gas generation and emission models.

Several measurement techniques are currently available, but none of them has been recognised as an international reference method. In addition, very few are commercially available - and then only in a handful of countries. A few new methods have been developed in the last few decades, albeit only in a small number of cases have the measurement techniques been compared to existing techniques and/or to gas generation models used in 
different countries. The main challenge in measuring $\mathrm{CH}_{4}$ emissions from landfills is their temporal and spatial variability. Several studies have shown high spatial variations in landfill surface $\mathrm{CH}_{4}$ emissions (Lando et al., 2017; Scheutz et al., 2008; 2003; Ishigaki et al., 2005; Czepiel et a1., 1996a; Verschut et al., 1991); for instance, rates can vary by up to seven orders of magnitude within a few metres, due to cracks or holes in the soil cover, thereby leading to emission hotspots (Bogner et al., 1997). Rachor et al. (2013; 2009) investigated variations in $\mathrm{CH}_{4}$ emissions within just one square metre and found that even on this small scale, emissions were very heterogeneous. Several studies have suggested that at some sites a substantial proportion (50-75\%) of the total emission occurs from a very small part of the total surface area dominated by hotspots (Gonzalez-Valencia et al., 2016; Scheutz et al., 2011a; 2011b; Bergamaschi et al., 1998; Czepiel et al., 1996a). Furthermore, the temporal variability of $\mathrm{CH}_{4}$ emissions is often caused by changes in atmospheric conditions, and it has been reported how both pressure changes and absolute pressure can lead to fluctuations within just a few hours (e.g. Xu et al., 2014; Fredenslund et al., 2010; Gebert and Gröngröft, 2006; Czepiel et al., 2003; Christophersen et al., 2001). Most of the studies reporting on temporal emission variation were carried out at landfills without active gas collection or even at sites with landfill gas venting (intended or unintended). It should be emphasised that operationally, at modern landfills, wellfield vacuums are frequently adjusted relative to weather conditions, and at such sites emissions could thus be expected to be less influenced by atmospheric pressure changes. However, only a few studies have investigated the influence of barometric pressure changes at landfills with gas collection. In three recent studies carried out at such locations, $\mathrm{CH}_{4}$ collection and emissions were found to vary significantly over time and to be related to changes in atmospheric conditions such as barometric pressure changes and changes in wind speed and direction (Rees-White et al., 2019; Aghdam et al., 2019; Fjelsted, et al., 2019). 
Temporal and spatial emission variations, combined with the large area and challenging topography of most landfills, make $\mathrm{CH}_{4}$ emission quantification a challenging task.

In general, landfill emission measurement techniques can be divided into two categories: surface emission factor techniques and mass emission techniques, also called 'bottom-up' and 'top-down' techniques. Surface emission factor techniques are based on quantifying emissions emanating from part of the surface of the landfill and obtaining an emission factor, which then is applied to the remaining areas of the landfill. Mass emission techniques, on the other hand, involve quantifying the landfill emission from a larger area or the whole site. The objective of this paper is to provide a review of the different measurement techniques by explaining the techniques as well as their applications, advantages and limitations when quantifying an entire landfill's $\mathrm{CH}_{4}$ emission. A second objective is to review studies on landfill $\mathrm{CH}_{4}$ emissions, using one or more of the measurement techniques, and then compare and reflect on these studies to enable the reader to choose the best method for his/her application.

\section{Methane measurement techniques}

The different measurement techniques available for quantifying $\mathrm{CH}_{4}$ emissions from landfills all measure against different scales. Measurements are made from the landfill surface, to several kilometres away (Fig. 1) and across different timescales, from minutes, to weeks or months. Measuring at the surface of the landfill has the advantage of excluding interference from surrounding $\mathrm{CH}_{4}$ sources, but it also involves the challenge of having to extrapolate the measurements to represent a large area with heterogeneous emissions, as it is practically impossible to cover the whole landfill area. Methods measuring at elevated heights are able to evaluate emissions from a larger area, thereby making extrapolation to full landfill size more 
applicable, while methods measuring at a greater distance away are able to quantify whole-site emissions, though they are more sensitive to potential surrounding sources. Table 1 provides an overview of qualitative reconnaissance techniques used to locate $\mathrm{CH}_{4}$ emission hotspots, while Table 3 provides an overview of the various $\mathrm{CH}_{4}$ measurement techniques employed for emission quantification at landfills. In the following sections, each technique is described in detail and its advantages and limitations are discussed.

\subsection{Qualitative reconnaissance techniques}

Methodology. A common reconnaissance technique involves screening the landfill surface for $\mathrm{CH}_{4}$, using a handheld gas analyser (such as a portable flame ionisation detector (FID), or other analysers based on optical or electrochemical measurement principles, gauging concentrations in ppm just above the landfill cover. A screening campaign can be performed by dividing the landfill into sections, whereby $\mathrm{CH}_{4}$ recordings are taken systematically at grid points or alternatively during walkovers (e.g. Scheutz et al., 2011a; 2011c). A survey of $\mathrm{CH}_{4}$ concentrations may give an indication of certain hotspots or installations with $\mathrm{CH}_{4}$ leakages. In the US, landfill operators are legally obliged to carry out $\mathrm{CH}_{4}$ surface screenings four times a year, and this is also mandatory in the United Kingdom. Surface $\mathrm{CH}_{4}$ screenings can be extended to include carbon dioxide $\left(\mathrm{CO}_{2}\right)$ concentrations, for example by using a handheld infrared (IR) detector or a portable cavity ring down spectrometer (CRDS), the latter of which has the advantage of being fast and able to measure concentration changes in sub-ppm levels. Recent developments of the method have made it portable (e.g. Juncher Jørgensen et al., 2015). Elevated $\mathrm{CO}_{2}$ to $\mathrm{CH}_{4}$ concentrations may indicate areas experiencing $\mathrm{CH}_{4}$ oxidation (confer section 2.3).

Theoretically, surface air concentrations recorded at a constant and short distance away from the soil/atmosphere interface should be positively correlated with surface fluxes. However, this 
correlation depends on interactions between the measuring device (e.g. pumping flow), the ground (e.g. soil characteristics, vegetation) and the atmosphere (weather conditions) - and thus it is not constant in time and space. Lando et al. (2017) found that landfill surface $\mathrm{CH}_{4}$ concentrations recorded using an open-path handheld laser detector were inversely proportional with wind speed, and thus the authors recommended that surface concentration measurements should be performed at wind speeds $<1 \mathrm{~m} \mathrm{~s}^{-1}$. It has been suggested that $\mathrm{CH}_{4}$ flux (after proper calibration) can be quantified from simple measurements of $\mathrm{CH}_{4}$ concentrations close to the landfill surface (Lando et al., 2017; Gonzalez-Valencia et al., 2016; 2015; Park et al., 2016; Mackie and Cooper 2009).

However, $\mathrm{CH}_{4}$ flux vs. surface concentration measurements often show relatively weak and varying correlations, depending on the measuring time and location, and they are thus associated with large uncertainties (Lando et al., 2017; Gonzalez-Valencia et al., 2016; 2015; Franzidis et al., 2008).

Other methods for identifying $\mathrm{CH}_{4}$ emission hotspots include the use of thermal infrared cameras that measure temperature differences (thermal anomalies) (Fjelsted et al., 2019; Tanda et al., 2017; Battaglini et al., 2013; Lewis et al., 2003). Areas with elevated temperatures may be caused by the leakage of landfill gas, which is warmer than the surroundings. Thermal infrared photography is best carried out at times when there are large temperature differences between the landfill gas and the surroundings, e.g. in the early morning when the air is cold. However, a number of factors, other than emissions of warm LFG, can cause temperature differences and result in measurement bias, which was thoroughly investigated in Lewis et al. (2003). Warmer areas in the surface can be caused by high biological activity, e.g. soil or compost respiration or $\mathrm{CH}_{4}$ oxidation. Measurement bias can also be caused by variability in emissivity of different surfaces. Different vegetation and soil conditions on the surface, having different emissivity, will cause temperature anomalies in thermal infrared images. As an example, dark areas, such as soil surfaces without vegetation or a dark plastic liner, will have higher heat absorption, and thus they will appear as 
warm areas in an infrared image and result in a false indication of a $\mathrm{CH}_{4}$ emission. Finally, a certain minimum $\mathrm{CH}_{4}$ flux can be expected before a temperature anomaly becomes detectable. Fjelsted and co-workers (2019) concluded that the minimum observable $\mathrm{CH}_{4}$ emission for the thermal infrared camera to identify an emission hotspot was $150 \mathrm{~g} \mathrm{CH}_{4} \mathrm{~m}^{-2} \mathrm{~d}^{-1}$ occurring from an area of more than 1 $\mathrm{m}^{2}$. In combination, these precautions most likely explain why studies presented in the literature remain somewhat inconclusive on the usefulness of thermal infrared technologies for identifying landfill $\mathrm{CH}_{4}$ emissions (e.g. Fjelsted et al., 2019; Capodici et al., 2015; Beaumont et al., 2014; Battaglini et al., 2013; Desideri et al., 2007; Ishigaki et al., 2005; Raco et al., 2005; Lewis et al., 2003).

Both thermal infrared cameras and lasers capable of measuring $\mathrm{CH}_{4}$ could be integrated with unmanned aerial vehicle (UAV) technology to overfly the landfills (e.g. Fjelsted et al. 2019; Tanda et al., 2017; Beaumont et al., 2014).

Finally, a visual inspection of the landfill surface is a simple and useful method, in that cracks in the surface, vegetation damage and damage to the gas collection system are potential areas of $\mathrm{CH}_{4}$ emissions. Table 1 provides an overview of qualitative reconnaissance techniques that can be used to study areas with $\mathrm{CH}_{4}$ emissions.

Advantages and limitations. The advantages of the qualitative reconnaissance techniques described herein are generally that they provide an opportunity for a relatively fast, easy and inexpensive overview of areas or installations with $\mathrm{CH}_{4}$ emissions that can subsequently be repaired. Analytical devices are often easy to employ and the measurements can be performed by landfill staff. Qualitative reconnaissance techniques are thus valuable tools in the daily operation and maintenance of the landfill cover and of site installations such as the gas collection and recovery systems. However, it must be emphasised that none of the reconnaissance techniques provides emission measurements in standard units for mass flux such as, for example, mass per area 
per time. At best, for instance using a field FID, they provide a semi-quantitative determination of atmospheric $\mathrm{CH}_{4}$ concentrations near the ground surface. It should also be noted that relatively low readings in the air above the cover layer are not necessarily an indication that there is no emission, and so surface $\mathrm{CH}_{4}$ fluxes can thus not be determined based on above-surface $\mathrm{CH}_{4}$ concentration readings. Where landfill surface $\mathrm{CH}_{4}$ concentrations are high, it may be possible to combine the field FID with a simple surface chamber apparatus for the direct measurement of fluxes (confer section 2.3). Similarly, thermal infrared photography can be coupled with surface flux measurements (e.g. Fjelsted et al., 2019; Capodici et al., 2015; Battaglini et al., 2013).

\subsection{Vertical soil gas concentration profiles}

Methodology. Vertical soil gas concentration profiles in the landfill top cover are obtained by inserting soil gas probes, with slits at the lowest part of the probe for the gas to enter, at different depths of the cover and, if necessary, in the upper part of the waste. Gas samples are withdrawn from the probes for determining pore gas composition $\left(\mathrm{CH}_{4}, \mathrm{CO}_{2}\right.$, oxygen $\left(\mathrm{O}_{2}\right)$ and nitrogen) in the cover layer. Soil gas profiles can provide useful qualitative information on gas transport and distribution (Scheutz et al., 2008; 2003; Christophersen and Kjeldsen, 2001; El-Fadel et al., 1995), dominant gas transport processes (diffusive vs. convective transport) and $\mathrm{CH}_{4}$ oxidation (Röwer et al. 2011; Gebert et al., 2011; Scheutz et al., 2011a; 2001c; Christophersen et al., 2001; Jones and Nedwell, 1990). As an example, $\mathrm{CH}_{4}$ and $\mathrm{CO}_{2}$ concentration gradients of the cover layer can provide information on whether $\mathrm{CH}_{4}$ oxidation is occurring and at what depth it takes place (Scheutz et al., 2009; 2008; 2003). $\mathrm{CH}_{4}$ and $\mathrm{CO}_{2}$ gas concentration profiles have also been used to quantify $\mathrm{CH}_{4}$ oxidation (Gebert et al., 2011). The methodology was developed and presented by Gebert et al. (2011) and has been used in a few emission studies (Gonzalez-Valencia et al., 2016; Pratt et al., 2013; Kjeld, 2013). 
It is important to be aware, however, that processes other than microbial $\mathrm{CH}_{4}$ oxidation contribute to $\mathrm{CO}_{2}$ generation, e.g. soil respiration, and thus the method could lead to an overestimation of the $\mathrm{CH}_{4}$ oxidation. It is therefore advised that background measurements (measurements performed in areas or soils without landfill gas exposure) are performed in order to assess background soil respiration. In some settings such as compost-based landfill covers, $\mathrm{CO}_{2}$ generation caused by compost respiration can be a significant or even the dominant $\mathrm{CO}_{2}$ generating process, and the method will thus not be applicable for $\mathrm{CH}_{4}$ oxidation evaluation.

Vertical soil gas concentration profiles can also be used in combination with soil sampling at the respective cover depths, and following subsequent incubation in the laboratory (by adding $\mathrm{CH}_{4}$ and $\mathrm{O}_{2}$ and subsequently measuring $\mathrm{CH}_{4}$ turnover) the $\mathrm{CH}_{4}$ oxidation potential of the cover soil can be determined. Incubation tests can be performed in different conditions, such as testing for temperature and moisture content, which can provide a better understanding of the influence of weather and climate conditions on $\mathrm{CH}_{4}$ oxidation (Scheutz et al., 2009; 2004).

Vertical soil gas concentrations combined with pressure gradient measurements in landfill covers can be used to calculate the flux of $\mathrm{CH}_{4}$ through the landfill cover (El-Fadel et al., 1995; Jones and Nedwell, 1990; Young, 1990). The advective flux can be calculated using Darcy's law, i.e. $\mathrm{u}=-\mathrm{K} \cdot(\mathrm{dP} / \mathrm{dz})$, where $\mathrm{u}$ is the mass flux of gas $\left(\right.$ in $\left.\mathrm{m}^{3} \mathrm{~s}^{-1} \mathrm{~m}^{-2}\right), \mathrm{K}$ is the medium's permeability for gas flow (in $\mathrm{m}^{2} \mathrm{~s}^{-1} \mathrm{~Pa}^{-1}$ ) and $\mathrm{dP} / \mathrm{dz}$ is the pressure gradient at depth $\mathrm{z}$ (in $\mathrm{Pa} \mathrm{m}^{-1}$ ) (Young, 1990). Often, $\mathrm{CH}_{4}$ flux will be governed by both advection and diffusion, where diffusive flux is driven by concentration differences. In such cases, Fick's first law of diffusion should be included, which requires knowledge of a number of factors such as diffusivity, porosity, water content and gas viscosity (Kjeldsen, 1996; El-Fadel et al., 1995). 
313 For a more correct description of the diffusion process, Stefan Maxwell equations may be 314 required instead of Fick's first law in case gas compositions vary significantly in the modelled 315 soil domain (Molins et al., 2008).

Advantages and limitations. Vertical soil gas concentrations combined with pressure gradient measurements have only been used a few times for evaluating a whole landfill's $\mathrm{CH}_{4}$ emissions (Bogner et al., 1995); however, the method has been used for evaluating the influence of atmospheric pressure on $\mathrm{CH}_{4}$ emissions (El-Fadel et al., 1995; Young, 1990). The technique lacks spatial (small sampling area of $<0.5 \mathrm{~m}^{2}$ ) and temporal resolution (samples are taken within 10-20 minutes), which is in conflict with the often heterogenic emissions escaping from landfill surfaces. Emissions from hotspots, such as cracks in the top cover, or from leachate wells cannot be captured using the gas concentration profile method. Additionally, the method is very labour-intensive. Its main advantage, though, is the ability to obtain useful information on mechanisms influencing the emissions, such as rapid changes in atmospheric pressure, the effect of wind velocity and relative emissions as the result of convection and diffusion. Soil gas profile measurements can also be useful in understanding $\mathrm{CH}_{4}$ sources and sinks, and they can therefore be useful for evaluating $\mathrm{CH}_{4}$ oxidation (Röwer et al. 2011; Gebert et al., 2011; Christophersen et al., 2001) and landfill gas migration (Christophersen and Kjeldsen, 2001; El-Fadel et al., 1995). Christophersen et al. (2001) studied lateral gas migration and oxidation at an old, completely and finally covered landfill, using gas profiles combined with static flux chambers, finding seasonal variations with no $\mathrm{CH}_{4}$ emissions during summer, due to increased oxidation in the soil. They also found that atmospheric pressure, temperature and especially soil moisture content had an influence on $\mathrm{CH}_{4}$ emissions, while offsite migrating $\mathrm{CH}_{4}$ was oxidised before entering into the atmosphere. 
In summary, vertical soil gas concentration profiles have limited applications as a standalone method for quantifying entire landfill $\mathrm{CH}_{4}$ emissions. The method has only been used for $\mathrm{CH}_{4}$ flux quantification in a few studies dating back to the $1990 \mathrm{~s}$, but it can nevertheless provide valuable information about landfill gas migration, oxidation and influencing factors (e.g. changes in weather conditions), and this supporting information could be useful in combination with other quantitative emission methods.

\subsection{Surface flux chambers}

The main idea behind the flux chamber is that gas escaping from the surface of a landfill site is captured inside the chamber, and changes in concentrations therein are then measured. Based on the rate of concentration change, the emission flux can be calculated. Many different variations of the flux chamber have been developed, but in general it has two basic setups, using either an open or a closed chamber. Fig. 2 shows the concepts of the open and closed chamber methods, including the basic equations used for calculating surface flux in each case. Table 2 provides an overview of the characteristics of the two types of chambers.

\subsubsection{Closed surface flux chambers}

Methodology. Closed flux chambers - also referred to as 'static chambers' - are historically likely to be the most commonly used techniques for estimating $\mathrm{CH}_{4}$ emissions from landfills. These closed chambers can be set up with or without recirculating the analysed gas flow. The recirculation mode is preferably used if the $\mathrm{CH}_{4}$ analyser withdraws a significant gas volume from the chamber, in order to avoid errors on the flux measurement by removing gas as part of the sampling activity. The chamber technique was originally developed to measure gas emissions from natural soils (e.g. Rolston, 1986), where surface emissions are 
controlled by diffusion and happen more homogeneously, and so minimal emission variations are expected over the emission area. The $\mathrm{CH}_{4}$ emission flux from the surface covered by the chamber is calculated from measuring changes in $\mathrm{CH}_{4}$ concentrations inside the chamber:

$$
\text { Flux }=\frac{d C}{d t} \cdot \frac{V}{A}
$$

Eq. 1

where $\mathrm{dC} / \mathrm{dt}$ is the change in concentration over time $\left(\right.$ mole $\left.\mathrm{m}^{-3} \mathrm{~h}^{-1}\right), \mathrm{V}$ is the volume of the chamber $\left(\mathrm{m}^{3}\right)$ and A is the surface area covered by the chamber $\left(\mathrm{m}^{2}\right)$.

The closed flux chamber has been used widely for quantifying gas emissions from landfill surfaces, where emissions are controlled by both pressure and concentration gradients (e.g. Lucernoni et al., 2016; Rachor et al., 2013; Abichou et al., 2011; Bogner et al., 1995; Kjeldsen and Fisher, 1995). Different chamber configurations and sizes have been used, from small-size (chamber footage area less than $0.1 \mathrm{~m}^{2}$ e.g. Scheutz el al. 2014; 2011) and mid-size (0.4-1 $\mathrm{m}^{2}$ e.g. Christophersen et al., 2001), to over-size (larger than $15 \mathrm{~m}^{2}$ e.g. Geck et al., 2016). A theoretically optimal chamber design was suggested by Lucernini et al. (2016) based on computational fluid dynamics simulations. In many cases, the chambers have been equipped with mechanical or electrical fans to assure the complete mixing of gases inside the chamber during sampling. In order to take repeated measurements at the exact same locations, chambers can be supplemented with a frame that is permanently installed in the landfill cover, topped by a removable lid (Pratt et al., 2013; Schroth et al., 2012; Christophersen et al., 2001). In order to minimise errors caused by increased pressure and concentration build-ups inside the chamber, measurements are often done over a very short time period, and preferably no more than a few minutes. A pressure build-up can be avoided by installing a vent consisting of a long smalldiameter tube, which can equalise pressure between the chamber and the surrounding air. 
Losses due to diffusion along the vent tube have been considered negligible (Hutchington and Mosier, 1981). However, due to the venturi effect, vents may potentially introduce more errors than they solve. Vented chambers have been used in a $\mathrm{CH}_{4}$ emission study performed on an old landfill (Rachor et al., 2013).

Due to its easy setup and inexpensive use, the chamber technique has been suggested for measuring entire landfill emissions (UK Environment Agency, 2010). To obtain a wholesite $\mathrm{CH}_{4}$ emission rate, measurements are sometimes done by using randomly distributed chambers or a systematic grid of single-point measurements, following which emissions for the entire site are found by calculating an average of the measured emissions multiplied by the landfill area, or by using geo-statistical tools (e.g. Gonzales-Valencia et al., 2016; Battaglini et al., 2013, Ishigaki et al., 2005).

Advantages and limitations. The surface flux chamber method is very simple to employ and does not require advanced analytical equipment; $\mathrm{CH}_{4}$ fluxes, for example, can be measured with an FID or an IR detector. The method is able to detect small fluxes of $\mathrm{CH}_{4}-$ in most cases positive $\left(\mathrm{CH}_{4}\right.$ release), though they can also be negative (uptake of atmospheric $\mathrm{CH}_{4}$ ). The surface flux chamber method is the only technique currently applicable for determining the flux of trace gases contained in LFG (non-methane volatile organic compounds; NMVOCs) (Scheutz et al., 2008; 2003). The flux chamber method, sometimes combined with soil gas profile measurements, is a well-proven and appropriate method for quantifying $\mathrm{CH}_{4}$ oxidation at a specific location on the surface (using the carbon mass balance method developed by Christophersen et al., 2001), or for studying environmental factors controlling $\mathrm{CH}_{4}$ emissions and oxidation. As mentioned in section 2.2., using $\mathrm{CO}_{2}$ surface fluxes to quantify $\mathrm{CH}_{4}$ oxidation could result in overestimations, and the $\mathrm{CO}_{2}$ flux contribution from soil or compost respiration should thus be determined either by performance of background flux measurements 
or by laboratory soil/compost incubation studies (Scheutz et al., 2017). Alternatively, by measuring the stable carbon isotope composition of $\mathrm{CH}_{4}$ in the flux chamber, in-situ $\mathrm{CH}_{4}$ oxidation can be determined (Chanton and Liptay, 2000; Liptay et al., 1998). However, the use of stable carbon isotopes to quantify $\mathrm{CH}_{4}$ oxidation should be interpreted with caution, as the isotopic fractionation during microbial oxidation is influenced by a number of factors, including temperature, soil moisture, $\mathrm{CH}_{4}$ and $\mathrm{O}_{2}$ supply (e.g. Gebert et al., 2017; Chanton et al., 2008b). Additionally, processes other than microbial activities contribute to isotopic fractionation, such as transport processes (Gebert et al., 2013). Several studies have used flux chambers to observe, for example, the influence of changes in atmospheric pressure, precipitation or temperature on the emission of $\mathrm{CH}_{4}$ (e.g. Fredenslund et al. 2010; Gebert and Gröngröft, 2006; Czepiel et al., 2003; Christophersen and Kjeldsen, 2001; Kjeldsen and Fischer, 1995).

One of the limitations of the surface flux chamber is that it is intended for measuring diffusional surface fluxes. At landfills, surface $\mathrm{CH}_{4}$ emissions are governed by both diffusion and advection, the most dominant of which is site-specific and can even vary between different areas of the landfill, e.g. hotspots versus non-hotspots. At sites (and/or during specific time periods) where the flux is controlled mainly by pressure differences over the landfill cover, surface flux can be underestimated, due to a fast pressure build-up in the static chamber (Senevirathna et al., 2007; Conen and Smith, 1998).

The main limitation of using closed surface flux chambers is that the measured emission represents only the small area covered by the flux chamber itself (often $0.5-1 \mathrm{~m}^{2}$ ), and it only captures the emission over a short period of time (minutes). In this way, the method has the same spatial and temporal limitations as the pore gas concentration profiles mentioned in the previous section. In an attempt to obtain a reliable estimate of the total $\mathrm{CH}_{4}$ emission 
from a landfill or section thereof, it is often proposed to apply a systematic testing strategy (Gonzalez-Valencia et al., 2015; Battaglini et al., 2013; Bour, 2007; Spokas et al., 2006; Lang, 2004; Rosevaer et al., 2004; Savanne et al., 1997; Bogner and Scott, 1995). Such a sampling strategy may be that the landfill is divided into grids of a certain size, followed by flux chamber measurements performed in the grid points. Geo-statistic models can then be used to estimate total $\mathrm{CH}_{4}$ emissions from the landfill (Gonzalez-Valencia et al. 2015; Spokas et al., 2003; Börjesson et al., 2000). Typical distances between the grid points are between 10 and 60 metres, and the more measurements performed, the more accurate a result can be expected. Back in the 1990s, the UK Environment Agency developed a best practice guideline on how to measure total $\mathrm{CH}_{4}$ emissions from a landfill by creating a network of flux chamber measurements and integrating individual flux measurements (UK Environment Agency, 2010). Large numbers of measurements are needed in this regard, and the UK EPA suggests these should be based on the size of the landfill area (or the area to be investigated), with a minimum of six measurements and an additional number of measurement points equal to 0.15 times the square root of the area (in $\mathrm{m}^{2}$ ) (UK Environment Agency, 2010). This results in 16 measurement points for a $5000 \mathrm{~m}^{2}$ site, 53 points for $100,000 \mathrm{~m}^{2}$ and 156 points at 1 million $\mathrm{m}^{2}$. However, even when performing a very large number of measurements, the measured $\mathrm{CH}_{4}$ emission will only represent what has leaked out from a very limited area $(<1 \%)$ of the total landfill. In addition, a significant part of the emitted $\mathrm{CH}_{4}$ occurs through small hotspots, as demonstrated by Rachor et al. (2013), and the likelihood of capturing one of these hotspots with a grid of chamber measurements is very small; thus, underestimating total landfill emission is to be expected from the surface flux chamber method (Scheutz et al., 2011c; 2011b; Babilotte et al., 2011; Green et al., 2010; Fredenslund et al., 2010; 2007; Goldsmith et al., 2008). 

measurements with qualitative screening methods, in order to identify hotspots (see section 2.1) and subsequently perform more flux chamber measurements in these areas. Here, time-consuming to perform flux chamber measurements, due to the large number that need to be performed. A proper measurement often requires that vegetation is cut down and that the however, it is important that emissions from the hotspot areas are weighed correctly with the other measurements, in order to obtain a correct average. Even though measuring devices that can $\log \mathrm{CH}_{4}$ concentration over short time intervals (seconds) are currently available, it is very chamber's contact with the surface is sealed with, for example, bentonite. If there is very high vegetation on the cover layer, it may in fact be a major challenge to perform flux chamber measurements, and so a campaign covering a whole landfill site will therefore often take from two to five days. During this period, changes in weather conditions (atmospheric pressure, temperature, precipitation, etc.) may cause significant changes in emissions, which may in turn complicate any interpretation of the results relative to what the measured emission represents. Finally, surface flux chambers cannot be used to measure emissions from leaks in the gas and leachate collection system (risers, pumping stations, extraction and leachate wells), which can be significant routes for landfill gas leakages (Scheutz et al., 2011c; Fredenslund et al. 2010).

\subsubsection{Open surface flux chambers}

Methodology. The open flux chamber method - also referred to as the 'dynamic chamber method' - is similar to the closed method, albeit the chamber is continuously flushed with air, to avoid possible errors caused by pressure and concentration build-up as a result of surface emissions and to enable measurements over longer periods of time (e.g. Tregoures et al., 1999). The emission rate is subsequently calculated by using flow through the chamber and concentrations at the inlet and outlet, as shown in Fig. 2. It is important to maintain pressure in 
the chamber comparable with ambient pressure, in order to obtain reliable emission rates. Similar to the closed chamber, an open chamber can be equipped with a vent to equalise pressure between the chamber and the surrounding air. Guidance on how to use both closed and open flux chambers was published by Eklund (1992). Open flux chambers have also been used in a few landfill emission studies as an alternative to the closed chamber approach, to measure $\mathrm{CH}_{4}$ emissions through landfill covers (Gallego et al., 2014; Park and Shin, 2001; Reinhart et al., 1992).

Advantages and limitations. The advantage of the open flux chamber is that it is continuously flushed with air, which limits the risk of pressure build-up and gas concentration accumulation underestimating the measured flux. Pressure built up inside the chamber will affect the flux through advection, whereas an accumulation in gas concentrations inside the chamber will affect the diffusional flux. In both cases, this can result in non-linear gas concentration accumulation curves, which will lead to underestimating the surface flux. In addition, using an open flux chamber allows measurements over a longer period of time (e.g. Huber-Humer and Lechner, 2001a; 2001b; Tregoures et al., 1999; Verschut, 1991). The flow through the open chamber (also referred to as the 'carrier gas') can consist of ambient air, or alternatively a synthetic gas can be used. If ambient air is used, it is important that the background concentration of the gaseous compound being analysed is constant. At landfill surfaces, $\mathrm{CH}_{4}$ background concentration will often not be constant, which is why it may be necessary to use a synthetic gas as a carrier when using open chambers. In comparison to closed chambers, the set-up for open chambers is more demanding in terms of pumps required to control the flow through the chamber and potentially synthetic gas containers, which will also make it more time-consuming to perform a flux measurement. Regarding the temporal and spatial challenge, open flux chambers have the same advantages and disadvantages as closed 
flux chambers, and if employed at landfill sites with emission hotspots, one will likely underestimate entire landfill site emission.

In summary, heterogeneous emissions from landfills make it difficult to quantify total $\mathrm{CH}_{4}$ emissions using the flux chamber approach. In spite of several studies using the approach to quantify whole landfill site emissions, this approach remains unvalidated in terms of its appropriateness for estimating accurately total $\mathrm{CH}_{4}$ emissions, and thus there is a need for further documentation (including appropriate numbers of measurements and statistical methods for data interpretation) and testing against other measuring methods. Currently, flux chambers are not recommended for whole landfill site $\mathrm{CH}_{4}$ emission quantification. However, flux chambers can be an important tool for obtaining emission rates for smaller areas, such as an engineered biocover for $\mathrm{CH}_{4}$ oxidation (e.g. Scheutz et al. 2017; 2011b; Geck et al., 2016) or smaller scale landfill cover studies (e.g. covered vs. non-covered cells, slopes vs. none-sloped area, etc.) (Wang et al., 2017; Di Trapani et al., 2013; Scheutz et al. 2008).

\subsection{The eddy covariance method}

Methodology. Micrometeorological eddy covariance measurement relies on the fact that emitted gases are mixed vertically by turbulent eddies in the atmospheric inversion layer. The method is often used for measuring emissions from larger surfaces such as fluxes of $\mathrm{CH}_{4}, \mathrm{~N}_{2} \mathrm{O}$ and $\mathrm{CO}_{2}$ from agricultural soils (e.g. Kroon et al., 2010; Hensen et al., 1996), but it has also been applied on landfills (Xu et al., 2015; McDermitt et al., 2013; Schroth et al., 2012; Eugster and Plüss, 2010; Lohilla et al., 2007; Laurila et al., 2005). In a micrometeorological eddy covariance setup, continuous measurements of the vertical gas mass fluxes of $\mathrm{CH}_{4}, \mathrm{CO}_{2}$ and water are often carried out (Fig. 3). The vertical flux of $\mathrm{CH}_{4}$ at this height takes place mainly through convection, and any emissions can therefore be found from $\mathrm{CH}_{4}$ concentrations and 
local vertical wind velocities. Due to air turbulence, the wind will sometimes have an upward component and at times a descending component. In the event that there is an emission from the surface, the concentration of $\mathrm{CH}_{4}$ through the plane will be slightly higher when the wind is rising, and so an average positive $\mathrm{CH}_{4}$ flux (in unit mass per time) can be measured. $\mathrm{CH}_{4}$ concentrations and vertical wind velocities are measured continuously and at high frequency ( 10 times per second). The measured data are then stored and the average $\mathrm{CH}_{4}$ emission is calculated for time intervals, for example of 15 minutes.

Measurements are taken on a tower with enough distance to the surface to cover the desired surface area. Typical heights will range between 0.5 and 10 metres, and the contributing emission area will (when the measuring time is long enough to capture wind directions from all angles) have a radius of approximately 100 times the height of the measurement point and form a drop shape with the tower located at the top of the drop (McDermitt et al., 2013).

The source area is estimated by using a dispersion model, and total emissions from the landfill are calculated by applying the obtained emissions per area to the total landfill area. Advantages and limitations. One of the advantages of micrometeorological eddy covariance measurements is the possibility of having continuous measurements over longer time periods, as well as measuring both $\mathrm{CH}_{4}$ and $\mathrm{CO}_{2}$, depending on the analytical device. The method can run automatically for months, providing insights regarding temporal variability as well as average emissions. $\mathrm{Xu}$ et al. (2015) measured the response of $\mathrm{CH}_{4}$ emissions to change in barometric pressure over a six-month period. Combined with other information such as landfill gas composition and gas recovery, the method can provide an indication of total landfill gas production and $\mathrm{CH}_{4}$ oxidation (Xu et al., 2015; Lohila et al. 2007; Scharff et al., 2003). However, a comparison of $\mathrm{CH}_{4}$ to $\mathrm{CO}_{2}$ ratios obtained from raw landfill gas 
composition analysis, with ratios based on surface flux measurements, should be done with caution, as soil respiration also results in $\mathrm{CO}_{2}$ surface fluxes. Similar to microbial $\mathrm{CH}_{4}$ oxidation, soil respiration depends on temperature and will thus vary over the season. The main disadvantage of the micrometeorological eddy covariance method is the limited surface area it covers, meaning that it most likely does not provide representative emissions for the whole landfill site. In addition, the covered area changes in line with changing wind speed, and the often challenging typography of a landfill is far from the flat surface that offers the ideal conditions for applying this method. Despite the challenges of typography and heterogeneous emissions, the micrometeorological eddy covariance method is considered by some as a suitable estimation technique for measuring $\mathrm{CH}_{4}$ emissions from landfills (Xu et al. 2015; Lohilla et al., 2007; Laurila et al., 2005), although Tregoures et al. (1999) found that it was not suitable for landfill gas emission quantification. From the comparison studies, it can be concluded that eddy covariance methods can be applied to landfills with relatively homogeneous emissions and flat surfaces. Lohilla et al. (2007) compared their eddy covariance measurements with closed chamber measurements and found good agreement, but closed chamber methods face the same challenges with heterogeneous emissions, and it is therefore questionable if the eddy covariance method can be validated by using chamber methods as a comparison.

\subsection{The stationary mass balance method}

Methodology. In the stationary mass balance method, $\mathrm{CH}_{4}$ concentrations are measured at different heights above the landfill surface (Fig. 3). By simultaneously measuring wind velocity and comparing it with the measured concentrations, the horizontal flux of $\mathrm{CH}_{4}$ can be calculated, which represents emissions from the landfill area upwind of the sampling point. 
The method is also called the ' $1 \mathrm{D}$ mass balance method', as it measures $\mathrm{CH}_{4}$ flux that passes 577 the target tower (1D) and not through a larger vertical plane (2D) as in other mass balance methods (see Sections 2.6, 2.7 and 2.9). It is important that the measured $\mathrm{CH}_{4}$ concentrations are corrected for any background concentration of $\mathrm{CH}_{4}$, as the $\mathrm{CH}_{4}$ flux will otherwise be overestimated. This is done by measuring at the top of the tower, assuming that the background concentration has the greatest influence on the measured $\mathrm{CH}_{4}$ concentration at this point. The height of the measurement point determines the source area contributing to elevated $\mathrm{CH}_{4}$ concentrations, and when measurements are taken at a sufficient height above the landfill, in theory, the whole $\mathrm{CH}_{4}$ plume is measured and the total $\mathrm{CH}_{4}$ emission flux is obtained (Scharff, 2003). Normally, however, this requires a very high tower, and in practice a lower tower is used, thereby obtaining data from a smaller part of the landfill. By performing measurements at a maximum height of 10 metres, emanations from an area with a radius of approximately 150 metres away from the tower will be covered (Scharff, 2003). The specific location and size of the emission area contributing to the measured emissions is determined by dispersion modelling, for which knowledge about atmospheric stability and the surrounding topography is required. Emissions from all directions are measured as the wind direction changes, thus enabling the method to provide emission rates from different areas of the landfill. It can be set up for automated, continuous measurements over a longer period, thereby enabling long emission data time series (weeks to months).

Advantages and limitations. The mass balance method shares many of the same advantages and limitations as the eddy covariance method. It can be automated so that emissions $\left(\mathrm{CH}_{4}\right.$ and other gases $\mathrm{CO}_{2}$ and $\left.\mathrm{N}_{2} \mathrm{O}\right)$ from the landfill can be measured over a longer period of time, providing information on the variability of the $\mathrm{CH}_{4}$ emission over time and partly providing a better determination of the average emission. Experiences with landfill 
600

601

602

emission quantification using the stationary mass balance method are very limited. The method was used for $\mathrm{CH}_{4}$ quantification at landfills in the Netherlands (Oonk and Boom, 1995) and was found to give similar emission fluxes in a comparison study with an inverse modelling method, along with tracer gas calibration (Scharff, 2003) (Table 3).

A major drawback is that the method does not measure emissions from the entire landfill but only from a small part thereof. In addition, it can be difficult to determine exactly which part of the landfill has contributed to the measured emission, so any results thus depend on assumptions about where $\mathrm{CH}_{4}$ emissions take place. If emissions occur mainly closer to the measuring tower than assumed, the overall emission will be overestimated. It is therefore advisable to perform a qualitative $\mathrm{CH}_{4}$ screening of the landfill surface, for example using an FID (see section 2.1), to evaluate any relevant areas before a final interpretation of the measured flux is made.

\subsection{Radial plume mapping}

Radial plume mapping (RPM) for measuring landfill $\mathrm{CH}_{4}$ emissions has been under development since the late 1990s. The method uses a combination of concentration measurements and wind profiles to obtain a surface emission factor from an upwind area. It can be used in two different configurations - horizontal (HRPM) or vertical (VRPM) (Fig. 4), with HRPM providing qualitative information on the location of emission hotspots, while VRPM is used for quantifying emissions.

Methodology. Quantifying emissions by VRPM is achieved by measuring the mass of $\mathrm{CH}_{4}$ crossing two vertical planes located upwind and downwind of an emission area, respectively. $\mathrm{CH}_{4}$ fluxes across the vertical planes are determined from the product of concentrations in the air and wind velocity measured at each point in the two planes, and the 
approach is thus considered a mass balance method. $\mathrm{CH}_{4}$ emissions from the area are found by subtracting the flux measured through the upwind plane from the flux measured through the downwind plane. If the concentration in the upwind plane (i.e. background $\mathrm{CH}_{4}$ concentration) can be assumed to be constant over both the plane itself and over the measurement period, the method can be simplified and the $\mathrm{CH}_{4}$ flux can be calculated from the product of wind velocity and the difference between the upwind and downwind $\mathrm{CH}_{4}$ concentrations. Multiple laser beam paths are used by pointing a laser beam at reflectors positioned at different heights (and at different distances to the laser across the plume) (Fig. 4). The laser and reflectors are placed as close to the landfill as possible or to the landfill area to be measured. Each laser beam path provides an average $\mathrm{CH}_{4}$ concentration, representing the beam's air package. Laser beam paths are typically up to $300 \mathrm{~m}$ long, and a typical maximum tower height for the vertical reflectors is $10 \mathrm{~m}$. Based on the measured average concentration paths, a cross-section concentration profile of the plume is modelled and a two-dimensional (2D) concentration profile is obtained, hence the name 'plume mapping'. This modelling step has a series of assumptions about the distribution of the plume, which adds to the level of uncertainty. Using the measured concentrations and modelling, the method provides information about the 2D distribution of $\mathrm{CH}_{4}$ concentrations in the vertical plane of the plume (Goldsmith et al., 2012; Hashmonay et al., 2008; Hashmonay et al., 2001; 1999; Wu et al., 1999). The area contributing to the measured $\mathrm{CH}_{4}$ flux is confined by the upwind and downwind measuring planes. If a setup with only one laser is used, the area contributing to the measured $\mathrm{CH}_{4}$ flux across the vertical measurement plane is determined by reverse dispersion modelling.

Advantages and limitations. The limitations of the method are that the measured $\mathrm{CH}_{4}$ flux normally represents only one part of the landfill (due to the limited range of the laser) and that it is difficult to determine the contributing area precisely. In order to determine emissions 
648 from the entire landfill, several measurements must be taken, or alternatively it must be 649 assumed that the measured emission is representative of the entire landfill and can then be 650 summarised to determine total emissions. A methodological challenge in this regard is that 651 both wind speed and $\mathrm{CH}_{4}$ concentration may vary over the measured plane. Thus, ideally, 652 measurements should be carried out simultaneously at different places in the upwind and 653 downwind planes, which require additional lasers, thereby adding considerably to the cost of 654 the instrumentation and the demand for staff. When using one laser, the area contributing to 655 the measured $\mathrm{CH}_{4}$ flux through the vertical plane is determined by inverse dispersion 656 modelling, thus adding further to the uncertainty of the method. Determining the correct area contributing to the measured emission can be a challenge on landfill sites with complex topography (Abichou et al., 2010; Goldsmith et al., 2008), and at some landfills (or parts of 659 landfills) the method cannot actually be applied. In many sites, part of the waste is deposited above ground, forming a small hill in the landscape. If measurements are carried out such that the plane through which the $\mathrm{CH}_{4}$ flux is measured is placed on top of the landfill, any emission 662 from the slope will not be included in the measurement, which may lead to a significant 663 underestimation of emissions, as hotspots are often seen on slopes, due to horizontal gas 664 transport and incomplete covers (Babilotte et al., 2009; 2008). Likewise, when reflectors and 665 lasers are placed on the downwind edge of a landfill, $\mathrm{CH}_{4}$ emitted from an upwind part of the 666 landfill may be at an elevation higher than 10 metres (often the maximum position above 667 ground of the reflector) when it reaches the measurement points, which will add significantly 668 to the uncertainty of the method. An additional disadvantage is that measurements are usually 669 taken in hours, and thus any temporal emission variation can be a challenge to capture. 670 Another drawback is that the method (theory, equipment and application) is generally difficult 
to understand for third parties, making it difficult for an independent body to assess the results of emission studies performed by this method.

The US-EPA has proposed the method for quantifying $\mathrm{CH}_{4}$ emissions from landfills and given it the name 'Other Test Method-10' (OTM-10). In its development, more than 1000 individual tracer gas measurements were conducted across 61 experiments. Capture efficiency was determined as a function of wind speed (WS) and wind-adjusted release distance (WARD). Thoma et al. (2010) calculated a simple equation for the capture efficiency factor, namely $\mathrm{CEF}=0.712-3.10 \times 10^{-3}(\mathrm{WARD})+0.102(\mathrm{WS})$, and reported that the maximum upwind distance included in the measured area was $295 \mathrm{~m}$ at a wind speed of $2 \mathrm{~m} \mathrm{~s}^{-1}$ and 460 $\mathrm{m}$ at $7 \mathrm{~m} \mathrm{~s}^{-1}$.

The method has been tested and used for quantifying 20 landfills in the USA, using a double laser and reflector system (Goldsmith et al., 2012; Abichou et al., 2010). Abichou et al. (2010) found that a change in wind direction could introduce an uncertainty factor of $20 \%$ and that the area contributing to the measured flux is a function of the atmospheric stability class with an uncertainty level of 10-30\%. Goldsmith et al. (2012) pointed out that the OTM-10 method may have an application for the landfill industry, although only $31 \%$ of the collected data in their comprehensive study of 20 landfills in the USA fulfilled quality requirements. The method is challenged by the complex topography of a landfill, and there are sites where the method is simply not applicable. In general, the output from RPM can be used to identify emission hotspots, which makes this method useful for performing site surveys before initiating remediation activities; however, it is highly important to assign the correct emission area to the measured emission, which can be difficult at landfills with a challenging topography (Goldsmith, 2008). The upshot of the disadvantages of the method is that it has 
been used infrequently in recent years and replaced by other methods (tracer gas dispersion, DIAL and most recently aircraft-based mass balance).

\subsection{Mass balance using aerial measurements}

Methodology. In recent years, the mass balance approach has been applied using atmospheric $\mathrm{CH}_{4}$ concentration measurements from aircrafts or UAVs. The method relies on concentration measurements across the downwind plume at several heights, preferably covering the total height and width of the $\mathrm{CH}_{4}$ plume. The measured concentrations are then used for creating a 2D concentration plane, which is combined with measured wind speed and direction for calculating the flux of $\mathrm{CH}_{4}$ through the downwind plane - and thus emissions from the landfill. Fast measuring instruments are needed for performing aerial $\mathrm{CH}_{4}$ measurements with sufficient temporal resolution, to create a $2 \mathrm{D}$ concentration plane. Such instrumentation includes cavity ring down spectroscopy, quantum cascade laser spectroscopy and thermal-infrared (TIR) imaging spectrometry (Cambaliza et al., 2017; 2015; Tratt et al., 2014; Hirst et al., 2013; Peischl et al., 2013). Measurements using aircraft are usually carried out several kilometres downwind of the landfill, as the aircraft can carry instrumentation sensitive enough to measure concentration differences (plume concentrations above background) at this distance. UAV-mounted instrumentation needs to be lighter in weight. Such instrumentation currently has less sensitivity, and the UAV must therefore measure closer to the landfill than aircraft (Allen et al., 2018). However, the fast development in instrument/sensor technology might soon change this situation.

Advantages and limitations. One advantage of the method is that aerial measurements do not require access to a landfill. When using an aircraft, each landfill is measured relatively quickly, and so many landfills (and other $\mathrm{CH}_{4}$ sources) in an area can be measured in one 
flight. An advantage compared to VRPM and DIAL is that $\mathrm{CH}_{4}$ concentrations at specific points in the total cross-section of the $\mathrm{CH}_{4}$ plume can be measured, resulting in a relatively detailed 2D concentration plane. The advantage of the using aircraft for $\mathrm{CH}_{4}$ plume measurements compared to using UAVs is that measurements performed further downwind of the landfill will give a more uniform and less changeable $\mathrm{CH}_{4}$ plume, which is easier to model correctly, as the measured concentrations can better be assumed to be constant in comparison to when measurements are performed closer to the landfill, where local wind turbulence and emission variations will result in larger concentration variations at individual $\mathrm{x}, \mathrm{y}$ and $\mathrm{z}$ points in the atmosphere. However, measurements taken far away from the landfill also introduce possible errors, due to reduced $\mathrm{CH}_{4}$ plume concentrations and to the risk of including $\mathrm{CH}_{4}$ for surrounding non-landfill emission sources.

One limitation is that it is not possible to quantify individual $\mathrm{CH}_{4}$ sources relatively close to each other, such as farms or wastewater treatment plants near to the measured landfill. Additionally, the creation of the 2D concentration plane is associated with uncertainty, as well as the wind field applied for calculating the flux. Ideally, the wind field (wind speed and direction) should be measured at different heights above ground surface. Another limitation is accessibility to an aircraft, sourcing fast and accurate instrumentation and associated costs.

\subsection{The tracer gas dispersion method}

Methodology. The tracer gas dispersion method uses simultaneous measurements of atmospheric $\mathrm{CH}_{4}$ concentrations and a tracer gas released at the emission source at a known rate (Fig. 5). It is assumed that $\mathrm{CH}_{4}$ and the tracer gas undergo the same fate (dispersion, chemical/photochemical reaction) in the atmosphere within the time span of the campaign, so for this reason, tracer gases with relatively long atmospheric lifetimes are used. $\mathrm{SF}_{6}$ has been 
used in many tracer gas studies, such as research on atmospheric dispersion (Martin et al., 2011), ventilation (Timko et al., 1984) and the $\mathrm{CH}_{4}$ emission of ruminants (Storm et al., 2012) and gas facilities (Lamb et al, 1995), as it has a very long lifetime in the troposphere $(3,200$ years) and negligible background concentrations (Ravishankara et al., 1993). However, $\mathrm{SF}_{6}$ is a very potent GHG (23,500 times more potent than $\mathrm{CO}_{2}$ on a 100-year scale) (Myhre et al., 2013), and so it is not valid for environmental studies. A move has been made toward using $\mathrm{N}_{2} \mathrm{O}$ instead (Galle et al., 2001), as it is stable in the atmosphere and measurable, although it is present in significant atmospheric concentrations, currently around $331 \mathrm{ppb}$ (NOAA, 2018). Nonetheless, $\mathrm{N}_{2} \mathrm{O}$ is also a strong GHG (298 times more potent than $\mathrm{CO}_{2}$ on a 100 -year scale) (Myhre et al., 2013), which in recent studies has led to the use of acetylene $\left(\mathrm{C}_{2} \mathrm{H}_{2}\right)$ as a tracer gas (Rees-White et al., 2019; Mønster et al., 2015; 2014; Foster-Wittig et al., 2015a; Green et al., 2010). Although highly flammable, $\mathrm{C}_{2} \mathrm{H}_{2}$ is not a potent $\mathrm{GHG}$, it is cheap and it is relatively easy to release at a constant flow rate.

Based on downwind atmospheric concentrations of $\mathrm{CH}_{4}$ and the tracer gas measured during its controlled release, $\mathrm{CH}_{4}$ emissions from the source can be calculated. The tracer dispersion method is generally divided into either a stationary or a dynamic approach (Fig. 5).

\subsubsection{The stationary tracer gas dispersion method}

The stationary tracer gas dispersion method relies on $\mathrm{CH}_{4}$ and tracer gas measurements performed at fixed single or multiple points in the plume downwind from the emission/release source. They have been used previously to study emissions from several different sources, such as aromatic hydrocarbons in refinery wastewater (Howard et al., 1992), $\mathrm{CH}_{4}$ from cattle barns (Kaharabata et al., 2000; Marik and Levin, 1996), $\mathrm{CH}_{4}$ from slurry tanks (Kaharabata et al., 1998) and ammonia from manure spreading (Galle et al., 2000). The first landfill application of 
the method was done by Czepiel et al. (1996), using $\mathrm{SF}_{6}$ as a tracer gas. Before $\mathrm{CH}_{4}$ and tracer gas measurements were conducted, the downwind plume was located by using an analyser placed in a vehicle. Subsequently, evacuated canisters were placed across the plume transect, in order to sample air in the plume. Similar setups have been used in other studies using evacuated canisters (e.g. Scharff et al., 2009; Jacobs et al., 2007; Scheutz et al., 2007; Tregoures et al., 1999) or sampling bags filled by small pumps (Scharff and Hensen, 2009; Babilotte et al., 2008). For landfills with poor access to downwind plume transects, Galle et al. (2001) developed a method based on air concentration measurements performed at a single point. $\mathrm{CH}_{4}$ and tracer gas concentrations were measured for hours at a single point downwind of the landfill, using $\mathrm{N}_{2} \mathrm{O}$ as the tracer gas, and the method was used for a number of landfills in Sweden (Börjesson et al., 2009).

Recent studies have shown that leachate wells can be significant point sources for $\mathrm{CH}_{4}$ emissions (Scheutz et al., 2011a, 2011b; Fredenslund et al., 2010). Fredenslund et al. (2010), for instance, suggested quantifying emissions from leachate wells, using a small-scale tracer gas dispersion method (Fig. 6), whereby tracer gas was released at the bottom of the leachate well and $\mathrm{CH}_{4}$ and tracer gas were measured at a single point a few metres downwind of the well.

Advantages and limitations. An important assumption is that the tracer gas should simulate the $\mathrm{CH}_{4}$ emission. In order to obtain a good mix of tracer gas and $\mathrm{CH}_{4}$, measurement or sampling campaigns have to be executed at a sufficient distance away from the landfill (e.g. Mønster et al., 2014; Delre et al., 2018). Misplacing the tracer gas can result in significant under- or overestimation of the emission, while the required measuring distance depends on the physical size of the source, atmospheric conditions and the topography between the landfill 
and the measurement/sampling point (e.g. Fredenslund et al., 2019b; Rees-White et al., 2019; Delre et al., 2018; Taylor et al. 2016).

One drawback of the static tracer dispersion method is that it can be hard to locate the $\mathrm{CH}_{4}$ plume. Samples are thus taken blindly and the method relies on a stable wind direction throughout the sampling period - a significant change in wind direction could move the downwind plume away from the sampling point(s). If the $\mathrm{CH}_{4}$ emission is not well simulated by the tracer gas, sampling at the fringe of the $\mathrm{CH}_{4}$ plume and tracer gas plume will result in false emission rates, as the ratio between the gases is not representative of the plume.

\subsubsection{The dynamic tracer gas dispersion method}

The dynamic tracer gas dispersion method is based on performing transects of the downwind plume and thereby measuring $\mathrm{CH}_{4}$ and trace gas concentrations near to ground level across the whole plume, along with the subsequent integration of the plumes. In order to use this method, a sensitive and relatively fast analytical instrument is needed. A Swedish group developed an FTIR instrument stable enough to be driven around in a van, enabling many successful studies of $\mathrm{CH}_{4}$ emissions from landfills (e.g. Scheutz et al., 2011b). This method was then developed further to use two or more trace gases for quantifying $\mathrm{CH}_{4}$ emissions from multiple sources close to each other (Scheutz et al., 2011b).

The analytical instruments used for tracer gas dispersion measurements have often been built specifically for this purpose and are large, heavy and power-demanding; consequently, they are expensive to run and require highly skilled personnel to operate and maintain them effectively. Recently, new instruments have been developed based on cavity ring down spectroscopy (CRDS). These instruments are smaller, lighter and easier to mount in a vehicle. The cavity ring down instrument developed for the tracer gas dispersion method focuses on 
measuring $\mathrm{CH}_{4}$ and $\mathrm{C}_{2} \mathrm{H}_{2}$ (tracer gas), and it has been used successfully for dynamic plume measurements at two Californian landfills (Green et al., 2010), 15-30 Danish landfills (Mønster et al., 2015; Fredenslund et al., 2019a), a number of landfills in the UK (Bourn et al., 2019; Rees-White et al., 2019) and 15 US landfills (Foster-Witting et al., 2015a). Besides, it was used in a model comparison study at a new landfill (de la Cruz et al., 2016) and a horizontal stationary plume approach using gas sampling from a weather balloon, for measuring in the plume centre, which was found to be situated at an elevated height (Han et al., 2010) and used for exploring emission variations and possible bias in the tracer gas dispersion method (Matacchiera et al., 2019; Delkash et al., 2015).

Advantages and limitations. The advantage of the dynamic tracer gas dispersion method is its simplicity, because when the $\mathrm{CH}_{4}$ and tracer gas plumes are mixed fully, analysis and calculation are relatively straightforward. An important advantage of the method is that it measures total emissions from the landfill, including those from hotspots and installations at the site, and may be used independently of the landfill structure or topography. Moreover, it can be applied at landfills of all sizes. When applied at larger landfills, it may be necessary to release tracer gas at several points (Rees-White et al., 2019; Aghdam et al., 2018; Mønster et al., 2014), but the method can also be used for improving the input data required for inverse modelling. Piccot et al. (1996) and Hensen and Scharff (2003) used tracer gas measurements to obtain accurate information about dispersion conditions during their measurement campaign, thus improving the dispersion model in use. The advantages and limitations of the CRDS based instrument have been explored and compared recently with simultaneous FTIR measurements (Delre et al., 2018; Mønster et al., 2014). Foster-Wittig et al. (2015a), for instance, published a study involving tracer gas dispersion measurements on a large number of US landfills, including suggestions for using data quality criteria for filtering measurements 
for downwind traverses where tracer and $\mathrm{CH}_{4}$ were not significantly mixed. Recent studies recommend that a minimum 10 plume transects, but preferably 15 , should be performed to reduce the variability of a measurement (Fredenslund et al. 2019b; Mønster et al., 2014), while learning how to establish the minimum detectable emission rate at individual sources has also been suggested (Delre et al., 2017). In another recent study, Taylor et al. (2016) explored the uncertainty of the tracer dispersion method by modelling downwind concentrations from released tracer gas. They found that the main potential error was the correct placement of the tracer gas bottles, while factors such as wind speed and direction had a much smaller influence but could nevertheless be emphasised by the physical layout of the landfill and the emission areas. Taylor et al. (2016) also concluded that the main uncertainties depend on the landfill and thus are site-specific. The disadvantages of the technique are its dependence on the right weather conditions (wind direction and wind speed) to ensure sufficient gas mixing, combined with proper road access, which makes it difficult to measure at some landfills with limited access and very few surrounding roads. Matacchiera et al. (2019) suggested that modelling could be used as an initial step in planning a tracer gas dispersion measurement campaign (tracer gas placement and measuring distance etc.), but the method alone cannot identify onsite emission sources, and so care must be taken regarding the presence of other $\mathrm{CH}_{4}$ sources (manure storage tanks, farms, composting facilities) in the surrounding area, which can cause extensive errors in site quantification. Furthermore, the instrumentation is expensive and requires expertise to operate it effectively. An additional disadvantage is that measurements are usually taken in hours (2-6 hours) or over a few days, and thus the temporal variation of landfill gas emission can be a challenge to capture. Recent and current research focuses on method validation (Fredenslund et al., 2019b; Matacchiera et al., 2019; Delre et al., 2018; 
Mønster et al., 2014) and the establishment of quality criteria for data processing (Fredenslund et al., 2019b; Foster-Wittig et al., 2015a).

\subsection{Differential absorption LiDAR method}

The differential absorption LiDAR (DIAL) method transmits pulsed laser radiation into the atmosphere. Part of this radiation is then backscattered by atmospheric constituents and can be measured by a detector to determine $\mathrm{CH}_{4}$ concentrations by tuning the laser to the appropriate absorption lines and comparing this with a laser at a slightly different wavelength that is reflected in a similar way to the first laser but not absorbed by $\mathrm{CH}_{4}$. The laser can be pointed in any direction, and for landfill applications, measurements are taken along several lines of sight, thereby obtaining a vertical concentration distribution downwind of the landfill or sections thereof for which emissions are to be quantified (see Fig. 7). This allows for capturing the entire vertical profile of the $\mathrm{CH}_{4}$ plume, and emissions from the landfill (or landfill section) can be calculated by combining the vertical concentration profile with wind speeds at different heights (Innocenti et al., 2017; Robinson et al., 2011; Babilotte, 2011; Babilotte et al., 2010).

Measurements are normally taken downwind and close to the landfill, in combination with upwind measurements, to check for interfering sources and to obtain background concentrations. Individual landfill sections can also be measured by 'shooting' the laser in a vertical plane immediately downwind of the targeted section at the landfill (Babilotte, 2011). A moveable DIAL system is a large setup mounted on a truck, and very few are currently available worldwide, and it has been applied mainly for quantifying fugitive emissions caused by petrochemical processes, while its use at landfill sites is still limited (Innocenti et al., 2017; Bourn et al., 2019; Babilotte, 2011; Robinson et al., 2011; Babilotte et al., 2010). 

size of the analytical setup and the complexity involved in data handling. The truck transporting the setup requires good, smooth roads for access, and measurements depend on wind direction and infrastructure. In addition, stable and accurately measured wind conditions are needed for precise flux quantification. Wind speed above ground level should be measured at different heights for optimal modelling of the wind profile. As with other remote sensing measurements, DIAL is sensitive to possible interfering sources in the vicinity of the measured area. Measurements are conducted over hours or days, and long-term temporal variations can therefore be difficult to capture. The advantage of the DIAL method is that it can measure $\mathrm{CH}_{4}$ over a distance of $400-800 \mathrm{~m}$, depending on atmospheric conditions, hence enabling measurements of the total vertical concentration plane of small landfills and thereby eliminating the effect of spatial emission variation. At larger landfills, it is necessary to perform more measurements, due to the limited range of the laser. In such cases, the challenge is to determine which area contributes to the $\mathrm{CH}_{4}$ flux measured through the vertical profile. The NPL (National Physics Laboratory) in England has two complete DIALs and has conducted measurements at several landfill sites in the country (Innocenti et al., 2017; Bourn et al., 2019). At a large landfill, a measurement campaign usually takes up to one week, with the first day used to prepare the analytical equipment. In the following days, the truck is moved around the landfill (or along its edge) and measurements are taken from different sections to be added up at the end of the measurement campaign. The DIAL has the option of measuring other atmospheric species by scattering light in infrared or ultraviolet spectra, such as ethane, hydrogen, sulphur oxide, ozone and benzene, below ppm level (Babilotte et al., 2010). 


\subsection{Inverse dispersion modelling method}

Inverse modelling relies on downwind concentration measurements. By combining these measurements with meteorological data, the emission rate from a source of known location can be calculated using the wind direction and the theory of gas dispersion in the atmosphere. The inverse modelling method can be divided into two approaches, using stationary or mobile measurements.

\subsubsection{Inverse modelling - stationary}

In stationary inverse modelling, one or several measurement points, or a path-integrated concentration, are used downwind of the landfill. Data are recorded either by taking continuous concentration measurements or by sampling for a fixed amount of time, aligned with subsequent analysis in the laboratory. Applying the concentration measurements in an appropriate model, together with information on atmospheric conditions and topography, provides an estimate of emission rates. Several different approaches to this method have been developed, using long-term sampling at one or multiple fixed points, by employing one or multiple continuous measurements or cross-plume-integrated concentration measurements (e.g. Riddick et al., 2017; Terent'eva et al., 2017; Foster-Wittig et al., 2015b; Zhu et al., 2013; Abichou et al., 2012; Figueroa et al., 2009). Different models have been developed based on the dispersion of gases, an example of which is the AERMOD steady-state Gaussian plume model, which simulates atmospheric dispersion in the boundary layer. It can handle both ground-level and elevated sources as well as different types of terrain, where the latter requires detailed information on elevation, surface structures, land use, etc. AERMOD was developed for regulatory purposes and to evaluate industrial emission, and it is thus not targeted specifically at landfills, though it has been used in various studies, for example to evaluate dust 
emissions (Westbrook et al., 2007), $\mathrm{CH}_{4}$ emissions from a Canadian landfill (Wyles et al., 2010) and suggested as a method to improve the planning of tracer gas dispersion measurements (Matacchiera et al., 2019).

Additionally, inverse dispersion modelling has been introduced for area sources (e.g. Flesch et al., 1995), and specific models have been developed for path-integrated concentrations and for point concentration measurements, e.g. LASAT (Janicke Consulting, Überlingen, Germany) and WindTrax (Thunder Beach Scientific, Nanaimo, Canada). Common to these models is the need for information about the surface and the shape of the source, the location of measurements and wind speed and direction. Additional information on surface-induced turbulence can be used for improving the model output. The LASAT model, using path-integrating concentration measurements combined with anemometer measurements, has been employed for estimating $\mathrm{CH}_{4}$ emissions from a landfill in Germany (Zhu et al., 2013) and a composting facility in Austria (Hrad et al., 2014). WindTrax has been used to estimate $\mathrm{CH}_{4}$ emissions, using singlepoint measurements performed 700 metres from a UK landfill (Riddick et al., 2018) and 300 metres from another UK landfill to compare with two other model approaches (a simple Gaussian plume model and a Lagrangian dispersion model) using measurements taken at one point $7 \mathrm{~km}$ from the landfill (Gaussian plume) and from four measurement points ranging from 7 to $100 \mathrm{~km}$ away from the landfill (Lagrangian dispersion model) (Riddick et al., 2017).

\subsubsection{Inverse modelling - dynamic}

Dynamic inverse modelling relies on concentration measurements across a plume downwind of an emission source. The method is equivalent to the dynamic tracer dispersion method, but it is done without releasing a tracer gas. Instead, measured concentration profiles are used in combination with wind data, to fit into an inverse model and calculate emission rates from the source. At landfill sites, measurements are typically done from $500 \mathrm{~m}$ to several 
kilometres downwind of the site, depending on the size of and emission rate from the landfill. The further the distance to the landfill, the more the spatial variation of the emission will be minimised, and the landfill can be seen as a single-point source in the calculations of emission rates, which is an important assumption when, for example, using a simple Gaussian model. The analytical equipment used for these kinds of measurements needs to be able to measure concentration differences of down to a few ppb, with a background concentration of $\mathrm{CH}_{4}$ normally sitting between 1800 and 2000 ppb. Currently available and capable instrumentations include quantum cascade laser spectroscopy, tuneable diode laser spectroscopy or cavity ring down spectroscopy, each of which has its own advantages and disadvantages in terms of temporal resolution and the number of measurable species.

Advantages and limitations. Mobile plume measurement with inverse modelling has the advantage of measuring the emission plume from the entire landfill site, regardless of size. The measured plume will also include emissions from the slopes of the landfill and the gas and leachate collection systems, which are often difficult to measure using on-site methods.

\section{Disadvantages include the need for specialised analytical equipment and a detailed emission} model of the landfill, which needs a number of input parameters such as atmospheric stability, surface-induced turbulence and wind speed. For optimal conditions, the landfill should be located in a relatively flat area with a road crossing the downwind plume at a suitable distance away. In addition, accurately measured and relatively stable meteorological conditions are desirable, such as stable wind direction and speed, minimal changes in atmospheric pressure and stable atmospheric conditions in relation to turbulence. Hensen and Scharff (2001) used inverse Gaussian modelling and calibrated their model using controlled emissions of $\mathrm{N}_{2} \mathrm{O}$ as a tracer gas, making it similar to a tracer gas dispersion method, albeit with subsequent inverse modelling, as measurements were taken too close to the landfill for total mixing of the tracer 
and $\mathrm{CH}_{4}$ plumes. The authors measured three landfills in the Netherlands and found emissions ranging between 40 and $392 \mathrm{~kg} \mathrm{CH}_{4} \mathrm{~h}^{-1}$. Lan et al. (2015) measured various $\mathrm{CH}_{4}$ emissions in the Barnett shale area, combining dynamic plume measurement and inverse Gaussian modelling. The emission quantifications included four landfills, with $\mathrm{CH}_{4}$ emissions ranging between 86 and $2086 \mathrm{~kg} \mathrm{~h}^{-1}$ and with an estimated uncertainty smaller than $60 \%$. Lamb et al. (2016) performed inverse modelling on various $\mathrm{CH}_{4}$ sources in Indianapolis, Indiana, to estimate the whole city's $\mathrm{CH}_{4}$ emissions, employing a tracer gas release approach for calibration. The measurements were comparable with emissions estimated from the mass balance modelling of aircraft measurements and inverse modelling from single-point (tower) stationary measurements (Lamb et al., 2016). Fredenslund et al. (2019a) used a similar approach, performing fast screenings of 91 Danish landfills, using downwind plume measurements and inverse Gaussian modelling to find landfills suitable for mitigation initiatives. $\mathrm{CH}_{4}$ emissions were modelled to range from no detectable plume and up to $43 \mathrm{~kg} \mathrm{~h}^{-}$ ${ }^{1}$. A good agreement between modelled emission rates with measured emission rates using the tracer gas dispersion method was shown (a correlation coefficient of 0.965 based on 24 measurement campaigns). Emission rates based on inverse Gaussian modelling were very sensitive to the choice of terrain and the Pasquill-Gifford stability class, which could affect the emission rate by more than $100 \%$ (Fredenslund et al., 2019a). Downwind $\mathrm{CH}_{4}$ plume measurements combined with inverse Gaussian modelling was thus found useful as a fast screening method but not appropriate for accurate landfill $\mathrm{CH}_{4}$ emission quantification.

In general, reverse modelling requires large amounts of high-quality input data to achieve a good emission estimate. Excellent atmospheric condition inputs (e.g. atmospheric stability, wind speed at different heights and surface-induced turbulence) from the exact area of emission are very important and can be difficult to obtain. Stationary measurements are also 
dependent on wind direction, and thus the correct placement of air sampling devices is of the utmost importance, as changes in wind direction can eliminate capturing $\mathrm{CH}_{4}$. The dynamic approach needs specialised analytical equipment, a detailed emission model of the landfill site and access to downwind roads. In an ideal world, the landfill should be located in a relatively flat area with a road crossing the downwind plume at a suitable distance away. In addition, accurately measured and relatively stable meteorological conditions are required, such as stable wind direction and speed, minimum changes in atmospheric pressure and stable atmospheric conditions in relation to turbulence. Static inverse modelling makes long time series possible, thereby overcoming the temporal variations of emissions. The dynamic approach has the advantage of measuring the emission plume from the whole landfill site, regardless of its size. The measured plume will also include emissions from the landfill's slopes and leachate collection systems. Generally, for the modelling methods, large numbers of input parameters are required, and the quality of these inputs influences significantly the outcome of the model's calculations. Obligatory factors such as wind speed, wind direction and atmospheric turbulence are highly variable over time, and correct values are difficult to obtain for accurate model calculations. Additionally, factors such as atmospheric stability class and surface roughness need to be determined or estimated.

\section{Methane emission comparison studies}

The different methodologies used to quantify $\mathrm{CH}_{4}$ emissions from landfills, in some cases, have been used in tandem to verify obtained emission rates (e.g. Lohila et al. 2007; Spokas et al. 2006; Börjesson et al. 2000; Mosher et al., 1999; Czepiel et al. 1996;). During the last couple of decades, a number of studies have evaluated available gas emission measurement methodologies by comparing them in field experiments, using controlled $\mathrm{CH}_{4}$ release or at 
actual landfill sites (Cambaliza et al., 2017; Babilotte, 2011; Babilotte et al., 2010;; Green et al., 2010; Goldsmith et al., 2008; Tregoures et al., 1999). Table 3 provides an overview of reported comparison studies in which three or more methods were compared. In recent studies, the flux chamber method has significantly underestimated actual $\mathrm{CH}_{4}$ emissions from landfill sites, while there has been better agreement between radial plume mapping and dynamic tracer gas dispersion (Green et al., 2010). The often underestimated emissions from flux chambers are most likely due to the fact that at many landfills a significant proportion of $\mathrm{CH}_{4}$ is emitted from small hotspot areas, which are not represented in the chamber meas urements. A similar result was observed by Schroth et al. (2012), who compared emission measurements from a 1500$\mathrm{m}^{2}$ landfill test area, using closed flux chambers and eddy covariance. Over five measurement days, the 16 randomly distributed flux chambers showed an uptake of $\mathrm{CH}_{4}$ (negative emissions) most of the time, while the eddy covariance measurements showed an emission during all five measurement days. Both quantification methods showed a large daily emission variation ranging from -0.07 to 5.1 (chamber) and 1.6 to $52.7 \mathrm{~kg} \mathrm{~h}^{-1}$ (eddy covariance). Tregoures et al. (1999) found slightly higher emissions, using static and dynamic flux chambers compared to static and dynamic tracer gas dispersion methods, and significantly higher results than using eddy covariance and static mass balance. Tregoures et al. (1999) concluded that the flux measured by eddy covariance and static mass balance was underestimated, as the setup and the dominant wind direction only allowed a small part of the landfill to be measured. The higher emission measured by chamber methods compared to tracer gas dispersion methods could be a result of tracer gas dispersion measurements being performed very close $(100-200 \mathrm{~m})$ to the landfill or that surface flux chamber measurements were performed at emission hotspots. Babilotte (2011) compared five methodologies at two landfills and three of the methods at a controlled release site at four different release configurations or rates (releases at one and two points with the 
same release rate, and releases at three points with different release rates (see Table 3 )). In the controlled release test, Babilotte (2011) found that VRPM slightly underestimated emissions (3 to $-13 \%)$ measured at a distance close to the source $(10 \mathrm{~m})$ and by -42 to $-48 \%$ at a distance $100 \mathrm{~m}$ away. The dynamic tracer gas dispersion method (using FTIR instrumentation and $\mathrm{N}_{2} \mathrm{O}$ as a tracer gas) overestimated emissions by between 4 and 19\%. The highest error rate occurred when the source furthest upwind did not release $\mathrm{CH}_{4}$, thus representing tracer gas misplacement and causing a higher dispersion of the tracer gas than the released $\mathrm{CH}_{4}$, therefore resulting in an overestimation. Plume measurements for the tracer gas dispersion method were taken $400 \mathrm{~m}$ to $450 \mathrm{~m}$ away from the release area, which was a sufficient distance to obtain well-mixed plumes of $\mathrm{CH}_{4}$ and tracer gas from a relatively small area, with 30 to 44 metres between emission spots. The DIAL method results showed both under- and overestimations, ranging from -21 to $+19 \%$, with no clear trends. Babilotte (2011) included closed flux instance, compared the eddy covariance method with static and dynamic inverse modelling at four landfills in The Netherlands and found comparable results, although the eddy covariance 
atmospheric stability parameters (Schaff et al., 2003). In addition, Babilotte et al. (2010) compared inverse modelling by using dynamic plume concentrations measured $300 \mathrm{~m}$ downwind of a landfill and $20 \mathrm{~m}$ downwind of the controlled release point. At the landfill, inverse modelling provided a significantly higher flux than for VRPM, tracer gas dispersion 1080 (static and dynamic) and DIAL (see Table 1). For the controlled release test, VRPM, both tracer gas methods (static and dynamic) and inverse modelling all seemed to overestimate emissions by factors of two to five, while DIAL underestimated by a factor of two. This study was carried out with a low release rate $\left(1.8 \mathrm{~kg} \mathrm{CH}_{4} \mathrm{~h}^{-1}\right)$. Later research showed that DIAL could quantify down to $3.6 \mathrm{~kg} \mathrm{CH}_{4} \mathrm{~h}^{-1}$ with an accuracy rate of $20 \%$ (Babilotte, 2011). Recently, Cambaliza et al. (2017) applied four quantification methods at a landfill in 1088 
method showed approximately twice as high a $\mathrm{CH}_{4}$ emission rate $\left(980 \mathrm{~kg} \mathrm{~h}^{-1}\right)$ as the tracer gas dispersion method $\left(480 \pm 110\right.$ and $\left.470 \pm 40 \mathrm{~kg} \mathrm{~h}^{-1}\right)$. The comparison of $\mathrm{CH}_{4}$ emissions measured using the static surface chamber and VRPM showed that the former was unable to capture the emissions observed with the VRPM method. Both methods were applied across the area with intermediate cover. The VRPM showed emissions ranging between 196 and $582 \mathrm{~kg}$ $\mathrm{h}^{-1}$, while the static chamber method ranged between 0.3 and $1.2 \mathrm{~kg} \mathrm{~h}^{-1}$.

\section{Conclusion and perspectives}

Historically, methane $\left(\mathrm{CH}_{4}\right)$ emission measurements from landfills were initiated primarily for research purposes, to obtain emissions at a specific place and time, or to monitor temporal variability over time. Surface emission monitoring using simple reconnaissance monitoring, such as FID walkovers, sometimes combined with surface flux chambers, are used by landfill operators to determine the spatial variability of the emission and for cover maintenance. Annual $\mathrm{CH}_{4}$ emissions reported for regulatory purposes are usually based on models, but when they are estimated solely from landfill gas generation models using waste data, these emissions are often overestimated due to a conservative approach and a lack of actual knowledge relating to deposited waste and $\mathrm{CH}_{4}$ oxidation. More detailed process-based models such as CALMIM have been developed to overcome some of these challenges. However, only a few of the available models have been validated, and it is uncertain as to what extent they describe actual $\mathrm{CH}_{4}$ emissions. For this reason, $\mathrm{CH}_{4}$ emission measurements are important and can provide further knowledge on actual emissions at individual landfills, which can then be used in model evaluation/validation and for greenhouse gas emission reporting. Current measurement methodologies do not allow continuous $\mathrm{CH}_{4}$ emission measurements at all landfills worldwide, but some countries are starting to work toward 
relevant regulations based on measurements instead of models. The recent development in mass emission techniques, especially the dynamic tracer gas dispersion method, certainly allows for shifting to measurement-based regulation. Measurements are also essential for quantifying the effect of emission mitigation initiatives, such as $\mathrm{CH}_{4}$ extraction and utilisation, or the engineered optimisation of $\mathrm{CH}_{4}$ oxidation at the surface, which can significantly lower the waste sector's emanations of greenhouse gases. One example is the nationwide implementation of biocovers at old landfills in Denmark, with compulsory emission measurements at all involved sites for quantifying the $\mathrm{CH}_{4}$ mitigation effect (Danish EPA, 2018; Scheutz and Kjeldsen, 2019). Another example is the approach proposed by Bourn et al. (2019) where landfills with gas collection have to fulfil a minimum methane collection efficiency based on annual methane emissions measurements.

The main challenges when quantifying landfill $\mathrm{CH}_{4}$ emissions are high spatial and temporal emission variations. No single emission measurement method is perfect, and many years of research and tests have revealed some of the advantages and disadvantages of individual approaches. To quantify the $\mathrm{CH}_{4}$ emission from an entire landfill, including a confidence interval, a mass emission method is required rather than a surface emission factor method. Both DIAL and tracer gas dispersion are mass emission methods, and by applying them accordingly, the total $\mathrm{CH}_{4}$ emissions from the landfill are measured - and thus the challenge with spatial emission variability is circumvented. Both the DIAL technique and the tracer gas dispersion method have been demonstrated successfully in several landfill studies. However, the DIAL method uses very complicated and expensive equipment, whereas the tracer gas dispersion method takes an easier approach and uses more affordable apparatus. The relatively high cost of the DIAL equipment and the requirement for highly skilled personnel is a potential barrier to routine measurements. Radial plume mapping, eddy covariance and the 
stationary mass balance method are all challenged by complex landfill topography and tend to cover only a fraction of the landfill, in which case extrapolation to the full landfill area is needed, thereby adding uncertainty to the measurements.

Methods measuring mass emissions from the whole landfill often result in higher emission rates in comparison to those measuring the emission rate from a given surface are a followed by extrapolation to the entire landfill. Surface flux chambers have been used widely for landfill $\mathrm{CH}_{4}$ emission measurements, but they are likely to underestimate emission rates, due to the heterogeneous nature of most landfill covers and the fact that emissions from wells, vents, etc. are not captured by flux chambers. Therefore, flux chambers are not recommended for whole landfill site $\mathrm{CH}_{4}$ emission quantification, but they can be combined with soil gas concentration profiles to provide useful information about landfill gas migration, $\mathrm{CH}_{4}$ oxidation and influencing factors (e.g. changes in weather conditions). Furthermore, this supporting information could be useful in combination with other quantitative emission methods.

Landfill $\mathrm{CH}_{4}$ emissions fluctuate over time (short-term within hours as well as seasonally) due to changes in landfill operation, environmental conditions, etc. Most of the current measuring techniques are employed for a short period and thus measure the emission over a short time interval (hours). An obvious challenge therefore remains in relation to how to plan measurement campaigns (number and frequency) and inevitably to interpolate the measured emissions at discrete times to annual emission rates useful for reporting and/or evaluation of mitigation actions. The development of cheaper emission techniques would allow for more frequent measurements, which in turn could be used for tuning existing landfill generation models and for estimating emissions over longer timescales. For measurements over longer time periods, static plume methods combined with inverse modelling, or eddy 
covariance and the static mass balance method, can be applied. These methods can be set up for continuous measurements and thereby capture temporal emission variations. An optimal approach could involve combining continuous measurements with frequent short-term measurements, using the DIAL or tracer gas dispersion methods. As a result, this approach could provide longer-term emission rate time series, which could be validated or adjusted by more accurate, albeit more expensive and infrequent, measurements.

In addition to quantitative methods, qualitative reconnaissance techniques exist. These are valuable tools in the daily operation and maintenance of the landfill cover and of site installations such as gas collection and recovery systems.

Currently, there is a fast development of potentially improved methods based on the flexibility of UAVs and aircraft. Accurate and high-precision $\mathrm{CH}_{4}$ instruments are currently too heavy to employ in UAVs, and aircraft-based measurements are still done mainly in the oil and gas sector. However, the fast development within both $\mathrm{CH}_{4}$ sensors and UAVs could soon allow the use of UAVs at landfills for measuring $\mathrm{CH}_{4}$ with sufficiently high accuracy and temporal resolution. In addition, satellites specifically measuring atmospheric $\mathrm{CH}_{4}$ concentrations are working on getting higher spatial resolution, in order to include area sources such as landfills.

Although several measuring methods for landfill $\mathrm{CH}_{4}$ emission quantification have been developed, the accuracy of many of these methods remains unknown. Determining this factor is a challenge, as accuracy and potential measurement errors stem from different influences extending far beyond the uncertainty of the analytical instrumentations applied. As an example, the choice of model input parameters, such as terrain conditions (open or urban, flat or elevated terrain, etc.), atmospheric conditions (mixing, stability, wind speed profiles, etc.) and spatial emission patterns (homogenous vs. inhomogeneous), will add to overall method uncertainty. This also means that 
uncertainty and potential errors are not only specific to each method and instrumentation applied, but also site-specific and depend on conditions on the measuring day. Moreover, some methods might not be applicable at all landfill sites and under all conditions, so their deployment in nonfavourable circumstances can cause large errors. Future research should hence focus on establishing method accuracy and developing best practice in terms of monitoring, data processing and interpretation guidelines.

With new technological capabilities for measuring $\mathrm{CH}_{4}$ emissions from landfills, there is a need to develop measurement plans and strategies to comply with current and future legislation, as well as to document mitigation actions. For regulatory purposes, an average emission rate is of interest, which is why measurement strategies must pay attention to the dynamic nature of landfill emissions. Future research should thus focus on developing measurement protocols and strategies to obtain emission rates representative of normal landfill operations and environmental conditions.

\section{References}

Abichou, T., Clark, J., Tan, S., Chanton, J., Hater, G., Green, R., Goldsmith, D., Barlaz, M.A., Swan, N., 2010. Uncertainties associated with the use of optical remote sensing technique to estimate surface emissions in landfill applications. J. Air Waste Manage. Assoc. 60, 460-470.

Abichou, T., Clark, J., Chanton, J., 2011. Reporting central tendencies of chamber measured surface emission and oxidation. Waste Manage. 31, 1002-1008.

Abichou, T., Clark, J., Chanton, J., Hater, G., Green, R., Goldsmith, D., Swan, N., 2012. A new approach to characterize emission contributions from area sources during optical remote sensing technique testing. J. Air Waste Manage. Assoc. 62, 1403-1410. 
Abichou, T., Kormi, T., Wang, C., 2015. A novel approach to estimate oxidation in interim landfill covers across the USA. International Journal of Environment and Waste Management. 15(4), 309-326.

Aghdam, E.F., Fredenslund, A.M., Chanton, J., Kjeldsen. P., Scheutz, C., 2018. Determination of gas recovery efficiency at two Danish landfills by performing downwind plume methane measurements and stable carbon isotope isotopic analysis. Waste Manage. 73, 220-229.

Aghdam, E.F., Scheutz, C., Kjeldsen. P., 2019. Impact of meteorological parameters on extracted landfill gas composition and flow. Waste Manage. In press. https://doi.org/10.1016/j.wasman.2018.01.045

Alexander, A., Burklin, C., Singleton, A., Landfill Gas Emissions Model (LandGEM) Version 3.02 User's Guide. US EPA Report number: EPA-600/R-05/047. Available at https://www3.epa.gov/ttn/catc/dir1/landgem-v302-guide.pdf . Accessed May 2018).Allen, G., Hollingsworth, P., Kabbabe, K., Pitt, J.R., Mead, M.I., Illingworth, S., Roberts, G., Bourn, M., Shallcross, D.E., Percival, C.J., 2018. The development and trial of an unmanned aerial system for the measurement of methane flux from landfill and greenhouse gas emission hotspots. Waste Manage. In press. https://doi.org/10.1016/j.wasman.2017.12.024

Afvalzorg. 2015. MS Excel sheet of the multiphase landfill gas generation and emission model, version April 2014. NV Afvalzorg Holding. http://afvalzorg.nl/EN/Landfill-sites/Emissionsmanagement/Methane-emissions/Download_MLGGR_Model.aspx. Accessed May 2018. Arya, S.P., 1988. Introduction to Micrometeorology. Academic Press, San Diego, CA, USA. Babilotte, A., Green, R., Hater, G., Watermolen, T., Staley, B., 2009. Field intercomparison of methods to measure fugitive methane emissions. Proceedings Sardinia 2009 Twelfth International Waste Management and Landfill Symposium, CISA Environmental Sanitary Engineering Centre, Cagliari, Italy. 
Babilotte, A., Lagier, T., Fiani, E., Taramini, V., 2010. Fugitive methane emissions from landfills: Field comparison of five methods on a French landfill, J. Env. Eng. 136, 777-784.

Babilotte, A., 2011. Field comparison of methods for landfill fugitive methane emissions measurements. Report prepared for Environmental Research \& Education Foundation. https://erefdn.org/wp-content/uploads/2015/12/FugitiveEmissions_FinalReport.pdf. Accessed July 2018.

Baldocchi, D.D., 2003. Assessing the eddy covariance technique for evaluating carbon dioxide exchange rates of ecosystems: past, present and future. Global Change Biology. 9, 479-492.

Battaglini, R., Raco, B., Scozzari, A., 2013. Effective monitoring of landfills: flux measurements and thermography enhance efficiency and reduce environmental impact. J. Geophys. Eng. 10, 64002.

Beaumont, B., Radoux, J., Defourny, P., 2014. Assessment of airborne and spaceborne thermal infrared remote sensing for detecting and characterizing landfills. Waste Manag. Environ. VII $180,237-248$.

Bergamaschi, P., Lubina, C., Konigstedt, R., Fischer, H., Veltkamp, A.C., Zwaagstra, O., 1998. Stable isotopic signatures (delta C13, delta D) of methane from European landfill sites. J. Geo. Res. Atmos. 103, 8251-8265.

Blanco G., Gerlagh, R., Suh, S., Barrett, J., de Coninck, H.C., Diaz Morejon, C.F., Mathur, R., Nakicenovic, N., Ofosu Ahenkora, A., Pan, J., Pathak, H., Rice, J., Richels, R., Smith, S.J., Stern, D.I., Toth, F.L., Zhou, P., 2014. Drivers, Trends and Mitigation. In: Climate Change 2014: Mitigation of Climate Change. Contribution of Working Group III to the Fifth Assessment Report of the Intergovernmental Panel on Climate Change [Edenhofer, O., PichsMadruga, R., Sokona, Y., Farahani, E., Kadner, S., Seyboth, K., Adler, A., Baum, I., Brunner, S., Eickemeier, P., Kriemann, B., Savolainen, J., Schlömer, S., von Stechow, C., Zwickel, T., 
Minx, J.C. (eds.)]. Cambridge University Press, Cambridge, United Kingdom and New York, NY, USA.

Bogner „J, Spokas, K, Corcoran, M., 2014. International field validation of CALMIM: A site-

Bogner, J., Scott, P., 1995. Landfill methane emissions: Guidance for field measurement. Final Report to International Energy Agency - Expert Working Group on Landfill Gas.

Bogner, J., Spokas, K., Burton, E., Sweeney, R., Corona, V., 1995. Landfills as atmospheric methane sources and sinks. Chemosphere. 31, 4119-4130.

Bogner, J., Meadows, M., Czepiel, P., 1997. Fluxes of methane between landfills and the atmosphere: natural and engineered controls. Soil Use and Management. 13, 268-277.

Börjesson, G., Danielsson, Å., Svensson, B.H., 2000. Methane fluxes from a Swedish landfill determined by geostatistical treatment of static chamber measurements. Environ. Sci. \& Technol. 34, 4044-4050.

Börjesson, G., Samuelsson, J., Chanton, J., 2007. Methane oxidation in Swedish landfills quantified with the stable carbon isotope technique in combination with an optical method for emitted methane. Environ. Sci. \& Technol. 41, 6684-90. 
Börjesson, G., Samuelsson, J., Chanton, J., Adolfsson, R., Galle, B., Svensson, B. H. Tellus B., 2009. A national landfill methane budget for Sweden based on field measurements, and an evaluation of IPCC models, Tellus B. 61, 424-435.

Bour, O., 2007. Participation aux travaux du C.R.P.E. concernant la métrologie des émissions diffuses, Rapport détude DRC-07-92463-15882A, INERIS.

Bourn, M., Robinson, R., Innocenti, F., Scheutz, C. 2019. Regulating landfills using measured methane emissions: An English perspective. Waste Manage. In press. https://doi.org/10.1016/j.wasman.2018.06.032

Cambaliza, M. O.L., Shepson, P.B., Bogner, J., Caulton, D.R., Stirm, B., Sweeney, C., ... Richardson, S., 2015. Quantification and source apportionment of the methane emission flux from the city of Indianapolis. Elementa: Science of the Anthropocene, 3, 37.

Cambaliza, M.O.L., Bogner, J.E., Green, R.B., Shepson, P.B., Harvey, T.A., Spokas, K.A., ... Corcoran, M., 2017. Field measurements and modeling to resolve $\mathrm{m}^{2}$ to $\mathrm{km}^{2} \mathrm{CH}_{4}$ emissions for a complex urban source: An Indiana landfill study. Elementa: Science of the Anthropocene, 5, 36.

Capodici, M., Ciraolo, G., Trapani, D.D.I., Viviani, G., 2015. Remote sensing analysis coupled to field measurements for the evaluation of methane emissions from a landfill site: a case study, in: Proceedings Sardinia 2015, Fifteenth International Waste Management and Landfill Symposium.

CEC, 2006. REGULATION (No. 166/2006) of the European Parliament and of the Council of 18 January 2006 concerning the establishment of a European Pollutant Release and Transfer Register and amending Council Directives 91/689/EEC and 96/61/EC, 4 February 20, 2006.

Chanton, J.P., Powelson, D.K., Green, R.B., 2009. Methane oxidation in landfill cover soils, is a 10\% default value reasonable? J. Environ. Qual. 38(2), 654-63. 
1313 Chanton, J.P., Powelson, D.K., Abichou, T., Hater, G., 2008a. Improved field methods to quantify 1314 methane oxidation in landfill cover materials using stable isotope carbon isotopes. Environ. Sci. 1315 Technol. 42, 665-670.

1316 Chanton, J.P., Powelson, D.K., Abichou, T., Fields, D., Green, R., 2008b. Effect of temperature and 1317 oxidation rate on carbon-isotope fractionation during methane oxidation by landfill cover materials. Environ. Sci. Technol. 42 (21), 7818-7823.

1319 Chanton, J., Liptay, K., 2000. Seasonal variation in methane oxidation in landfill cover soils as determined by an in situ stable isotope technique. Global Biogeochemical Cycles. 14, 51-60.

Chanton, J.P., Rutkowski, C.M., Mosher, B.M., 1999. Quantifying methane oxidation from landfills using stable isotope analysis of downwind plumes. Environ. Sci. Technol. 33, 3755-3760.

Christophersen M., Kjeldsen, P., 2001. Lateral gas transport in soil adjacent to an old landfill: factors governing gas migration. Waste Manage. Res. 19, 579-594.

Christophersen M., Kjeldsen P., Holst H., Chanton, J., 2001. Lateral gas transport in soil adjacent to an old landfill: factors governing emissions and methane oxidation. Waste Manage. Res. 19, 595-612.

Conen, F., Smith, K.A., 2000. An explanation of linear increases in gas concentration under closed chambers used to measure gas exchange between soil and the atmosphere. European Journal of Soil Science. 51, 111-117.

Conen, F., Smith, K.A., 1998. A re-examination of closed flux chamber methods for the measurement of trace gas emissions from soils to the atmosphere. European Journal of Soil Science. 49, 701-707.

Cui, Y. Y., et al. 2015, Top-down estimate of methane emissions in California using a mesoscale inverse modelling technique: The South Coast Air Basin. J. Geophys. Res. Atmos. 120, 66986711. 
Czepiel P.M., Mosher B., Harris R.C., Shorter J.H., McManus J.B., Kolb C.E., Allwine E., Lamb C.E., 1996a. Landfill methane emissions measured by enclosure and atmospheric tracer methods. Journal of Geophysical Research. 101, 16711-16719.

Czepiel P.M., Mosher B., Crill P.M., Harris R.C., 1996b. Quantifying the effect of oxidation on landfill methane emissions. Journal of Geophysical Research. 101, 16721-16729.

Czepiel, P.M., Shorter, J.H., Mosher, B., Allwine, E., McManus, J. B., Harriss, R.C., Kolb, C.E., Lamb, B.K., 2003. The influence of atmospheric pressure on landfill methane emissions. Waste Manage. 23, 593-598.

Danish EPA, 2018. http://mst.dk/affald-jord/affald/deponering/biocover-tilskudsordning/ (in Danish). Accessed June 2018.

De la Cruz, F.B., Green, R.B., Hater, G.R., Chanton, J.P., Thoma, E.D., Harvey, T.A., Barlaz, M.A., 2016. Comparison of field measurements to methane emissions models at a new landfill. Environ. Sci. \& Techno. 50, 9432-9441.

Delkash, M., Zhou, B., Han, B., Chow, F.K., Rella, C.W., Imhoff, P.T., 2015. Short-term landfill methane emissions dependency on wind. Waste Manage. 55, 288-298.

Delre A., Mønster J., Samuelsson J., Fredenslund A.M., Scheutz C., 2018. Emission quantification using the tracer gas dispersion method: the influence of instrument, tracer gas species and source simulation. Science of the Total Environment. 634, 59-66.

Delre A., Mønster J., Scheutz C., 2017. Greenhouse gas emission quantification from wastewater treatment plants, using a tracer gas dispersion method. Science of the Total Environment. 605606, 258-268.

Desideri, U., Leonardi, D., Proietti, S., 2007. Application of infrared thermography to study behaviour of biogas captation wells, in: Proceedings Sardinia 2007, Eleventh International Waste Management and Landfill Symposium. 
Di Trapani, D., Di Bella, G., Viviani, G., 2013. Uncontrolled methane emissions from a MSW landfill surface: Influence of landfill features and side slopes. Waste Manage. 33, 2108-2115.

Dlugokencky, E., 2018. National Oceanic and Atmospheric Administration, Earth System Research Laboratory, Global Monitoring Division: www.esrl.noaa.gov/gmd/ccgg/trends_ch4/. Accessed May 2018.

EEA (European Environment Agency), 2016. Annual European Community Greenhouse Gas Inventory 1990-2014 and Inventory Report 2016. Submission to the UNFCCC Secretariat. EEA Technical report, no. 15. 2016.

Eklund, B., 1992. Practical guidance for flux chamber measurements of fugitive volatile organic emission rates. Journal of the Air and Waste Management Association. 42(12), 1583-1591.

El-Fadel, M., Findikakis, A.N., Leckie, J.O., 1995. Migration and atmospheric emission of landfill gas. Environmental Engineering Science. 12(4), 309.

Eugster, W., Plüss, P., 2010. A fault-tolerant eddy covariance system for measuring $\mathrm{CH}_{4}$ fluxes. Agricultural and Forest Meteorology. 150, 841-851.

Figueroa, V.K., Mackie, K.R., Guarriello, N., Cooper, C.D., 2009. A robust method for estimating landfill methane emissions. J. Air Waste Manage. Assoc. 59, 925-935.

Fischedick M., Roy, J., Abdel-Aziz, A., Acquaye, A., Allwood, J.M., Ceron, J.-P., Geng, Y., Kheshgi, H., Lanza, A., Perczyk, D., Price, L., Santalla, E., Sheinbaum, C., Tanaka, K., 2014. Industry. In: Climate Change 2014: Mitigation of Climate Change. Contribution of Working Group III to the Fifth Assessment Report of the Intergovernmental Panel on Climate Change [Edenhofer, O., Pichs-Madruga, R., Sokona, Y., Farahani, E., Kadner, S., Seyboth, K., Adler, A., Baum, I., Brunner, S., Eickemeier, P., Kriemann, B., Savolainen, J., Schlömer, S., von Stechow, C., Zwickel, T., Minx, J.C. (eds.)]. Cambridge University Press, Cambridge, United Kingdom and New York, NY, USA. 
Fjelsted, L., Christensen, A.G., Larsen, J.E., Kjeldsen, P., Scheutz, C., 2019. Assessment of a landfill methane emission screening method using an unmanned aerial vehicle mounted thermal infrared camera - A field study. Waste Manage. In press. https://doi.org/10.1016/j.wasman.2018.05.031

Flesch, T.K., Wilson, J.D., Yee, E., 1995. Backward-time Lagrangian stochastic dispersion models and their application to estimate gaseous emissions. Journal of Applied Meteorology 34, 13201332.Foster-Wittig, T.A., Thoma, E.D., Green, R.B., Hater, G.R., Swan, N.D., Chanton, J.P., 2015a. Development of a mobile tracer correlation method for assessment of air emissions from landfills and other area sources. Atmospheric Environment. 102, 323-330.

Foster-Wittig, T.A, Thoma, E.D., Albertson, J.D., 2015b. Estimation of point source fugitive emission rates from a single sensor time series: A conditionally-sampled Gaussian plume reconstruction. Atmospheric Environment. 115, 101-109.

Fowler, D., Duyzer, J.H., 1989. Micrometeorological techniques for the measurement of trace gas exchange. In: Andreae, M.O. \& Schimel, D.S. (eds.): Exchange of Trace Gases between Terrestrial Ecosystems and the Atmosphere, Dahlem Workshop Report, Life Science Research Reports 47, pp 189-208. Wiley Interscience, Berlin.

Fowler, D., Hargreaves, K.J., Skiba, U., Milne, R., Zahniser, M.S., Moncrieff, J.B., Beverland, I.J., Gallagher, M.W., 1995. Measurements of $\mathrm{CH}_{4}$ and $\mathrm{N}_{2} \mathrm{O}$ fluxes at the landscape scale using micrometeorological methods. Philosophical Transactions of the Royal Society of London, Series A, No. 1696, 341, 205-416.

Franzidis, J-P., Héroux, M., Nastev, M., Guy, C., 2008. Lateral migration and offsite surface emission of landfill gas at City of Montreal landfill site. Waste Manage. Res. 26, 121-131.

Fredenslund A.M., Lemming, G., Scheutz, C. Kjeldsen, P., 2007. Implementing biocover on Fakse landfill: landfill characterization, gas production modeling and mapping spatial variability in 

symposium, 1-5 October, Sardinia, Italy. Proceeding; CD-ROM-Cagliari, Italy.

1411

Fredenslund, A.M., Scheutz, C. Kjeldsen, P., 2010. Tracer method to measure landfill gas emissions from leachate collection systems. Waste Manage. 30, 2146-2152.

Fredenslund, A.M., Mønster, J., Scheutz, C., Kjeldsen, P., 2019a. Development and implementation of a screening method to categorize greenhouse gas mitigation potential of 91 landfills. Waste Manage. In press. https://doi.org/10.1016/j.wasman.2018.03.005

Fredenslund, A.M., Rees-White, T.C., Beaven, R.P., Delre, A., Finlayson, A., Helmore, J., Scheutz, C. 2019b. Controlled release validation of the mobile tracer gas dispersion method for measurement of fugitive emissions from area sources. Waste Manage. 83, 68-78.

Galle, B., Klemedtsson, L., Bergqvist, K., Ferm, M., Gri, D.W.T., Jensen, N., Hansen, F., 2000. Measurements of ammonia emissions from spreading of manure using gradient FTIR techniques. Atmospheric Environment. 34, 4907-4915.

Galle, B., Samuelsson J., Svensson, B.H., Borjesson, G., 2001. Measurements of methane emissions from landfills using a time correlation tracer method based on FTIR absorption spectroscopy. Environ. Sci. Technol. 35, 21-25.

Gallego, E., Perales, J.F., Roca, F.J., Guardino, X., 2014. Surface emission determination of volatile organic compounds (VOC) from a closed industrial waste landfill using a self-designed static flux chamber. Science of the Total Environment. 470, 587-599.

Gebert, J., Groengroeft, A., 2006. Passive landfill gas emission - influence of atmospheric pressure and implications for the operation of methane-oxidising biofilters. Waste Manage. 26, 245251. 
1431 Gebert, J., Streese-Kleeberg, J., 2017. Coupling stable isotope analysis with gas push-pull tests to 1432 derive in situ values for the fractionation factor $\alpha_{\mathrm{ox}}$ associated with the microbial oxidation of methane in soils. Soil Science Society of America. Journal, 81(5), 1107-1114.

1434 Gebert, J., Streese-Kleeberg, J., Pfeiffer, E.M., 2013. Limitations to the quantification of methane oxidation using stable isotopes. Proceedings Sardinia $201314^{\text {th }}$ International Waste Management and Landfill Symposium, CISA Environmental Sanitary Engineering Centre, Cagliari, Italy.

Gebert, J., Rower, I.U., Scharff, H., Roncato, C.D., Cabral, A.R., 2011. Can soil gas profiles be used to assess microbial $\mathrm{CH}_{4}$ oxidation in landfill covers? Waste Manage. 31, 987-994.

1440 Geck, C., Scharff, H., Pfeiffer, E.M., Gebert, J., 2016. Validation of a simple model to predict the performance of methane oxidation systems, using field data from a large scale biocover test field. Waste Manage. 56, 280-289.

Glinski, J., Stepniewski, W., 1985. Soil aeration and its role for plants. CRC Press, Boca Raton, FL, USA.

Goldsmith, C.D., Hater, G., Green, R., Abichou, T., Barlaz, M. Chanton, J., 2008. Comparison of optical remote sensing with static chambers for quantification of landfill methane emission. Proceedings of the Global Waste Management Symposium, 7-10 September 2008, Copper Conference Center, Colorado, USA.

Goldsmith, C.D., Chanton, J., Abichou, T., Swan, N., Green, R., Hater, G., 2012. Methane emissions from 20 landfills across the United States using vertical radial plume mapping. Journal of the Air \& Waste Management Association, 62, 183-197.

Gonzalez-Valencia, R., Magana-Rodriguez, F., Maldonado, E., Salinas, J., Thalasso, F., 2015. Detection of hotspots and rapid determination of methane emissions from landfills via a ground-surface method. Environmental Monitoring and Assessment, 187, 4083. 
1455 Gonzalez-Valencia, R., Magana-Rodriguez, F., Cristobal, J., Thalasso, F., 2016. Hotspot detection 1456 and spatial distribution of methane emissions from landfills by a surface probe method. Waste 1457 Manage. 55, 299-305.

1458 Green, R.B., Hater, G.R., Thoma, E.D., DeWees, J., Rella, C.W., Crosson, E.R., Goldsmith, C.D., 1459 Swan, N., 2010. Methane emissions measured at two Californian landfills by OTM-10 and an 
Tignor, M., Allen, S.K., Boschung, J., Nauels, A., Xia, Y., Bex, V., Midgley, P.M. (eds.)]. Cambridge University Press, Cambridge, United Kingdom and New York, NY, USA.

Hashmonay, R.A., Yost, M.G., 1999. Innovative approach for estimating fugitive gaseous fluxes using computed tomography and remote optical sensing techniques. Journal of the Air \& Waste Management Association, 49 (8), 966-972.

Hashmonay, R.A., Natschke D.F., Wagoner K., Harris D.B., Thompson E.L., Yost M.G., 2001. Field evaluation of a method for estimating gaseous fluxes from area sources using open-path Fourier transform infrared. Environmental Science Technology. 35, 2309-2313.

Hashmonay, R.A., Varma R.M., Modrak M.T., Kagann R.H., Segall R.R., Sullivan P.D., 2008. Radial plume mapping: A US EPA test method for area and fugitive source emission monitoring using optical remote sensing. Advanced Environmental Monitoring, 21-36, edited by Y.J. Kim and U. Platt, Springer.

Hensen, A., Scharff, H., 2001. Methane emission estimates from landfills obtained with dynamic plume measurements. Water, Air, Soil Pollution. Focus. 455-464.

Hensen, A., Vermeulen, A.T., Wyers, G.P., Zhang, Y., 1996. Eddy correlation and relaxed eddy accumulation measurements of $\mathrm{CO}_{2}$ fluxes over grassland. Physics and Chemistry of the Earth. $21,(5-6) 383-388$.

Hirst, B., Jonathan, P., González del Cueto, F., Randell, D., \& Kosut, O. 2013. Locating and quantifying gas emission sources using remotely obtained concentration data. Atmospheric Environment. 74, 141-158.

Hovde, D.C., Stanton, A.C., Meyers, T.P., Matt, D.R., 1995. $\mathrm{CH}_{4}$ emissions from a landfill measured by eddy correlation using a fast response diode laser sensor. Journal of Atmospheric Chemistry. 20, 141-162. 
Howard, T., Lamb, B.K., Bamesberger, W.L., Zimmerman, P.R., 1992. Measurement of hydrocarbon emissions fluxes from refinery wastewater impoundments using atmospheric tracer techniques. Journal of Air Waste Management Association. 42, 1336-1344.Hrad, M., Binner, E., Piringer, M., Huber-Humer, M., 2014. Quantification of methane emissions from full-scale open windrow composting of biowaste using an inverse dispersion technique. Waste Manage. 34, 2445-2453.

Huber-Humer M., Lechner P., 2001a. Microbial methane oxidation for the reduction of landfill gas emissions. Journal of Solid Waste Technology and Management. 27, 146-151.

Huber-Humer, M., Lechner, P., 2001b. Design of a landfill cover layer to enhance methane oxidation - results of a two year field investigation. Sardinia 2001. Eight International Waste Management and Landfill Symposium, Cagliari, Italy, vol. II, pp. 541-550.

Hutchinson, G.L., Livingston, G.P., 2001. Vents and seals in non-steady-state chambers used for measuring gas exchange between soil and the atmosphere. European Journal of Soil Science. 52(4), 675-682.

Intergovernmental Panel on Climate Change. 2006. 2006 IPCC guidelines for national greenhouse gas inventories. Hayama, Japan: IPCC. http://www.ipccnggip.iges.or.jp/public/2006gl/vol5.html

Innocenti, F., Robinson, R., Gardiner, T., Finlayson, A., Connor, A., 2017. Differential absorption lidar (DIAL) measurements of landfill methane emissions. Remote Sensing. 9(9), pp. $953 .$.

Ishigaki, T., Yamada, M., Nagamori, M., Ono, Y., Inoue, Y., 2005. Estimation of methane emission from whole waste landfill site using correlation between flux and ground temperatures. Environ. Geol. 48, 845-853.

Jacobs, J., Scharff, H., Hensen, A., Kraai, A., Scheutz, C. Samuelsson, J., 2007. Testing a simple and low cost methane emission measurement method. Proceedings Sardinia 2007, Eleventh 
International Waste Management and Landfill Symposium S. Margherita di Pula, Cagliari, Italy; 1 - 5 October 2007. (C2007 by CISA, Environmental Sanitary Engineering Centre, Italy.

Jones, H., Nedwell, D., 1990. Soil atmosphere concentration profiles and methane emission rates in the restoration covers above landfill sites: Equipment and preliminary results. Waste Manage. Res. 8, 21-31.

Juncher Jørgensen, C., Lund Johansen, K. M., Westergaard-Nielsen, A., Elberling, B., 2015. Net regional methane sink in High Arctic soils of northeast Greenland. Nature Geoscience. 8(1), 20-23.

Kaharabata, S.K., Schuepp, P.H., 1998. Methane emissions from aboveground open manure slurry tanks. Global Biogeochemical Cycles. 12, 545-554.

Kaharabata, S. K., Schuepp, P.H., Desjardins, R.L., 2000. Estimating methane emissions from dairy cattle housed in a barn and feedlot using an atmospheric tracer. Environmental Science \& Technology. 34, 3296-3302.

Kjeld, A., 2013. Microbial methane oxidation at the Fiflholt landfill in Iceland. MSC Thesis. Faculty of Civil and Environmental Engineering, School of Engineering and Natural Sciences, University of Iceland, Reykjavik, Iceland, 87 p.

Kjeldsen, P., Fischer, E.V., 1995. Landfill gas migration - field investigations at Skellingsted Landfill, Denmark. Waste Manage. Res. 13, 467-585.

Kjeldsen, P., 1996. Landfill gas migration in soil. In: Christensen, T.H., Cossu, R., Stegmann, R. (eds.), Landfilling of waste: Biogas,. E. \& FN Spon. London, GB. pp. 87-132

Krautwurst, S., Gerilowski, K., Jonsson, H., Thompson, D., Kolyer, R., Thorpe, A., ... Bovensmann, H. 2016. Methane emissions from a Californian landfill, determined from airborne remote sensing and in-situ measurements Methane emissions from a Californian 
landfill, determined from airborne remote sensing and in-situ measurements. Atmos. Meas. Tech. (December), 3429-3452.

1551

Kroon, P.S., Schrier-Uijl, A.P., Hensen, A., Veenendaal, E.M., Jonker, H.J.J., 2010. Annual balances of $\mathrm{CH}_{4}$ and $\mathrm{N}_{2} \mathrm{O}$ from a managed fen meadow using eddy covariance flux measurements. European Journal of Soil Science. 61(5), 773-784.

Lamb, B.K., Mcmanus, J.B., Shorter, J.H., Kolb, C.E., Mosher, B., Allwine, E., Zimmerman, P.A.T., 1995. Development of atmospheric tracer methods to measure methane emissions from natural-gas facilities and urban areas. Environ. Sci. Technol. 29(6), 1468-1479.

Lamb, B.K., Cambaliza, M.O.L., Davis, K.J., Edburg, S.L., Ferrara, T.W., Floerchinger, C., ... Whetstone, J., 2016. Direct and indirect measurements and modeling of methane emissions in Indianapolis, Indiana. Environ. Sci. Technol. 50(16), 8910-8917.

Lan, X., Talbot, R., Laine, P., Torres, A., 2015. Characterizing fugitive methane emissions in the Barnett Shale area using a mobile laboratory. Environ. Sci. Technol. 49(13), 8139-8146.

Lando, A.T., Nakayama, H., Shimaoka, T., 2017. Application of portable gas detector in point and scanning method to estimate spatial distribution of methane emission in landfill. Waste Manage. 59, 255-266.

Laurila, T., Tuovinen, J.-P., Lohila, A., Hatakka, J., Aurela, M., Thum, T., Pihlatie, M., Rinne, J., Vesala, T., 2005. Measuring methane emissions from a landfill using a cost-effective micrometeorological method. Geophysical Research Letters. 32, Issue 19, 1-5.

Lewis, A.W., Yuen, S.T.S., Smith, A.J.R., 2003. Detection of gas leakage from landfills using infrared thermography - applicability and limitations. Waste Manag. Res. 21, 436-447.

Liptay, K., Chanton, J., Czepiel, P., Mosher, B., 1998. Use of stable isotopes to determine methane oxidation in landfill cover soils. Journal of Geophysical Research. 103, 8243-8250. 
Lohila, A, Laurila, T., Pekkatuovinen, J., Aurela, M., Hataka, J., Thum, T., Pihlatie, M., Rinne, J., Vesala, T., 2007. Micrometeorological measurements of methane and carbon dioxide fluxes at a municipal landfill, Environ. Sci. Technol. 41, 2717-2722.

Long, T., 2004. R\&D Technical Report E87a, Surveillance of greenhouse gas releases, UK Environmental Agency.

Lucernoni, F., Rizzotto, M., Tapparo, F., Capelli, L., Sironi, S., Busini, V., 2016. Use of CFD for static sampling hood design: An example for methane flux assessment on landfill surfaces. Chemosphere. 163, 259-269.

Mackie, K. R., \& Cooper, C. D. 2009. Landfill gas emission prediction using Voronoi diagrams and importance sampling. Environmental Modelling \& Software. 24(10), 1223-1232.

Masson-Delmotte, V., M. Schulz, A. Abe-Ouchi, J. Beer, A. Ganopolski, J.F. González Rouco, E. Jansen, K. Lambeck, J. Luterbacher, T. Naish, T. Osborn, B. Otto-Bliesner, T. Quinn, R. Ramesh, M. Rojas, X. Shao and A. Timmermann, 2013: Information from Paleoclimate Archives. In: Climate Change 2013: The Physical Science Basis. Contribution of Working Group I to the Fifth Assessment Report of the Intergovernmental Panel on Climate Change [Stocker, T.F., D. Qin, G.-K. Plattner, M. Tignor, S.K. Allen, J. Boschung, A. Nauels, Y. Xia, V. Bex and P.M. Midgley (eds.)]. Cambridge University Press, Cambridge, United Kingdom and New York, NY, USA.

Matacchiera, F., Manes, C., Beaven, R.P., Rees-White, T.C., Boano, F., Mønster, J., Scheutz, C. 2019. AERMOD as a Gaussian dispersion model for planning tracer gas dispersion tests for landfill methane emission quantification. Waste Manage. In press. https://doi.org/10.1016/j.wasman.2018.02.007

Marik, T., Levin, I., 1996. A new tracer experiment to estimate the methane emissions from a dairy cow shed using sulfur hexafiuoride ( $\left.\mathrm{SF}_{6}\right)$. Global Biogeochemical Cycles. 10, 413-418. 
Martin, D., Petersson, K.F., Shallcross, D.E., 2011. The use of cyclic perfluoroalkanes and $\mathrm{SF}_{6}$ in atmospheric dispersion experiments. Quarterly Journal of the Royal Meteorological Society. 137, 2047-2063.

Mcdermitt, D., Xu, L., Lin, X., Amen, J., Welding, K., 2013. Impact of changes in barometric pressure on landfill methane emission, EGU conference in Vienna. 15, 5435.

Molins, S., Mayer, K.U., Scheutz, C., Kjeldsen, P. 2008. Role of transport mechanisms in the attenuation of landfill gas in cover soils: a multicomponent modelling study. Journal of Environmental Quality. 37, 459-468.

Mønster, J. G., Samuelsson, J., Kjeldsen, P., Rella, C.W., Scheutz, C., 2014. Quantifying methane emission from fugitive sources by combining tracer release and downwind measurements - A sensitivity analysis based on multiple field surveys. Waste Manage. 34(8), 1416-1428.

Mønster, J., Samuelsson, J., Kjeldsen, P., Scheutz, C., 2015. Quantification of methane emissions from 15 Danish landfills using the mobile tracer dispersion method. Waste Manage. 35, 177186.

Mosher, B. W., Czepiel, P., Harriss, R., Shorter, J., Kolb, C., McManus, J.B., Allwine, E., Lamb, B., 1999. $\mathrm{CH}_{4}$ emissions at nine landfill sites in the northeastern United States. Environ. Sci. Technol. 33 (12), 2088-2094.

Mou, Z.S., Scheutz, C., Kjeldsen, P. 2015. Evaluation and application of site-specific data to revise the first-order decay model for estimating landfill gas generation and emissions at Danish landfills. Journal of the Air and Waste Management Association. 65, 686-698.

Myhre, G., Shindell, D., Bréon, F.-M., Collins, W., Fuglestvedt, J., Huang, J., Koch, D., Lamarque, J.-F., Lee, D., Mendoza, B., Nakajima, T., Robock, A., Stephens, G., Takemura, T., Zhang, H., 2013. "Anthropogenic and Natural Radiative Forcing". In: Climate Change 2013: The Physical Science Basis. Contribution of Working Group I to the Fifth Assessment Report of the 
Intergovernmental Panel on Climate Change. Stocker, T.F., D. Qin, G.-K. Plattner, M. Tignor, S.K. Allen, J. Boschung, A. Nauels, Y. Xia, V. Bex and P.M. Midgley (eds.). Cambridge University Press, Cambridge, United Kingdom and New York, NY, USA.

National Oceanic \& Atmospheric Administration (NOAA) 2018. Earth System Research Laboratory, Global Monitoring Division: Nitrous Oxide $\left(\mathrm{N}_{2} \mathrm{O}\right)$ - Combined Data Set: https://www.esrl.noaa.gov/gmd/hats/combined/N2O.html. Accessed June 2018.

Oonk, H., Boom, A., 1995. Landfill gas formation, recovery and emissions, TNO-report R95-203, TNO-MEP, Apeldoorn, The Netherlands.

Park, J.W., Shin, H.C., 2001. Surface emission of landfill gas from solid waste landfill. Atmospheric Environment. 35 (20), 3445-3451.

Jin-Kyu Park, J-K., Kang, J-Y., Lee, N-H., 2016. Estimation of methane emission flux at landfill surface using laser methane detector: Influence of gauge pressure. Waste Manage. Res. 34(8), 784-792.

Peischl, J., Ryerson, T. B., Brioude, J., Aikin, K. C., Andrews, A. E., Atlas, E., ... Parrish, D. D. 2013. Quantifying sources of methane using light alkanes in the Los Angeles basin, California. Journal of Geophysical Research Atmospheres. 118(10), 4974-4990.

Piccot, S. D., Masemore, S.S., Lewis-Bevan, W., Ringler, E.S., Harris, D.B., 1996. Field assessment of a new method for estimating emission rates from volume sources using openpath FTIR spectroscopy. Journal of the Air \& Waste Management Association. 46 (2), 159171.

Pratt, C., Walcroft, A.S., Deslippe, J., Tate, K.R., 2013. $\mathrm{CH}_{4} / \mathrm{CO}_{2}$ ratios indicate highly efficient methane oxidation by a pumice landfill cover-soil. Waste Manage. 33 (2), 412-419. 
Rachor I. Streese-Kleeberg J., Gebert J., 2009. Spatial and temporal variability of gas emissions from old landfills, Proceedings Sardinia 2009, Twelfth International Waste Management and Landfill Symposium, S. Margherita di Pula, Cagliari, Italy; 5-9 October 2009.

Rachor, I.M., Gebert, J., Grongroft, A., Pfeiffer, E.M., 2013. Variability of methane emissions from an old landfill over different time-scales. European Journal of Soil Science. 64, 16-26.

Raco, B., Scozzari, A., Guidi, M., Lelli, M., Lippo, G., 2005. Comparison of two non-invasive methodologies to monitor diffuse biogas emissions from MSW landfills soil: a case study, in: Proceedings Sardinia 2005, Tenth International Waste Management and Landfill Symposium.

Ravishankara, A.R., Solomon, S., Turnipseed, A.A., Warren, R.F., 1993. Atmospheric lifetimes of long-lived halogenated species. Science. 259, 194-199.

Rees-White T.C., Mønster, J., Beaven R.P., Scheutz, C., 2019. Measuring methane emissions from a UK landfill using the tracer dispersion method and the influence of operational and environmental factors. Waste Manage. In press. https://doi.org/10.1016/j.wasman.2018.03.023

Reinhart, D.R., Cooper, D.C., Walker, B.L., 1992. Flux chamber design and operation for the measurement of municipal solid-waste landfill gas emission rates. Journal of the Air \& Waste Management Association. 42, 1067-1070.

Riddick, S.N., Connors, S., Robinson, A.D., Manning, A.J., Jones, P.S.D., Lowry, D., ... Harris, N.R.P. 2017. Estimating the size of a methane emission point source at different scales: from local to landscape, Atmos. Chem. Phys. 7839-7851.

Riddick, S.N., Hancock, B., Robinson, A.D., Connors, S., Davies, S., Allen, G., Pitt, J., Harris, N.R., 2018. Development of a low-maintenance measurement approach to continuously estimate methane emissions: A case study. Waste Manage. 73, 210-219. 
1664 Robinson, R., Gardiner, T., Innocenti, F., Woods, P., Coleman, M., 2011. Infrared differential 1665 absorption Lidar (DIAL) measurements of hydrocarbon emissions. Journal of Environmental 1666 Monitoring. 13(8), 2213-2220.

1667 Rolston, D., 1986. Gas diffusity and gas flux. In Klute, A. (ed.): Methods of Soil Analysis, Part I. 1668 Physical and Mineralogical Methods, Agronomy Monograph No. 9, 2nd edn, pp. 1089-1119.

Rosevear, A., Deed, C., Gronow, J., Keenlyside, J., Smith, R., Braithwaite, P., 2004. Guidance on monitoring landfill gas surface emissions, UK Environment Agency.

Röwer, I. U., Geck, C., Gebert, J., Pfeiffer, E.-M., 2011. Spatial variability of soil gas concentration and methane oxidation capacity in landfill covers. Waste Manage. (New York, N.Y.), 31(5), 926-934.

Savanne, D., Arnaud, A., Beneito, A., Berne, P., Burkhalter, R., Cellier, P., Gonze, M. A., Laville, P., Levy, F., Milward, R., Pokryszka, Z., Sabroux, J. C., Tauziede, C., Tregoures, A., 1997. Comparison of different methods for measuring landfill methane emissions, Sardinia 97 6th International Landfill Symposium,13-17 October 1997, Cagliari, Italy, volume IV, 81-86.

Scharff, H., Hensen, A., 2009. Further development of a cheap and simple methane emission measurement method. Proceedings Sardinia 2009, Twelfth International Waste Management and Landfill Symposium S. Margherita di Pula, Cagliari, Italy; 5 - 9 October 2009.

Scharff, H., Jacobs, J., 2006. Applying guidance for methane emission estimation for landfills. Waste Manage. 26, 417-429.

Scharff, H., Martha, A., v. Rijn, D. M. M., Hensen, A., Flechard, C., Oonk, H., Vroon, R., de Visscher, A., Boeckx, P., 2003. A comparison of measurement methods to determine landfill methane emissions, NV Afvalzorg, Haarlem, The Netherlands. Pp. 103.Scheutz C., Kjeldsen, 
P. 2019. Guidelines for landfill gas emission monitoring using the tracer gas dispersion method. Accepted for publication in Waste Manage.

Scheutz, C., Cassini, F., Schoenmaeker, Jan De., Kjeldsen, P., 2017. Mitigation of methane emissions in a pilot-scale biocover system at the AV Miljø Landfill, Denmark: 2. Methane oxidation. Waste Manage. 63, 203-212

Scheutz, C., Fredenslund, A.M., Nedenskov, J., Samuelsson, J., Kjeldsen, P., 2011a. Gas production, composition and emission at a modern disposal site receiving waste with a low organic content. Waste Manage. 31, 946-955.

Scheutz, C., Samuelsson, J., Fredenslund, A.M., Kjeldsen, P., 2011b. Quantification of multiple methane emission sources at landfills using a double tracer approach. Waste Manage. 31, 10091017. 1028.

Scheutz, C., Fredenslund, A.M., Chanton, J., Pedersen, G.B., Kjeldsen, P. 2011c Mitigation of methane emission from Fakse landfill using a biowindow system. Waste Manage. 31, 1018-

Scheutz, C., Kjeldsen, P., Bogner, J. E., De Visscher, A., Gebert, J., Hilger, H. A, Huber-Humer, M., Spokas, K., 2009. Microbial methane oxidation processes and technologies for mitigation of landfill gas emissions. Waste Manage. Res. 27, 409-455.

Scheutz, C., Bogner, J., Chanton, J.P., Blake, D., Morcet, M., Aran,C., Kjeldsen, P., 2008. Atmospheric emissions and attenuation of non-methane organic compounds in cover soils at a French landfill. Waste Manage. 28, 1892-1908.

Scheutz, C., Fredenslund, A.M., Samuelsson, J., Jacobs, J., Scharff, H., Hensen, A. and Kjeldsen, P., 2007. Whole landfill methane emission. Report for project Biocover. Institute of Environment \& Resources, Technical University of Denmark (www.biocover.env.dtu.dk). 
1710

1711

1712

1713

1714

1715

1716

1717

1718

1719

1720

1721

1722

1723

1724

1725

1726

1727

1728

1729

1730

1731

1732

1733

Scheutz, C., Kjeldsen, P., 2004. Environmental factors influencing methane oxidation and cooxidation of HCFCs in landfill cover soils. Journal of Environmental Quality. 33, 61-71.

Scheutz, C., Bogner, J., Chanton, J., Blake, D., Morcet, M., Kjeldsen, P., 2003. Comparative oxidation and net emissions of methane and selected non-methane organic compounds in landfill cover soils. Environ. Sci. Technol. 37, 5150-5158.

Schroth, M.H., Eugster, W., Gomez, K.E., Gonzalez-Gil, G., Niklaus, P.A., Oester, P., 2012. Above- and below-ground methane fluxes and methanotrophic activity in a landfill-cover soil. Waste Manage. 32(5), 879-889.

Senevirathna, D.G.M., Achari, G., Hettiaratchi, J.P.A., 2007. A mathematical model to estimate errors associated with closed flux chambers. Environmental Modeling \& Assessment. 12, 1-11.

Spokas K, Bogner J, Corcoran M, Walker S., 2015. From California dreaming to California data: Challenging historic models for landfill $\mathrm{CH}_{4}$ emissions. Elem Sci Anth. 3, 51.

Spokas, K., Bogner, J., \& Chanton, J. 2011. A process-based inventory model for landfill $\mathrm{CH}_{4}$ emissions inclusive of seasonal soil microclimate and $\mathrm{CH}_{4}$ oxidation. Journal of Geophysical Research: Biogeosciences. 116(4).

Spokas, K., Bogner, J., 2011. Limits and dynamics of methane oxidation in landfill cover soils, Waste Manage. 31, 823-832.

Spokas, K., Bogner, J., Chanton, J. P., Morcet, M., Aran, C., Graff, C., Moreau-Le Golvan, Y., Hebe, I., 2006. Methane mass balance at three landfill sites: What is the efficiency of capture by gas collection systems? Waste Manage. 26, 516-52.

Spokas, K., Graff, C., Morcet, M., Aran, C., 2003. Implications of the spatial variability of landfill emission rates on geospatial analyses. Waste Manage. 23, 599-607.

Storm, I.M.L.D., Hellwing, A.L.F., Nielsen, N.I., Madsen, J., 2012. Methods for Measuring and Estimating Methane Emission from Ruminants. Animals. 2, 160-183. 
1734 Tanda, G., Migliazzi, M., Chiarabini, V., Cinquetti, P., 2017. Application of close-range aerial 1735 infrared thermography to detect landfill gas emissions: a case study. J. Phys. Conf. Ser. 796, $1736 \quad 12016$.

1737 Taylor, D.M., Chow, F.K., Delkash, M., Imhoff, P.T., 2016. Numerical simulations to assess the 1738 tracer dilution method for measurement of landfill methane emissions. Waste Manage. 56, $1739 \quad 298-309$.

1740 Terent'eva, I., Sabrekov, A. F., Glagolev, M.V., 2017. Methane Emission from Municipal Solid 1741 Waste Landfills. Russian Meteorology and Hydrology. 42(5), 327-334.

1742 Themelis N.J., Ulloa, P.A., 2007. Methane generation in landfills. Renewable Energy, 32, 1243$1743 \quad 1257$.

1744 Thoma, E.D., Green, R.B., Hater, G.R., Goldsmith, C.D., Swan, N.D., Chase, M.J., Hashmonay, 1745 R.A., 2010. Development of EPA OTM 10 for landfill applications. Journal of Environmental $1746 \quad$ Engineering. 136, 769-776.

1747 Timko, R.J., Lagus, P.L., Thimons, E.D., 1984. SF 6 adds a new dimension to mine ventilation $1748 \quad$ analysis. Engineering and Mining Journal. 185 (2), 50-51.

1749 Tratt, D.M., Buckland, K.N., Hall, J.L., Johnson, P.D., Keim, E.R., Leifer, I., .. Young, S.J., 2014. 1750 Remote Sensing of Environment Airborne visualization and quantification of discrete methane 1751 sources in the environment. Remote Sensing of Environment. 154, 74-88.

1752 Tregoures, A., Beneito, A., Berne, P., Gonze, M.A., Sabroux, J.C., Savanne, D., Pokryszka, Z., 1753 Tauziede, C., Cellier, P., Laville, P., Milward, R., Arnaud, A., Levy, F., Burkhalter, R., 1999. 1754 Comparison of seven methods for measuring methane flux at a municipal solid waste landfill $1755 \quad$ site. Waste Manage. Res. 17, 453-458.

1756 UK Environmental Agency, 2010. Guidance on monitoring landfill gas surface emissions. Report 1757 published by the Environmental Agency, UK. 
https://www.gov.uk/government/uploads/system/uploads/attachment_data/file/321614/LFTGN 07.pdf Accessed June 2018.

US EPA, 2011. EPA Handbook: Optical remote sensing for measurement and monitoring of emissions flux. http://www.epa.gov/ttnemc01/guidlnd/gd-052.pdf. Accessed June 2018.

US EPA, 2016. Inventory of U.S. Greenhouse gas emissions and sinks: 1990-2014 https://www.epa.gov/sites/production/files/2017-04/documents/us-ghg-inventory-2016-maintext.pdf. Accessed June 2018.

Verschut C., Oonk H., Mulder W., 1991. Broeikasgassen uit vuilstorts in Nederland, TNO-raport 91-444, TNO, Apeldoorn, the Netherlands.

Victor D.G., D. Zhou, E.H.M. Ahmed, P.K. Dadhich, J.G.J. Olivier, H-H. Rogner, K. Sheikho, Yamaguchi, M., 2014. Introductory Chapter. In: Climate Change 2014: Mitigation of Climate Change. Contribution of Working Group III to the Fifth Assessment Report of the Intergovernmental Panel on Climate Change [Edenhofer, O., R. Pichs-Madruga, Y. Sokona, E. Farahani, S. Kadner, K. Seyboth, A. Adler, I. Baum, S. Brunner, P. Eickemeier, B. Kriemann, J. Savolainen, S. Schlömer, C. von Stechow, T. Zwickel and J.C. Minx (eds.)]. Cambridge University Press, Cambridge, United Kingdom and New York, NY, USA.

Wang, X.J., Jia, M.S., Lin, X.Y., Xu, Y., Ye, X., Kao, C.M., Chen, S.H., 2017. A comparison of $\mathrm{CH}_{4}, \mathrm{~N}_{2} \mathrm{O}$ and $\mathrm{CO}_{2}$ emissions from three different cover types in a municipal solid waste landfill. Journal of the Air \& Waste Management Association. 67(4), 507-515.

Westbrook, J.A., Sullivan, P.S., 2007. Fugitive dust modeling with AERMOD for PM10 emissions from a municipal waste landfill. Air and Waste Management Association - Guideline on Air Quality Models: Applications and FLAG Developments 2006, an A and WMA Specialty Conference, 164 CP, 207-223. 
1781 Wu, C., Yost M.G., Hashmonay R.A., Park D.Y., 1999. Experimental evaluation of a radial beam 1782 geometry for mapping air pollutants using optical remote sensing and computed tomography, $1783 \quad$ Atmospheric Environment. 33, 4709-4716.

1784 Wyles, R., Wong, C.L.Y., Ramkellawan, J., 2010. Determining fugitive methane emission rates at 1785 the springhill landfill. Proceedings of the Air and Waste Management Association's Annual $1786 \quad$ Conference and Exhibition, AWMA, 4, 2839-2852.

1787 Xu, L., Lin, X., Amen, J. Welding, K., McDermitt, D., 2014. Impact of changes in barometric 1788 pressure on landfill methane emission, Global Biogeochem. Cycles, 28, 679-695.

1789 Young, A., 1990. Volumetric change in landfill gas flux in response to variations in atmospheric $1790 \quad$ pressure. Waste Manage. Res. 8, 379-385.

1791 Zhu, H., Letzel, M. O., Reiser, M., Kranert, M., Bächlin, W., Flassak, T., 2013. A new approach to 1792 estimation of methane emission rates from landfills. Waste Manage. 33(12), 2713-9. 
1794 Table 1. Qualitative reconnaissance techniques for locating landfill 'hotspots' or determining

1796 should be used in combination with the quantitative techniques described in Table 2, but they

\begin{tabular}{|c|c|c|c|}
\hline Application & Advantages & Limitations & Status and references \\
\hline \multicolumn{4}{|c|}{ Portable $\mathrm{CH}_{4}$ analyser } \\
\hline $\begin{array}{l}\text { Qualitative or semi- } \\
\text { quantitative measurement of } \\
\mathrm{CH}_{4} \text { concentrations directly } \\
\text { above the landfill surface. } \\
\text { Applied as point } \\
\text { measurements or } \\
\text { random/systematic walkover } \\
\text { surveys. }\end{array}$ & $\begin{array}{l}\text { Rapid and simple to deploy in the } \\
\text { field. Relatively inexpensive - } \\
\text { only requires a portable } \\
\text { instrument and a GPS for } \\
\text { walkover surveys. }\end{array}$ & $\begin{array}{l}\text { Above-surface } \mathrm{CH}_{4} \\
\text { concentrations are affected by } \\
\text { interfering } \mathrm{CH}_{4} \text { sources, } \\
\text { meteorological and soil variables } \\
\text { and site topography. Recorded } \\
\text { above-surface } \mathrm{CH}_{4} \text { concentrations } \\
\text { are not universally correlated to } \\
\mathrm{CH}_{4} \text { surface fluxes. }\end{array}$ & $\begin{array}{l}\text { A widely used technique as a tool to } \\
\text { determine the need for cover } \\
\text { remediation and maintenance. }\end{array}$ \\
\hline \multicolumn{4}{|c|}{ Field infrared survey } \\
\hline $\begin{array}{l}\text { Uses thermal infrared } \\
\text { techniques to detect points or } \\
\text { areas with elevated } \\
\text { temperatures. Assumes } \\
\text { elevated surface temperatures } \\
\text { are caused by warm emitted } \\
\text { landfill gas. Deployed either } \\
\text { on site (inspection using } \\
\text { handheld instruments) or on } \\
\text { UAVs or aircraft, depending } \\
\text { on the scale and required } \\
\text { sensitivity. }\end{array}$ & $\begin{array}{l}\text { Rapid and simple to deploy in the } \\
\text { field, including aerial } \\
\text { measurements with UAVs. } \\
\text { Relatively inexpensive, } \\
\text { depending on the scale and } \\
\text { complexity of the field } \\
\text { measurement programme. Best } \\
\text { suited for identifying larger } \\
\text { localised gas leakages. }\end{array}$ & $\begin{array}{l}\text { Thermal anomalies may be due to } \\
\text { processes other than the emission } \\
\text { of warm landfill gas, e.g. } \\
\text { microbial processes (respiration } \\
\text { or } \mathrm{CH}_{4} \text { oxidation), or variability } \\
\text { in the emissivity of different } \\
\text { surfaces potentially causing } \\
\text { sampling bias. In warm climates } \\
\text { thermal anomalies due to } \\
\text { emission hotspots may not be } \\
\text { visible. }\end{array}$ & $\begin{array}{l}\text { Thermal infrared cameras mounted } \\
\text { on UAVs are used widely for } \\
\text { leakage searches in the gas industry, } \\
\text { but they are still to be proven useful } \\
\text { at landfills, as multiple causes of } \\
\text { observed thermal anomalies must } \\
\text { be considered (e.g. Fjelsted et al., } \\
2019 \text {; Tanda et al., 2017; Battaglini } \\
\text { et al., 2013; Lewis et al., 2003). }\end{array}$ \\
\hline \multicolumn{4}{|c|}{ UAV survey } \\
\hline $\begin{array}{l}\text { Atmospheric } \mathrm{CH}_{4} \\
\text { concentration measurements } \\
\text { recorded by sensors or } \\
\text { instruments in a UAV. } \\
\text { Rotary UAVs are often } \\
\text { preferred due to the } \\
\text { possibility of slower flight } \\
\text { speed and easier take-off and } \\
\text { landing. }\end{array}$ & $\begin{array}{l}\text { A survey flight can be pre- } \\
\text { programmed and performed much } \\
\text { faster than traditional walkover } \\
\text { surveys. }\end{array}$ & $\begin{array}{l}\text { The extent of its use is limited by } \\
\text { the safety regulations covering } \\
\text { UAV application at the landfill } \\
\text { site, battery time (rotary UAVs) } \\
\text { and weather constraints (rain and } \\
\text { wind). }\end{array}$ & $\begin{array}{l}\text { A promising emerging technique. } \\
\text { UAVs are getting cheaper and } \\
\text { better (longer battery time, better } \\
\text { navigation systems, etc.). } \mathrm{CH}_{4} \\
\text { sensors are getting cheaper and } \mathrm{CH}_{4} \\
\text { measuring instruments are getting } \\
\text { smaller. }\end{array}$ \\
\hline \multicolumn{4}{|c|}{ Visual inspection } \\
\hline $\begin{array}{l}\text { Visual and olfactory } \\
\text { inspection of the landfill } \\
\text { cover. Emission hotspots can } \\
\text { often be located by the odour } \\
\text { of trace components in the } \\
\text { landfill gas, by changes in } \\
\text { vegetation and irregularities } \\
\text { in the cover (cracks and } \\
\text { fissures). }\end{array}$ & $\begin{array}{l}\text { Rapid and simple first approach } \\
\text { for routine inspection procedures. }\end{array}$ & $\begin{array}{l}\text { Subjective with many possible } \\
\text { influences, including wind speed } \\
\text { and direction, soil moisture, site } \\
\text { topography and landfill cover } \\
\text { maintenance. }\end{array}$ & $\begin{array}{l}\text { A useful first step. Site personnel } \\
\text { should be instructed to keep alert } \\
\text { for odours and vegetation } \\
\text { abnormalities indicating landfill gas } \\
\text { emissions. }\end{array}$ \\
\hline
\end{tabular}


Table 2. Characteristics of the closed and the open surface flux chamber.

\begin{tabular}{|l|l|}
\hline Closed chambers & Open chambers \\
\hline $\begin{array}{l}\text { Also called a static chamber } \\
\text { No exchange of air inside the chamber with } \\
\text { external air }\end{array}$ & $\begin{array}{l}\text { Also called a dynamic chamber } \\
\text { The chamber is continuously flushed with a flow of } \\
\text { gas (a carrier gas) - this can be ambient air or a } \\
\text { synthetic gas }\end{array}$ \\
$\begin{array}{l}\text { If gas concentrations are measured by pumping } \\
\text { flow can be recirculated back to the chamber to } \\
\text { avoid an internal pressure decrease } \\
\begin{array}{l}\text { The chamber can have a vent to reduce the } \\
\text { influence of internal pressure build-up }\end{array}\end{array}$ & $\begin{array}{l}\text { The emission is determined by measuring } \\
\text { concentrations in the inlet and outlet flows. If a } \\
\text { synthetic gas is used, only gas concentration in the } \\
\text { outlet flow needs to be analysed } \\
\text { The chamber can have a vent to reduce the influence } \\
\text { of internal pressure build-up }\end{array}$ \\
\hline
\end{tabular}




\begin{tabular}{|c|c|c|c|}
\hline Application & Advantages & Limitations & Status and references \\
\hline \multicolumn{4}{|c|}{ Vertical soil gas concentration profiles } \\
\hline $\begin{array}{l}\text { Single-point measurements of } \\
\text { gas concentrations and pressure } \\
\text { gradients in soil cover profiles, } \\
\text { with a calculation of flux using } \\
\text { equations for diffusional and } \\
\text { pressure-driven flux. }\end{array}$ & $\begin{array}{l}\text { Useful for diffusive and } \\
\text { convective flux studies, including } \\
\text { the influence of pressure changes, } \\
\text { passing storm fronts and changes } \\
\text { in the wind. Can be used to } \\
\text { understand the direction of the } \\
\text { diffusional flux and the presence } \\
\text { of subsurface } \mathrm{CH}_{4} \text { sources and } \\
\text { sinks. }\end{array}$ & $\begin{array}{l}\text { Difficult to apply appropriately if } \\
\text { emissions are associated with } \\
\text { high spatial variability. The } \\
\text { method is thus not useful for up- } \\
\text { scaling for whole-cell/site } \\
\text { emission quantification. }\end{array}$ & $\begin{array}{l}\text { Limited to a few and often older } \\
\text { landfill field studies but the basis } \\
\text { for many transport models. Not } \\
\text { appropriate for whole-site } \mathrm{CH}_{4} \\
\text { emission quantification (Glinski } \\
\text { and Stepniewski, 1985; El-Fadel } \\
\text { et al., 1995; Christophersen et al., } \\
\text { 2001; Röwer et al. 2011; Gebert } \\
\text { et al., 2011). }\end{array}$ \\
\hline \multicolumn{4}{|c|}{$\begin{array}{c}\text { Closed surface flux chambers } \\
\end{array}$} \\
\hline $\begin{array}{l}\text { Single-point measurements, } \\
\text { using a chamber placed on the } \\
\text { surface combined with } \\
\text { measurements of change in gas } \\
\text { concentration within the } \\
\text { chamber vs. time. Typically, a } \\
\text { measurement takes less than } 1 \\
\text { hour. }\end{array}$ & $\begin{array}{l}\text { Good for process studies of } \\
\text { emissions. Combined with } \\
\text { vertical soil gas concentration } \\
\text { profiles, } \mathrm{CH}_{4} \text { oxidation can be } \\
\text { accessed. The only technique that } \\
\text { can measure both the emission } \\
\text { and the uptake of } \mathrm{CH}_{4} \text {. Can also } \\
\text { be used for non- } \mathrm{CH}_{4} \text { gases and } \\
\text { isotopic composition analysis. } \\
\text { Not sensitive to other } \mathrm{CH}_{4} \\
\text { sources. Simple to deploy with } \\
\text { low limits of detection for fluxes } \\
\text { (depending on analytical } \\
\text { instrumentation). }\end{array}$ & $\begin{array}{l}\text { Time- and labour-intensive, and } \\
\text { appropriate geostatistical } \\
\text { techniques must be used for } \\
\text { whole landfill site studies. Not an } \\
\text { appropriate method for measuring } \\
\text { convective fluxes. Often, } \\
\text { emission hotspots will not be } \\
\text { included in the measurements, } \\
\text { leading to whole-site emission } \\
\text { underestimation. Temporary } \\
\text { disturbance of soil surface can } \\
\text { influence the emission. }\end{array}$ & $\begin{array}{l}\text { The method is historically the } \\
\text { most applied for quantifying } \mathrm{CH}_{4} \\
\text { emissions from landfills. Not } \\
\text { appropriate for whole-site } \mathrm{CH}_{4} \\
\text { emission quantification. Still used } \\
\text { in many countries, due to lack of } \\
\text { other and more appropriate } \\
\text { methods } \\
\text { (e.g. Rolston, 1986; Kjeldsen and } \\
\text { Fisher, 1995; Tregoures et al., } \\
\text { 1999; Conen and Smith, 2000; } \\
\text { Christophersen and Kjeldsen, } \\
\text { 2001a, Gebert and Gröngröft, } \\
\text { 2006, Scheutz et al., 2011a; 2008; } \\
\text { 2003). }\end{array}$ \\
\hline \multicolumn{4}{|c|}{ Open surface flux chambers } \\
\hline $\begin{array}{l}\text { Single-point measurements } \\
\text { using a chamber placed on the } \\
\text { surface, which is continuously } \\
\text { flushed with air or a synthetic } \\
\text { carrier gas. } \\
\text { Measures flux based on gas } \\
\text { flow and the difference between } \\
\text { incoming and outgoing chamber } \\
\mathrm{CH}_{4} \text { concentrations. }\end{array}$ & $\begin{array}{l}\text { Same advantages as closed } \\
\text { chambers except cannot quantify } \\
\text { negative } \mathrm{CH}_{4} \text {. }\end{array}$ & $\begin{array}{l}\text { Same disadvantages as closed } \\
\text { chambers. Not able to quantify } \\
\text { very low fluxes because of } \\
\text { dilution of chamber gas with } \\
\text { carrier gas. }\end{array}$ & $\begin{array}{l}\text { A technique commonly applied at } \\
\text { landfills. Not appropriate for } \\
\text { whole-site } \mathrm{CH}_{4} \text { emission } \\
\text { quantification } \\
\text { (e.g. Rolston, 1986; Huber- } \\
\text { Humer and Lechner, 2001a; } \\
\text { 2001b; Hutchinson and } \\
\text { Livingston, 2001). }\end{array}$ \\
\hline \multicolumn{4}{|c|}{ Eddy covariance } \\
\hline $\begin{array}{l}\text { Measurements of the turbulent } \\
\text { transfer of gases between the } \\
\text { ground surface and the } \\
\text { atmosphere. Need fast } \\
\text { measurements of atmospheric } \\
\mathrm{CH}_{4} \text { concentration, wind speed } \\
\text { and direction. }\end{array}$ & $\begin{array}{l}\text { Gives an integrated measure of } \\
\text { landscape-scale fluxes. Good for } \\
\text { flat terrain with uniform } \\
\text { emissions. Does not disturb the } \\
\text { emission pathways. Useful for } \\
\text { long- and short-term temporal } \\
\text { studies under changing } \\
\text { atmospheric conditions. }\end{array}$ & $\begin{array}{l}\text { Difficult to apply in variable } \\
\text { topography and with interfering } \\
\mathrm{CH}_{4} \text { sources. Measured footprint } \\
\text { is dependent on metrological } \\
\text { conditions. Requires fast ( }>10 \\
\mathrm{~Hz} \text { ) gas-specific instrumentation } \\
\text { with high precision. }\end{array}$ & $\begin{array}{l}\text { Widely used for landscape-scale } \\
\text { fluxes from terrestrial } \\
\text { ecosystems. Has not been used } \\
\text { often for landfill } \mathrm{CH}_{4} \text { fluxes } \\
\text { (e.g. Fowler and Duyzer, 1989; } \\
\text { Arya, 1988; Fowler et al., 1995, } \\
\text { Hovde, 1995; Laurila et al., 2005; } \\
\text { Schroth et al., 2012; Xu et al., } \\
\text { 2014). }\end{array}$ \\
\hline \multicolumn{4}{|c|}{ Stationary mass balance } \\
\hline $\begin{array}{l}\mathrm{CH}_{4} \text { concentrations are } \\
\text { measured at different heights } \\
\text { above the landfill surface, and } \\
\text { by combining these with } \\
\text { simultaneously measured } \\
\text { atmospheric conditions, the } \\
\text { horizontal flux of } \mathrm{CH}_{4} \text { can be } \\
\text { calculated. }\end{array}$ & $\begin{array}{l}\text { Same advantages as eddy } \\
\text { covariance. }\end{array}$ & $\begin{array}{l}\text { Same disadvantages as eddy } \\
\text { covariance, but does not require } \\
\text { as fast instrumentation. }\end{array}$ & $\begin{array}{l}\text { Has rarely been used for landfill } \\
\mathrm{CH}_{4} \text { fluxes, but has been used in } \\
\text { the Netherlands (e.g. Scharff, } \\
\text { 2003). }\end{array}$ \\
\hline \multicolumn{4}{|c|}{ Radial plume mapping } \\
\hline $\begin{array}{l}\text { Uses one or more lasers and } \\
\text { mirrors to measure the } \\
\text { downwind, cross-plume } \\
\text { concentration. In combination } \\
\text { with measured and modelled } \\
\text { wind profiles, surface emissions }\end{array}$ & $\begin{array}{l}\text { Gives an integrated measure of } \\
\mathrm{CH}_{4} \text { emission from the area } \\
\text { upwind of the laser and reflectors } \\
\text { and includes edge leakages and } \\
\text { other on-site hotspots. Method } \\
\text { well described by the US EPA. }\end{array}$ & $\begin{array}{l}\text { Rely on a relatively stable wind } \\
\text { direction throughout the } \\
\text { measurement. Two sets of } \\
\text { instrumentation are needed if } \\
\text { background (upwind) } \\
\text { measurements need to be }\end{array}$ & $\begin{array}{l}\text { Was developed in the late 1990s } \\
\text { and made an "Other Test Method } \\
\text { (OTM)" by the US EPA. } \\
\text { Coverage increases with the } \\
\text { development of better laser } \\
\text { systems (e.g. Hashmonay et al., }\end{array}$ \\
\hline
\end{tabular}




\begin{tabular}{|c|c|c|c|}
\hline $\begin{array}{l}\text { from the upwind area can be } \\
\text { calculated. }\end{array}$ & & $\begin{array}{l}\text { measured simultaneously. Laser } \\
\text { coverage depends on visibility, } \\
\text { and multiple measurements are } \\
\text { needed for a whole landfill } \\
\text { measurement. Method can be } \\
\text { challenged by the topography of } \\
\text { the landfill. }\end{array}$ & $\begin{array}{l}\text { 1999; Wu et al., 1999; } \\
\text { Hashmonay et al., 2001; 2008; } \\
\text { Goldsmith, 2008; } \\
\text { Abichou et al., 2010; Thoma et } \\
\text { al., 2010; Goldsmith et al., 2012). }\end{array}$ \\
\hline \multicolumn{4}{|c|}{ Mass balance using aerial measurements } \\
\hline $\begin{array}{l}\mathrm{CH}_{4} \text { concentrations are } \\
\text { measured across the downwind } \\
\text { plume from the landfill, using } \\
\text { an aircraft. Based on the } \\
\text { measured concentrations, a 2D } \\
\text { concentration plane is modelled } \\
\text { and combined with } \\
\text { simultaneously measured } \\
\text { atmospheric conditions, the } \\
\text { horizontal flux of } \mathrm{CH}_{4} \text { through } \\
\text { the 2D plane can be calculated. }\end{array}$ & $\begin{array}{l}\text { Gives an integrated emission } \\
\text { from the whole landfill without } \\
\text { having to access it. }\end{array}$ & $\begin{array}{l}\text { Requires accurate weather data } \\
\text { and an aircraft with high- } \\
\text { precision instrumentation. } \\
\text { Closely located sources can be } \\
\text { difficult to separate. The whole } \\
\text { plume should be covered. }\end{array}$ & $\begin{array}{l}\text { Has been applied at landfills in } \\
\text { the US and UK. The } \\
\text { methodology is still under } \\
\text { development. With the } \\
\text { development of new and light } \\
\text { high-precision } \mathrm{CH}_{4} \text { sensors and } \\
\text { laser instruments the method has } \\
\text { high future potential (e.g. Peischl } \\
\text { et al., 2013; Krautwurst et al., } \\
\text { 2016; Cambaliza et al., 2015; } \\
\text { 2017; Allen et al., 2017). }\end{array}$ \\
\hline \multicolumn{4}{|c|}{ Stationary tracer gas dispersion } \\
\hline $\begin{array}{l}\text { Simultaneous measurement of } \\
\text { atmospheric } \mathrm{CH}_{4} \text { and a tracer } \\
\text { gas at one or more fixed points } \\
\text { in the downwind plume. The } \\
\text { tracer gas is released at a known } \\
\text { rate and the } \mathrm{CH}_{4} \text { emission rate } \\
\text { can be determined from the } \\
\text { measured concentration ratio. }\end{array}$ & $\begin{array}{l}\text { Gives an integrated measurement } \\
\text { of whole-cell or whole-landfill } \\
\text { fluxes, including edge leakages } \\
\text { and other on-site hotspots. Does } \\
\text { not rely on measurements of } \\
\text { atmospheric conditions. }\end{array}$ & $\begin{array}{l}\text { Difficult to apply in the case of } \\
\text { interfering } \mathrm{CH}_{4} \text { sources. Proper } \\
\text { source simulation (correct tracer } \\
\text { gas placement) is challenged } \\
\text { even by small changes in wind } \\
\text { direction while performing } \\
\text { measurements. Historically, } \\
\text { potent greenhouse gases such as } \\
\mathrm{SF}_{6} \text { and } \mathrm{N}_{2} \mathrm{O} \text { have been used. }\end{array}$ & $\begin{array}{l}\text { Method is well proven and has } \\
\text { been used in several older landfill } \\
\text { studies. The method is being } \\
\text { replaced by the dynamic tracer } \\
\text { gas dispersion approach, as } \\
\text { development in instrumentation } \\
\text { allows this transition (e.g. } \\
\text { Czepiel et al., 1986; Trégourès et } \\
\text { al., 1999; Galle et al., 2001; } \\
\text { Börjesson et al., 2007). }\end{array}$ \\
\hline \multicolumn{4}{|c|}{ Dynamic tracer gas dispersion } \\
\hline $\begin{array}{l}\text { Measurements of } \mathrm{CH}_{4} \text { and } \\
\text { tracer gas while driving across } \\
\text { the downwind plume. Using the } \\
\text { plume-integrated concentration } \\
\text { ratio and known tracer release, } \\
\text { the } \mathrm{CH}_{4} \text { emission rate can be } \\
\text { determined. }\end{array}$ & $\begin{array}{l}\text { Same as static tracer gas } \\
\text { dispersion. Gives a downwind } \\
\text { plume, providing more details } \\
\text { about the location of the emission } \\
\text { compared to the tracer release. } \\
\text { Does not rely on measurements } \\
\text { or the modelling of atmospheric } \\
\text { conditions. }\end{array}$ & $\begin{array}{l}\text { Requires a road at a suitable } \\
\text { distance downwind of the landfill } \\
\text { and with no interfering } \mathrm{CH}_{4} \\
\text { sources in between. The most } \\
\text { commonly used tracer gas is } \mathrm{N}_{2} \mathrm{O} \text {, } \\
\text { which is a potent greenhouse gas } \\
\text { but has been replaced with } \mathrm{C}_{2} \mathrm{H}_{2} \\
\text { in recent applications. }\end{array}$ & $\begin{array}{l}\text { A method of growing interest as } \\
\text { better instrumentation has } \\
\text { become available. US EPA is in } \\
\text { the process of describing the } \\
\text { method among their OTMs } \\
\text { (e.g. Scheutz et al., 2011; Green } \\
\text { et al., 2010, 2012; Mønster et al., } \\
\text { 2014, 2015; Foster-Wittig et al., } \\
\text { 2015). }\end{array}$ \\
\hline \multicolumn{4}{|c|}{ Differential absorption LiDAR (DIAL) } \\
\hline $\begin{array}{l}\text { A laser is shot into the } \\
\text { atmosphere and the } \\
\text { backscattered part is measured. } \\
\text { DIAL is used for landfills by } \\
\text { measuring the appropriate } \mathrm{CH}_{4} \\
\text { absorption lines. A 2D } \\
\text { downwind concentration plan is } \\
\text { modelled and combined with } \\
\text { measured and modelled } \\
\text { information on wind speed and } \\
\text { direction. }\end{array}$ & $\begin{array}{l}\text { Can give both whole-site and } \\
\text { individual area emissions. Very } \\
\text { little interference from other } \mathrm{CH}_{4} \\
\text { sources in the surroundings. Can } \\
\text { give detailed information on } \\
\text { emission patterns. }\end{array}$ & $\begin{array}{l}\text { DIAL's analytical setup is large } \\
\text { and expensive, and data handling } \\
\text { is complex. The method relies on } \\
\text { accurate wind measurement and } \\
\text { modelling. }\end{array}$ & $\begin{array}{l}\text { Mainly used for VOC emissions } \\
\text { in the petrochemical industry, but } \\
\text { has also been applied to landfills } \\
\text { for } \mathrm{CH}_{4} \text { emission quantification } \\
\text { (e.g. Babilotte et al., 2010, 2011; } \\
\text { Robinson et al., 2011; Bourn et } \\
\text { al., 2019; Innocenti et al., 2017). }\end{array}$ \\
\hline \multicolumn{4}{|c|}{ Inverse modelling - stationary } \\
\hline $\begin{array}{l}\text { Continuous concentration } \\
\text { measurements or sampling in } \\
\text { one or more downwind points, } \\
\text { or cross-plume concentration, } \\
\text { fed into an appropriate inverse } \\
\text { atmospheric transport model, } \\
\text { together with information on } \\
\text { wind speed and direction. }\end{array}$ & $\begin{array}{l}\text { Can give whole-site emission } \\
\text { estimates and is good for long } \\
\text { time series and thus able to } \\
\text { capture emission variations. }\end{array}$ & $\begin{array}{l}\text { Relies on good data on } \\
\text { atmospheric conditions and large } \\
\text { amounts of measurement data. Is } \\
\text { sensitive to interfering sources } \\
\text { and complex topography. Data } \\
\text { treatment is complex. Will often } \\
\text { result in an emission with } \\
\text { significant uncertainty. }\end{array}$ & $\begin{array}{l}\text { Different model approaches have } \\
\text { been suggested, but the method } \\
\text { has yet to prove accurate for } \\
\text { landfill emission rate estimates } \\
\text { (e.g. Figueroa et al., 2009; } \\
\text { Abichou et al., 2012; Zhu et al., } \\
\text { 2013; Foster-Wittig et al., } \\
\text { 2015b). }\end{array}$ \\
\hline \multicolumn{4}{|c|}{ Inverse modelling - dynamic } \\
\hline $\begin{array}{l}\text { Measurement of downwind } \\
\text { plume and combined with } \\
\text { accurate atmospheric condition } \\
\text { measurements, the emission } \\
\text { rate from the landfill can be } \\
\text { estimated. }\end{array}$ & $\begin{array}{l}\text { Measurements are fast to perform } \\
\text { and can give whole-site emission } \\
\text { estimates. }\end{array}$ & $\begin{array}{l}\text { Instrumentation must be fast and } \\
\text { precise. Good measurements of } \\
\text { atmospheric conditions with high } \\
\text { temporal resolution. Will often } \\
\text { result in an emission with } \\
\text { significant uncertainty. }\end{array}$ & $\begin{array}{l}\text { Not a widely used approach but } \\
\text { has been used as a fast screening } \\
\text { tool for finding old landfills with } \\
\text { significant emissions } \\
\text { (e.g. Hensen and Scharff 2001; } \\
\text { Fredenslund et al., 2019a). }\end{array}$ \\
\hline \multicolumn{4}{|c|}{ Inverse modelling - aerial } \\
\hline $\begin{array}{l}\text { Measurement of downwind } \\
\text { plume and combined with }\end{array}$ & $\begin{array}{l}\text { Measurements are fast to perform } \\
\text { and can give whole-site emission }\end{array}$ & $\begin{array}{l}\text { Instrumentation must be fast, } \\
\text { precise and deployable in UAV }\end{array}$ & $\begin{array}{l}\text { Has been applied at various } \\
\text { sources in the US, including }\end{array}$ \\
\hline
\end{tabular}


accurate atmospheric condition

measurements, the emission

rate from the landfill can be

estimated. estimates. No access to landfill needed.

or aircraft. Good measurements

of atmospheric conditions with

high temporal resolution. Will

often result in an emission with

significant uncertainty. 
quantifying $\mathrm{CH}_{4}$, either from landfills or controlled $\mathrm{CH}_{4}$ release imitating landfill emission.

\begin{tabular}{|c|c|c|c|}
\hline Application & Methodologies & Emission & Comment \\
\hline \multirow{8}{*}{$\begin{array}{l}\text { Landfill } \\
\text { (Tregoures et } \\
\text { al. 1999) }\end{array}$} & & Unit: $\left(m^{3} \mathrm{CH}_{4} d^{-1}\right)$ & \\
\hline & Closed flux chamber (no recirculation) & $3750-14200$ & \multirow{2}{*}{$20 \times 20 \mathrm{~m}$ grid } \\
\hline & Closed flux chamber (with recirculation) & $10512-11375$ & \\
\hline & Tracer gas dispersion method $1\left(\mathrm{SF}_{6}\right)$ & $7720 \pm 2650$ & $\begin{array}{l}\text { Downwind plume sampled in two ways: static, } \\
\text { multiple points (100 m downwind) and dynamic, } \\
\text { multiple distances (115, } 130 \text { and } 200 \mathrm{~m} \\
\text { downwind) }\end{array}$ \\
\hline & Tracer gas dispersion method $2\left(\mathrm{SF}_{6}\right)$ & $6340 \pm 2070$ & $\begin{array}{l}\text { Landfill divided into strips, each measured } \\
\text { downwind at the edge of landfill }\end{array}$ \\
\hline & Eddy covariance & $11.2 \pm 3.4$ & Only one mast location. Wind direction enabled \\
\hline & Static mass balance & $24 \pm 8$ & only a small part of the landfill to be measured \\
\hline & $\begin{array}{l}\text { Remote sensing (airborne IR } \\
\text { thermography) }\end{array}$ & No & Only used for finding hotspots \\
\hline \multirow{4}{*}{$\begin{array}{l}\text { Four landfills } \\
\text { (LF1-4) } \\
\text { (Scharff et al. } \\
\text { 2003) }\end{array}$} & & Unit: $\left(m^{3} h^{-1}\right)$ & \\
\hline & Static mass balance & $\begin{array}{l}\text { LF1: } 530 \pm 130 \\
\text { LF2: } 109 \pm 30 \\
\text { LF3: } 390 \pm 100 \\
\text { LF4: } 70 \pm 8\end{array}$ & Sampling 10,15 and $25 \mathrm{~m}$ above ground \\
\hline & Inverse modelling (static) & $\begin{array}{l}\text { LF1: } 440 \pm 180 \\
\text { LF2: } 277 \pm 71 \\
\text { LF3: } 690 \pm 230 \\
\text { LF4: } 184 \pm 81 \\
\end{array}$ & $\begin{array}{l}\text { Four sample bags collecting gas in different wind } \\
\text { directions }\end{array}$ \\
\hline & Inverse modelling (dynamic) & $\begin{array}{l}\text { LF1: } 540-900 \pm 50-125 \\
\text { LF2: } 315 \pm 33 \\
\text { LF3: } 300 \pm 10 \\
\text { LF4: } 135 \pm 32\end{array}$ & $\begin{array}{l}\text { Using tracer gas for model calibration. } \\
\text { At LF1, three experiments were done }\end{array}$ \\
\hline \multirow{4}{*}{$\begin{array}{l}12 \text { landfill } \\
\text { sections } \\
\text { (P1 to } \mathrm{P} 12) \\
\text { (Goldsmith et } \\
\text { al. 2008) }\end{array}$} & & Unit: $\left(\mathrm{g} \mathrm{m}^{-2} \mathrm{~d}^{-1}\right)$ & \\
\hline & Closed flux chamber & $\begin{array}{c}\text { P1: 34.5, P2: 20.0, P3:- } \\
\text { 0.3, P4: 2.3, P5: 2.2, P6: } \\
\text { 1.1, P7: 5.7, P8: 53.6, P9: } \\
\text { 0.3, P10: 5.8, P11: } 1.1 \\
\text { P12: } 0.1\end{array}$ & \multirow{3}{*}{$\begin{array}{l}\text { Each landfill part was measured and compared } \\
\text { individually }\end{array}$} \\
\hline & Radial plume mapping (100 m path) & $\begin{array}{c}\text { P1: 184.8 P2: 53.7, P3: } \\
\text { 1.8, P4: 19.3, P5: 27.3, } \\
\text { P6: 56.8, P7: 87.5, P8: } \\
\text { 41.4, P9: 5.5, P10: } 89.1 \\
\text { P11: } 0.0, \text { P12: } 0.0\end{array}$ & \\
\hline & Radial plume mapping (200 m path) & $\begin{array}{c}\text { P1: 92.4 P2: 26.9, P3: } \\
\text { 0.9, P4: 9.7, P5: 13.7, P6: } \\
\text { 28.4, P7: 43.8, P8: 20.7, } \\
\text { P9: 2.7, P10: 44.5, P11: } \\
\text { 0.0, P12: } 0.0\end{array}$ & \\
\hline \multirow{7}{*}{$\begin{array}{l}\text { Landfill } \\
\text { (Babilotte et al. } \\
\text { 2010) }\end{array}$} & & Unit: $\left(\mathrm{gCH}_{4} \mathrm{~s}^{-1}\right)$ & \\
\hline & Radial plume mapping & $25.2 \pm 2.4$ & Individual cells were also quantified \\
\hline & Tracer gas dispersion (static) $\left(\mathrm{N}_{2} \mathrm{O}\right)$ & $83 \pm 36$ & $\begin{array}{l}15 \text { canisters sampled over } 4 \mathrm{~h} \text { across a plume } 200 \\
\mathrm{~m} \text { downwind }\end{array}$ \\
\hline & Tracer gas dispersion (dynamic) $\left(\mathrm{N}_{2} \mathrm{O}\right)$ & $41 \pm 17$ & $\begin{array}{l}\text { Real-time TDL measurements across a plume } 200 \\
\mathrm{~m} \text { downwind }\end{array}$ \\
\hline & DIAL & $12.1 \pm 2.4$ & \\
\hline & Inverse modelling & 163 & $\begin{array}{l}\text { Real-time measurements } 300 \mathrm{~m} \text { downwind using } \\
\text { instrumentation able to measure ppb changes in } \\
\mathrm{CH}_{4} \text { concentration and applied to a Gaussian } \\
\text { model software }\end{array}$ \\
\hline & Helicopter-borne spectroscopy & No & Able to find hotspots \\
\hline \multirow{6}{*}{$\begin{array}{c}\text { Controlled } \\
\text { release } \\
0.5 \pm 0.04 \\
\left(\mathrm{~g} \mathrm{CH}_{4} \mathrm{~s}^{-1}\right) \\
\text { (Babilotte et al. } \\
2010)\end{array}$} & Radial plume mapping & $0.89 \pm 0.05$ & Individual cells were also quantified \\
\hline & Tracer gas dispersion (dynamic) $\left(\mathrm{N}_{2} \mathrm{O}\right)$ & $1.7 \pm 1$ & Measurements $100 \mathrm{~m}$ downwind \\
\hline & Tracer gas dispersion (dynamic) $\left(\mathrm{N}_{2} \mathrm{O}\right)$ & $2.3 \pm 0.5$ & Model + measurements $100 \mathrm{~m}$ downwind \\
\hline & DIAL & $0.23 \pm 0.12$ & \\
\hline & Inverse Modelling & 1.5 & $\begin{array}{l}\text { Real-time measurements only } 20 \mathrm{~m} \text { downwind } \\
\text { using instrumentation able to measure ppb changes } \\
\text { in } \mathrm{CH}_{4} \text { concentration and applied to a Gaussian } \\
\text { model software }\end{array}$ \\
\hline & Helicopter-borne spectroscopy & No & Able to locate release area \\
\hline Two landfills & & Unit: $\left(\mathrm{g} \mathrm{m}^{-2} d^{-1}\right)$ & \\
\hline
\end{tabular}




\section{2}

\begin{tabular}{|c|c|c|c|}
\hline \multirow{5}{*}{$\begin{array}{l}\text { (Green et al. } \\
\text { 2010) }\end{array}$} & Closed flux chamber & $0.018 / 0.125$ & 26 points at each landfill \\
\hline & Radial plume mapping & $9.4 / 8.1$ & Area calculated on atmospheric stability class \\
\hline & Radial plume mapping & $16.7 / 10.5$ & $\begin{array}{l}\text { Area calculated by multiple linear regression } \\
\text { model }\end{array}$ \\
\hline & Tracer gas dispersion (static) $\left(\mathrm{C}_{2} \mathrm{H}_{2}\right)$ & $8.5 / 14.3$ & CRDS instrumentation \\
\hline & Tracer gas dispersion (dynamic) $\left(\mathrm{C}_{2} \mathrm{H}_{2}\right)$ & $7.9 / 13.1$ & CRDS instrumentation \\
\hline \multirow{6}{*}{$\begin{array}{l}\text { Two landfills } \\
(\# 1 / \# 2) \\
\text { (Babilotte et al. } \\
\text { 2010) }\end{array}$} & & Unit: $\left(\mathrm{kg} \mathrm{h} h^{-1}\right)$ & \\
\hline & Closed flux chamber & $290 / 868$ & $1-3 \%$ of total area measured \\
\hline & Eddy covariance & $1005 / 1146$ & $\sim 30 \%$ of total area measured \\
\hline & Radial plume mapping & $1325 / 1244$ & $10-15 \%$ of total area measured \\
\hline & DIAL & $659 / 314$ & Whole landfill \\
\hline & Tracer gas dispersion (dynamic) $\left(\mathrm{N}_{2} \mathrm{O}\right)$ & $916 / 789$ & $30-45 \%$ of total area measured \\
\hline \multirow{17}{*}{$\begin{array}{c}\text { Four } \\
\text { Controlled } \\
\text { releases } \\
\text { (Babilotte et al. } \\
\text { 2011) }\end{array}$} & & Unit: $g s^{-1}( \pm S D)$ & \\
\hline & Release \#1 & $1.095 \pm 0.005$ & One release point \\
\hline & Radial plume mapping & $\begin{array}{c}1.04 \pm 0.22 / 0.71 \pm 0.23 / 0.6 \\
2 \pm 0.20\end{array}$ & $10 / 50 / 100 \mathrm{~m}$ from source \\
\hline & DIAL & $0.86 \pm 0.27$ & $10 \mathrm{~m}$ from source \\
\hline & Tracer gas dispersion (dynamic) $\left(\mathrm{N}_{2} \mathrm{O}\right)$ & $1.16 \pm 0.10$ & $450 \mathrm{~m}$ from source \\
\hline & Release \#2 & $1.095 \pm 0.005$ & Two release points \\
\hline & Radial plume mapping & $\begin{array}{c}1.06 \pm 0.23 / 0.79 \pm 0.19 / 0.5 \\
7 \pm 0.15 \\
\end{array}$ & $10 / 50 / 100 \mathrm{~m}$ from source \\
\hline & DIAL & $0.90 \pm 0.25$ & $40 \mathrm{~m}$ from source \\
\hline & Tracer gas dispersion (dynamic) $\left(\mathrm{N}_{2} \mathrm{O}\right)$ & $1.31 \pm 0.09$ & $400 \mathrm{~m}$ from source \\
\hline & Release \#3 & $3.284 \pm 0.013$ & Three release points \\
\hline & Radial plume mapping & $\begin{array}{c}2.98 \pm 0.65 / 2.65 \pm 0.73 / 1.9 \\
2 \pm 0.45\end{array}$ & $10 / 50 / 100 \mathrm{~m}$ from source \\
\hline & DIAL & $0.90 \pm 0.25$ & $40 \mathrm{~m}$ from source \\
\hline & Tracer gas dispersion (dynamic) $\left(\mathrm{N}_{2} \mathrm{O}\right)$ & $1.31 \pm 0.09$ & $400 \mathrm{~m}$ from source \\
\hline & Release \#4 & $1.642 \pm 0.007$ & Three release points \\
\hline & Radial plume mapping & $\begin{array}{c}1.42 \pm 0.29 / 1.24 \pm 0.22 / 0.9 \\
6 \pm 0.22\end{array}$ & $10 / 50 / 100 \mathrm{~m}$ from source \\
\hline & DIAL & $1.96 \pm 0.46$ & $40 \mathrm{~m}$ from source \\
\hline & Tracer gas dispersion (dynamic) $\left(\mathrm{N}_{2} \mathrm{O}\right)$ & $1.72 \pm 0.11$ & $400 \mathrm{~m}$ from source \\
\hline \multirow[t]{5}{*}{$\begin{array}{c}\text { One landfill } \\
\text { (Cambaliza et } \\
\text { al. 2017) }\end{array}$} & & Unit: $\left(\mathrm{mol} \mathrm{s}^{-1}\right)$ & \\
\hline & Closed flux chamber & $0.005-0.02$ & Only intermediate cover measured \\
\hline & Radial plume mapping & $1.7-10.1$ & Only final and intermediate cover measured \\
\hline & Aircraft-based mass balance & $7-17$ & Whole landfill (from 2009 to $2012, \mathrm{n}=20$ ) \\
\hline & Tracer gas dispersion (dynamic) $\left(\mathrm{C}_{2} \mathrm{H}_{2}\right)$ & $8-13$ & Whole landfill (in 2012 and 2014, $\mathrm{n}=2$ ) \\
\hline
\end{tabular}




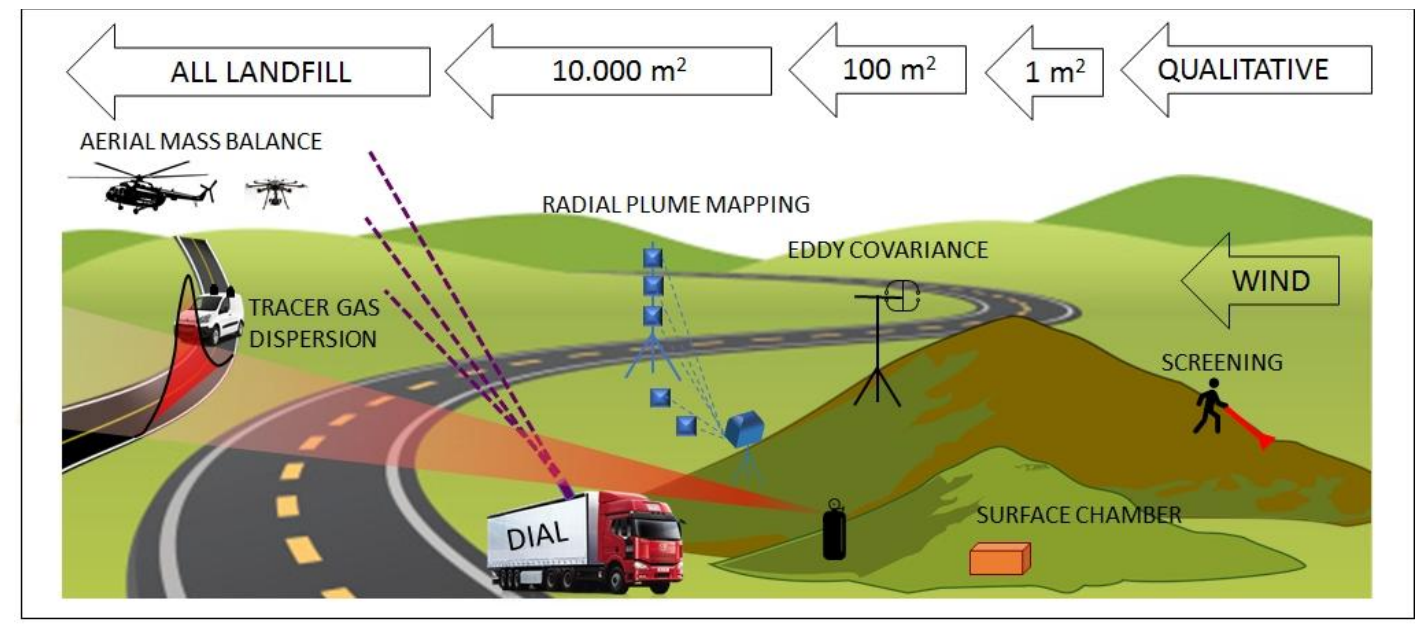

1817 Fig. 1. Overview of the most common methods used to identify and quantify $\mathrm{CH}_{4}$ emissions 1818 from landfills. 


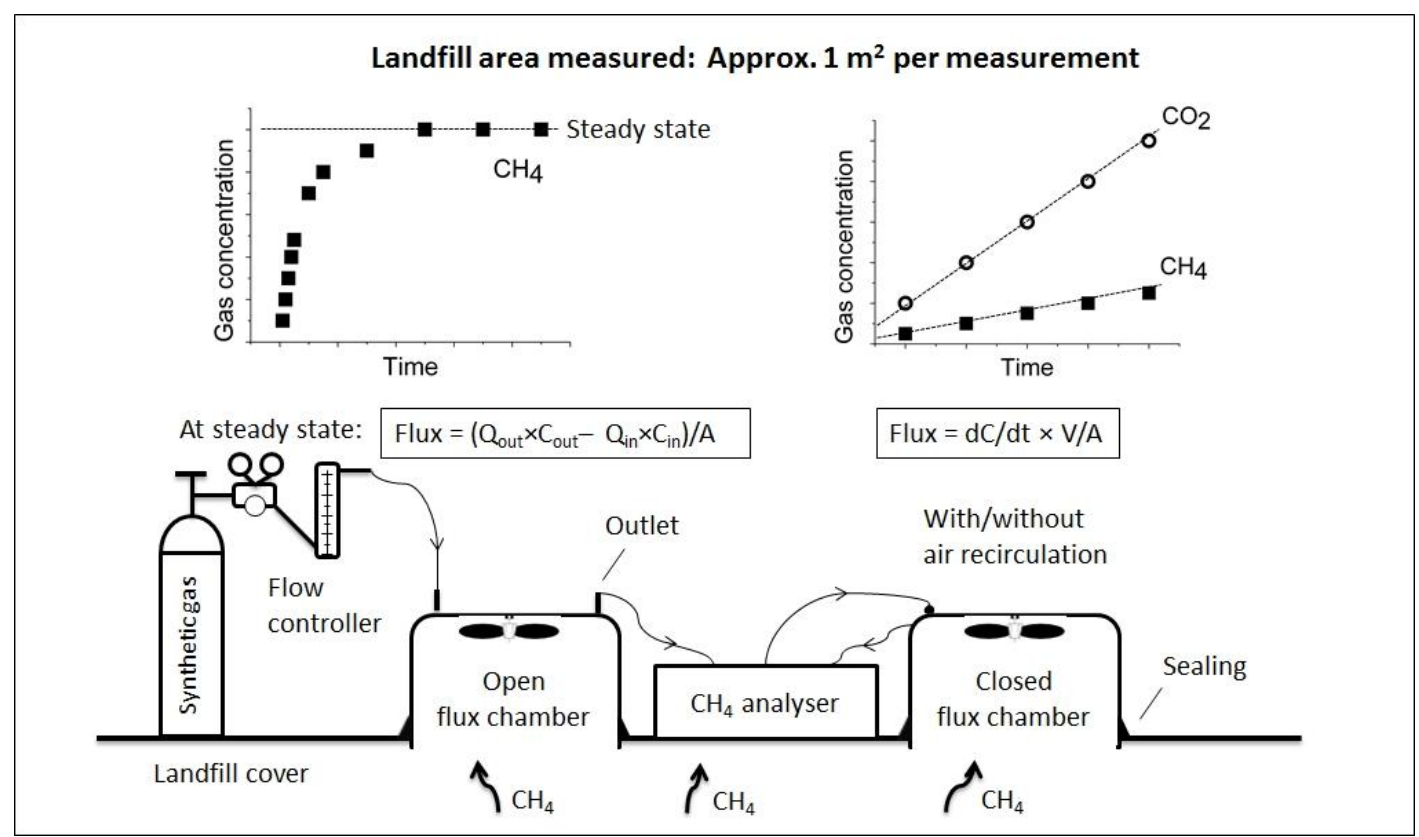

1822 Fig. 2. Schematic overview of open and closed flux chambers for quantifying $\mathrm{CH}_{4}$ fluxes from 1823 landfills. 


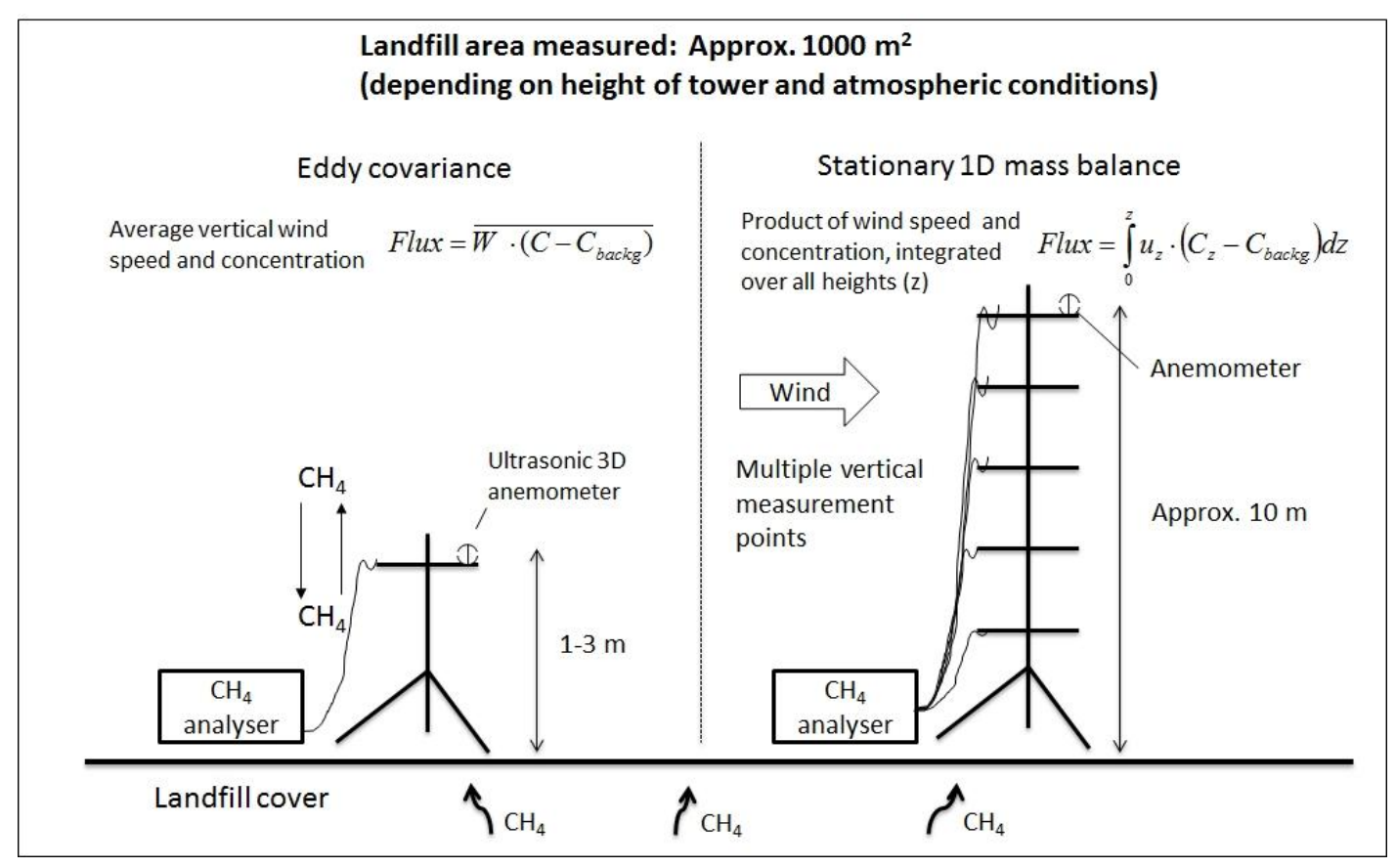

1826 Fig. 3. Simplified drawing of the eddy covariance and mass balance methods. Eddy covariance 1827 uses an ultrasonic anemometer to measure turbulence, while the mass balance approach uses a 1828 standard anemometer to measure wind speed and direction. 


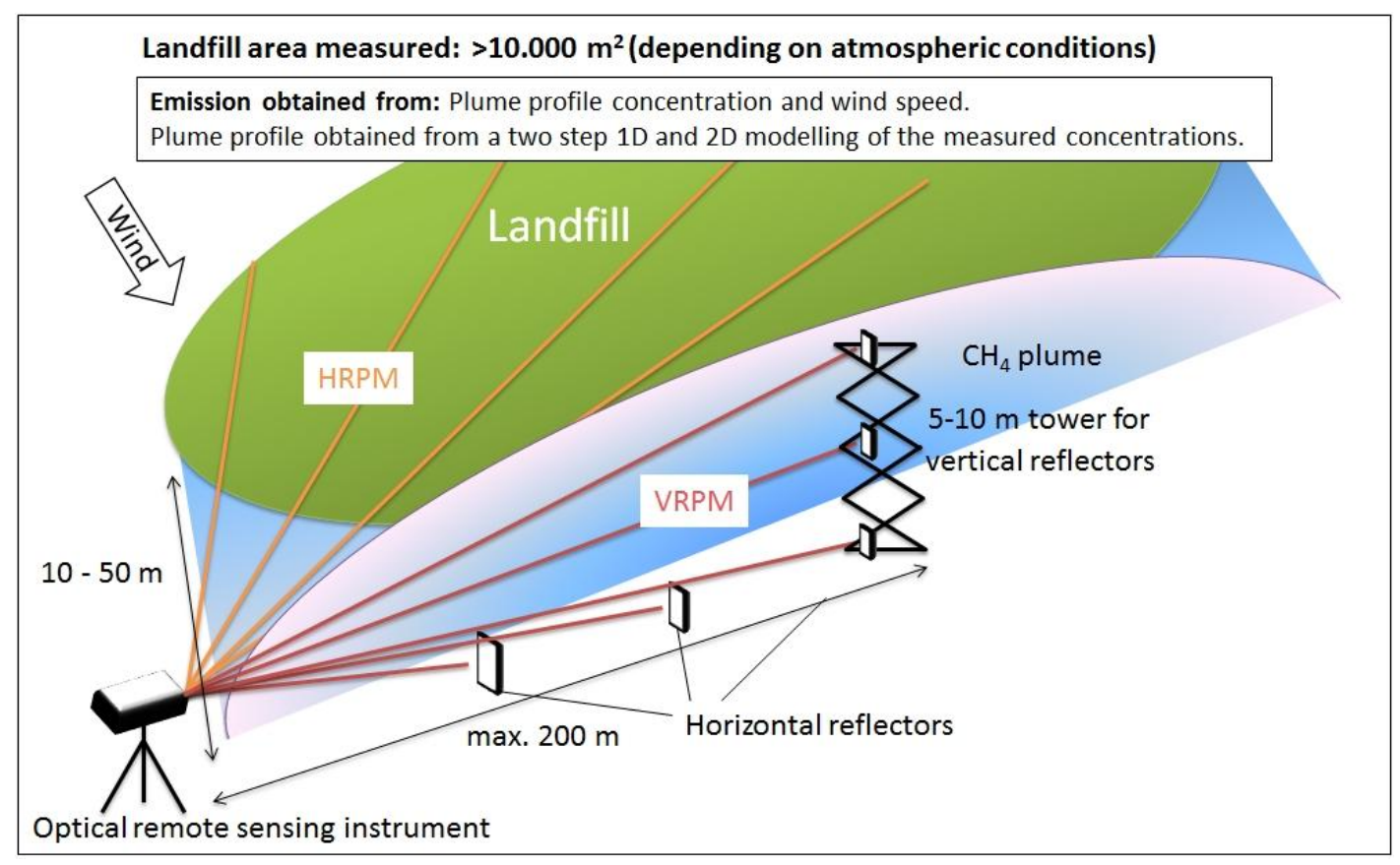

1832 Fig. 4. Horizontal (HRPM) and vertical (VRPM) radial plume mapping with setup, as 1833 suggested in the OTM10 method (Hashmonay et al., 2008). 


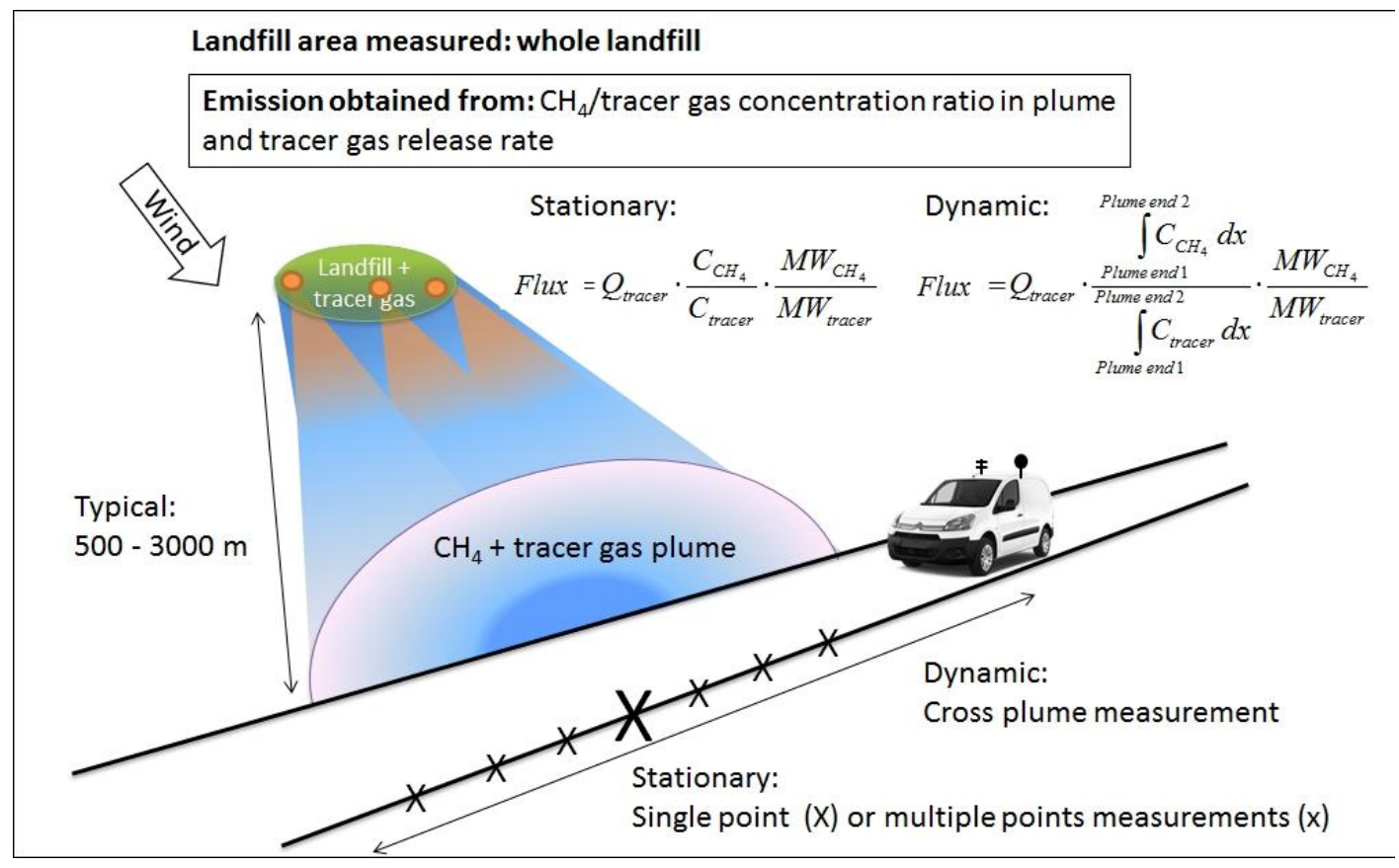

1837 Fig. 5. Tracer dispersion method using the stationary or dynamic approach. Stationary can be 1838 done using sampling or direct measurements, while dynamic requires fast, direct 1839 measurements. 


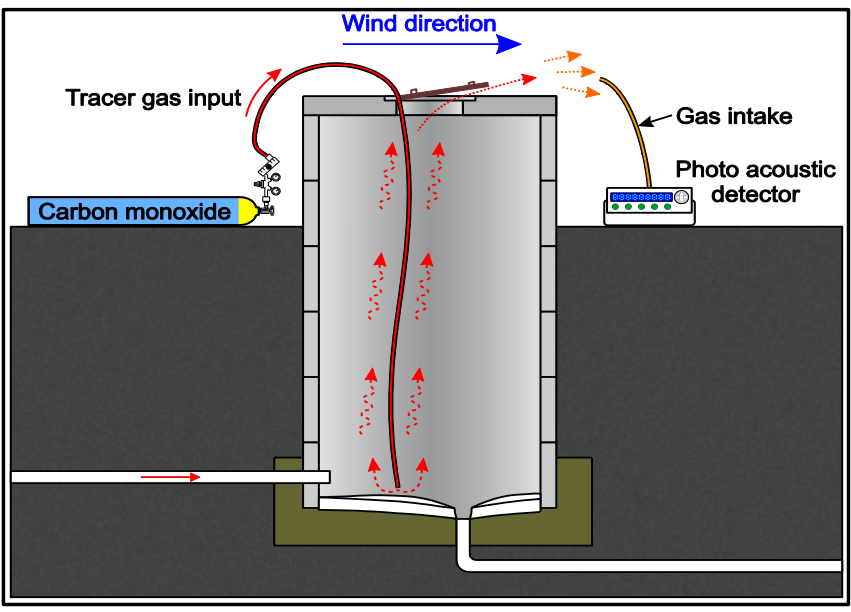

1843 Fig. 6. Small-scale tracer dispersion method for quantifying $\mathrm{CH}_{4}$ emissions through a leachate 1844 well. From Fredenslund et al. (2010).

1845

1846

1847 


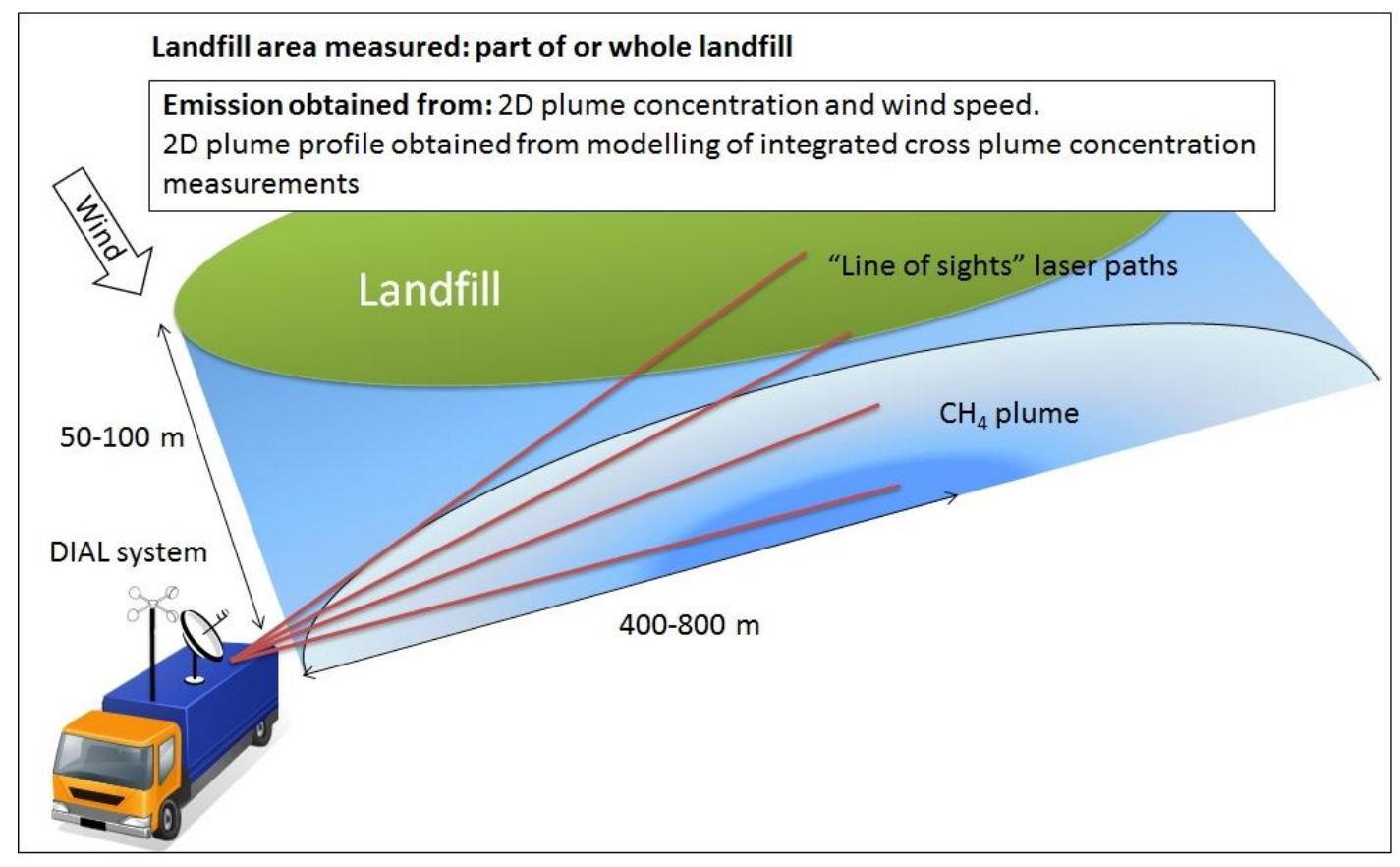

1849 Fig. 7. The DIAL method, using multiple 'line of sight' laser shooting with subsequent model 1850 fitting to create a two-dimensional cross-plume concentration profile. 